\title{
An in-situ TEM study into the role of disorder, temperature and ballistic collisions on the accumulation of helium bubbles and voids in glass-ceramic composites
}

\author{
Anamul H. Mir ${ }^{1 *}$, Neil C. Hyatt ${ }^{2}$, Stephen. E. Donnelly ${ }^{1}$
}

${ }^{1}$ MIAMI Irradiation Facility, School of Computing and Engineering, University of Huddersfield, HD1 3DH, UK

${ }^{2}$ Department of Materials Science and Engineering, University of Sheffield, S13JD, UK

*Corresponding author Email: a.h.mir@hud.ac.uk

\section{Abstract}

Different types of glass-ceramic composites are being researched around the world as potential matrices for nuclear waste conditioning. To demonstrate their long-term durability and build a safety case for geological disposal, accelerated irradiation tests simulating He accumulation and the effects of recoil nucleus damage are needed. To study the behaviour of He in these materials, particularly, in zirconolite-based glass-ceramics, transmission electron microscopy (TEM) with in-situ ion irradiation was employed. This research work provides a detailed overview of the various parameters such as the implantation temperature, He concentration, structural disorder, grain boundaries, glass-ceramic interfaces, ballistic collisions etc on He accumulation and bubble formation in these materials. These results are then discussed in the context of nuclear waste disposal in ceramics and glass-ceramic-matrix based materials.

Keywords: Glass-ceramics, Zirconolite, He bubbles, In-situ TEM, Ion irradiation, Nuclear waste

\section{Introduction}

Reprocessing of spent nuclear fuel in the UK is estimated to have resulted in about 128 metric tons of plutonium dioxide $\left(\mathrm{PuO}_{2}\right)$ powder [1]. At least $5 \%$ of this inventory ( 6.4 tons, referred to as plutonium residues) due to contamination, primarily from the PVC containers, is unsuitable for any future use (e.g. in MOX fuel fabrication) and requires safe disposal. There is ongoing research in the UK and around the world on several ceramics and glass-ceramic-matrix composites for their use in nuclear waste conditioning [2-7]. Especially, zirconolite-based glass-ceramics are being explored for the management of plutonium residues in the UK. To demonstrate their long-term durability, it is important to understand how these waste forms will evolve as a result of the selfirradiation damage. Self-irradiation damage due to alpha decays will result in amorphisation and He accumulation, and potentially in the nucleation of helium bubbles - the effects of which need to be understood. There are currently no detailed studies on the behaviour of He in glass-ceramics, especially, zirconolite-based glass-ceramics. However, several studies on understanding the radiation damage effects in zirconolite have been performed. A majority of these studies using either actinide doping or ion/neutron irradiations as a surrogate to recoil nucleus damage have focussed on the swelling and amorphisation of zirconolite. For the sake of brevity, a 
detailed and critical analysis of some of the studies available in the literature is presented in the supplementary information (SI). Some of the important conclusions that can be drawn from such studies are listed below.

I. Actinide doped Zirconolite specimens of varying compositions mainly show a bulk swelling of about 5 to 6 $\%$ after about $5 \times 10^{18} \mathrm{\alpha} / \mathrm{g}$ and complete amorphisation at a similar or slightly lower level (at least for $\mathrm{T}<$ $350 \mathrm{~K})[8-14]$.

II. Complete amorphisation of natural zirconolites containing $\operatorname{Th}^{232}$ and $U^{238}$ requires about $1 \times 10^{19} \alpha / g$ [10] which is higher compared to the doped zirconolite. This is due to the relatively higher temperature (100 to $200^{\circ} \mathrm{C}$ ) under geological conditions which favours defect healing over long time periods [10].

III. Amorphisation leads to a decrease in the metal-oxygen (M-O) distances in the coordination polyhedra, a reduction in the coordination number of $\mathrm{Ti}$ and an increase in the distortion of the polyhedra compared to the undamaged specimens [15] (mainly 5-fold coordination for Ti in amorphous zirconolite).

IV. The defect recovery rate in the naturally occurring radioactive zirconolites is small and amorphous state is achieved albeit delayed. Therefore, for amorphisable nuclear waste forms such as zirconolite, it is essentially the amorphous state that will be achieved and retained in the long-term.

V. Ion irradiation studies (e.g. 1.5 MeV Xe, $1 \mathrm{MeV} \mathrm{Kr,} 2 \mathrm{MeV} \mathrm{Au}, 40-200 \mathrm{keV} \mathrm{Pb}$ ions. See the SI for more details) have shown that zirconolite $\left(\mathrm{CaZrTi}_{2} \mathrm{O}_{7}\right)$ amorphises after about 0.5 dpa or less at room temperature. The critical amorphisation temperature $T_{c}$ (the temperature above which there is no amorphisation) seems to depend on the chemical composition of the zirconolite and slightly on the ion mass ( $710 \mathrm{~K}$ for $\mathrm{Xe}$ and $654 \mathrm{~K}$ for $\mathrm{Kr}$ ) with values in the range of 650 to $1000 \mathrm{~K}$ [16-18].

VI. As far as the behaviour under He irradiation is concerned, there are only a few studies available in the literature. Helium usually does not induce amorphisation even up to about $1.4 \mathrm{dpa}$ at room temperature. Although, He bubbles have been observed at $1 \times 10^{17} \mathrm{He}_{\mathrm{cm}}{ }^{-2}$, the lower limit of He concentration at which the He bubbles start to form is not known [19][20].

The aim of this article is to explore in detail the effects of various factors such as He concentration, irradiation temperature, structural disorder, interfaces and grain boundaries etc on He bubble formation in zirconolite and zirconolite-based glass-ceramics. For the sake of clarity, we will use the terms voids and bubbles to refer to empty cavities and gas (e.g. He) filled cavities respectively. In the latter case, the actual physical state (e.g. solid, liquid/supercritical fluid, gas) is not known. The subject dealing with the identification of the physical state of the implanted noble gases and the associated complexities is discussed at length in an earlier article [21].

\section{Experimental Details}

\subsection{Specimen preparation and ion irradiation}

Zirconolite-based glass-ceramics ( $\mathrm{Zr}-\mathrm{GC})$ were prepared using hot isostatic pressing as detailed elsewhere [22][23] and briefly in section-4 in the SI. The specimens mainly contained about $70 \%$ zirconolite phase and 30 


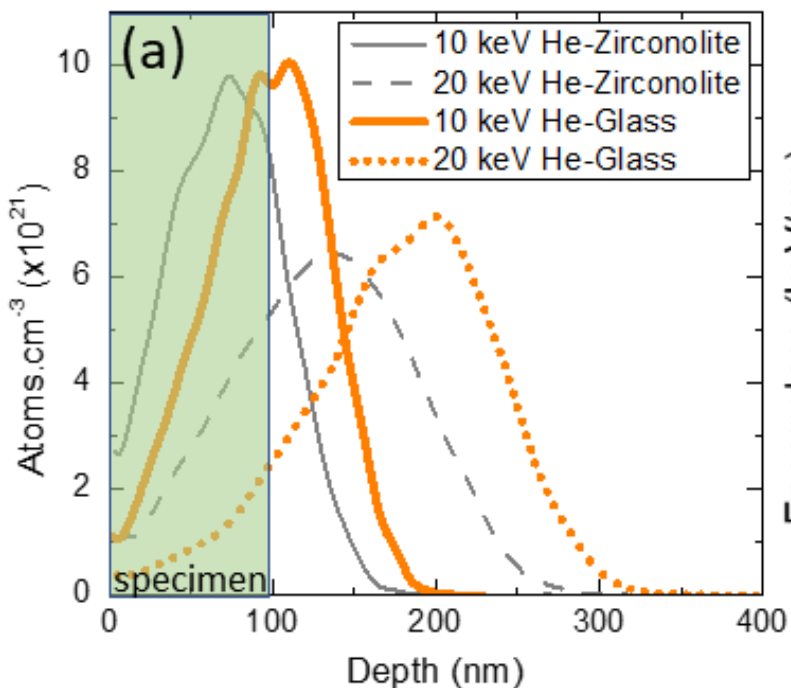
ion irradiation conditions used are listed in Table-I.

In addition to the irradiations of the FIB lamellae, a small quantity of $\mathrm{Zr}$-GC was also crushed in ethanol using an agate mortar and pestle and a few drops of this were dispersed onto holey carbon TEM grids to obtain thin zirconolite grains. These powdered grains were then irradiated with $20 \mathrm{keV} \mathrm{He}$ ions to study the He induced amorphisation at various temperatures. The irradiations with $20 \mathrm{keV}$ He ions for amorphisation studies were performed at an angle of 7 to 8 degree from the specimen normal. Throughout this study, an electron beam of $300 \mathrm{keV}$ was used for TEM imaging and it was switched off during ion implantation/irradiation to avoid any electron beam induced damage. Images were captured using TEM onscreen magnification of $100 \mathrm{k}$ to be able to detect the small He bubbles (usually 1- $2 \mathrm{~nm}$ ). In addition to the He irradiation, specimens in certain cases were also irradiated with $\mathrm{Kr}$ ions ranging in energy from 80 to $600 \mathrm{keV}$ to obtain amorphous zirconolite and to study the effects of ballistic collisions on the pre-existing He bubbles (obtained by prior He implantation). The various

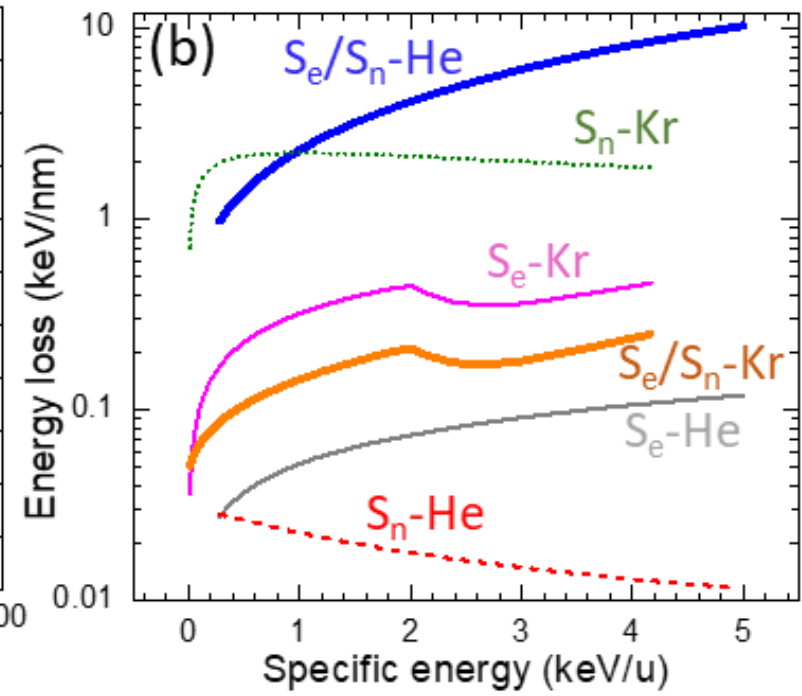

Figure 1: Implantation and energy loss profiles obtained using SRIM [25]. (a) 10 and $20 \mathrm{keV} \mathrm{He} \mathrm{implantation} \mathrm{profile} \mathrm{in} \mathrm{the}$ glass and zirconolite phases (the $y$-axis showing atoms. $\mathrm{cm}^{-3}$ is for a fluence of $1 \times 10^{16}$ ions.cm ${ }^{-2}$ ). Thicker and thinner lines/dots are for the glass and zirconolite respectively. The coloured rectangle shows the typical specimen thickness. Note that 

relatively lesser quantity of He is implanted within the specimen for $20 \mathrm{keV} \mathrm{He} \mathrm{compared} \mathrm{to} \mathrm{the} 10 \mathrm{keV} H e$ for a given fluence; (b) electronic $\left(S_{e}\right)$ and nuclear $\left(S_{n}\right)$ energy losses and their ratio $\left(S_{e} / S_{n}\right)$ for 20 keV He and 350 keV Kr ions in zirconolite as a function of the specific ion energy (ion energy divided by the ion mass number).

Table-I: Ion irradiation conditions. The ion energy is in keV, flux is in ions. $\mathrm{cm}^{-2} . \mathrm{s}^{-1}$, fluence is in ions. $\mathrm{cm}^{-2}$ and $S_{e}$ and $S_{n}$ in $\mathrm{keV} / \mathrm{nm}$. SRIM 2008 [25] was used for the range and dpa calculations with displacement energies of 48, 43, 25 and $15 \mathrm{eV}$ for $\mathrm{Ca}, \mathrm{Zr}$, $\mathrm{Ti}$ and $\mathrm{O}$ in the zirconolite phase using full damage calculation (density $=4.5 \mathrm{~g} \cdot \mathrm{cm}^{-3}$ ). The peak dpa is the maximum dpa value in a $100 \mathrm{~nm}$ thick specimen. Default values for displacement energy were taken for the glass phase. The projected ranges for various ions in zirconolite are $210 \pm 70 \mathrm{~nm}$ for $600 \mathrm{keV} \mathrm{Kr}, 120 \pm 40 \mathrm{~nm}$ for $350 \mathrm{keV} \mathrm{Kr,} 30 \pm 12 \mathrm{~nm}$ for $80 \mathrm{keV} \mathrm{Kr}$, $65 \pm 30 \mathrm{~nm}$ for $10 \mathrm{keV} \mathrm{He}, 120 \pm 45 \mathrm{~nm}$ for $20 \mathrm{keV} \mathrm{He}$. The projected ranges for various ions in the glass phase are $315 \pm 80$ $\mathrm{nm}$ for $600 \mathrm{keV} \mathrm{Kr}, 180 \pm 50 \mathrm{~nm}$ for $350 \mathrm{keV} \mathrm{Kr,} 45 \pm 14 \mathrm{~nm}$ for $80 \mathrm{keV} \mathrm{Kr}, 90 \pm 40 \mathrm{~nm}$ for $10 \mathrm{keV}$ He and $180 \pm 60$ nm for 20 keV He. $\phi_{\text {th }}$ represents the bubble formation threshold fluence in the ceramic phase (the minimum fluence at which the He

\begin{tabular}{|c|c|c|c|c|}
\hline $\begin{array}{l}\text { Ion energy } \\
\text { and species }\end{array}$ & $\mathrm{T}(\mathrm{K})$ & $\begin{array}{c}\text { Flux } \\
\left(\text { ions.cm }{ }^{-2} \cdot \mathrm{s}^{-1}\right)\end{array}$ & $\begin{array}{l}\text { Maximum } \\
\text { fluence } \\
\text { (ions.cm }{ }^{-2} \text { ) } \\
\text { [peak dpa] }\end{array}$ & $\begin{array}{l}\text { Bubble formation } \\
\text { threshold fluence } \\
\text { in the ceramic } \\
\text { phase (ions.cm-2) }\end{array}$ \\
\hline $\begin{array}{l}10 \mathrm{keV} \mathrm{He} \\
{\left[S_{e}=0.08,\right.} \\
\left.S_{n}=0.016\right]\end{array}$ & 143 & $3.27 \times 10^{13}$ & $1.7 \times 10^{17}[\sim 7.7]$ & $\begin{array}{c}4 \times 10^{16}<\varphi_{\text {th }} \\
\leq 8 \times 10^{16}\end{array}$ \\
\hline $10 \mathrm{keV} \mathrm{He}$ & 295 & $2.19 \times 10^{13}$ & $1.5 \times 10^{17}[\sim 6.8]$ & $\sim 4 \times 10^{16}$ \\
\hline $10 \mathrm{keV} \mathrm{He}$ & 373 & $2.13 \times 10^{13}$ & $2.5 \times 10^{16}[\sim 1.1]$ & $\sim 2.1 \times 10^{16}$ \\
\hline $10 \mathrm{keV} \mathrm{He}$ & 473 & $2.15 \times 10^{13}$ & $1 \times 10^{17}[\sim 4.5]$ & $\sim 2 \times 10^{16}$ \\
\hline $\begin{array}{c}10 \mathrm{keV} \mathrm{He} \mathrm{+} \\
350 \mathrm{keV} \mathrm{Kr} \\
{\left[S_{e}=0.46\right.} \\
\left.S_{n}=1.85\right]\end{array}$ & 143 & $\begin{array}{c}4.6 \times 10^{12} \text { (for } \mathrm{Kr} \text { ) } \\
1.5 \times 10^{13} \text { (for } \\
\mathrm{He} \text { ) }\end{array}$ & $\begin{array}{c}1.93 \times 10^{15}(\text { for } \mathrm{Kr}) \\
{[\sim 6.1]} \\
1.1 \times 10^{17}(\text { for } \mathrm{He}) \\
{[\sim 5]}\end{array}$ & $\begin{array}{c}7.2<\varphi_{\text {th }} \leq \\
8.2 \times 10^{16}\end{array}$ \\
\hline $\begin{array}{l}10 \mathrm{keV} \mathrm{He} \mathrm{+} \\
350 \mathrm{keV} \mathrm{Kr}\end{array}$ & 373 & $\begin{array}{l}3.98 \times 10^{12}(\mathrm{Kr}) \\
2.13 \times 10^{13}(\mathrm{He})\end{array}$ & $\begin{array}{l}1.25 \times 10^{15}(\text { for } \mathrm{Kr}) \\
2.5 \times 10^{16}(\text { for } \mathrm{He})\end{array}$ & \\
\hline $\begin{array}{l}350 \mathrm{keV} \mathrm{Kr}+ \\
10 \mathrm{keV} \mathrm{He} \mathrm{+} \\
350 \mathrm{keV} \mathrm{Kr}\end{array}$ & 143 & $\begin{array}{c}1.6 \times 10^{12}(\mathrm{Kr}) \\
1.65 \times 10^{13}(\mathrm{He})\end{array}$ & $\begin{array}{c}1.48 \times 10^{15} \text { (for } \\
\mathrm{Kr})^{* 1} \\
\left.4.11 \times 10^{16} \text { (for } \mathrm{He}\right)\end{array}$ & $\sim 3.2 \times 10^{16}$ \\
\hline $\begin{array}{c}350 \mathrm{keV} \mathrm{Kr}+ \\
10 \mathrm{keV} \mathrm{He}\end{array}$ & 295 & $\begin{array}{l}4.78 \times 10^{12}(\mathrm{Kr}) \\
2.9 \times 10^{13}(\mathrm{He})\end{array}$ & $\begin{array}{l}3.8 \times 10^{14}(\text { for } \mathrm{Kr})^{* 2} \\
\left.1.5 \times 10^{17} \text { (for } \mathrm{He}\right)\end{array}$ & $\sim 4 \times 10^{16}$ \\
\hline $300 \mathrm{keV} \mathrm{He}$ & 295 & $2.55 \times 10^{13}$ & $1.4 \times 10^{17}[\sim 0.8]$ & No bubbles \\
\hline $80 \mathrm{keV} \mathrm{Kr}$ & 295 & $1.67 \times 10^{12}$ & $1.82 \times 10^{16}$ & Kr bubbles \\
\hline $\begin{array}{l}10 \text { keV He + } \\
\text { Annealing }\end{array}$ & 473 & $\begin{array}{l}2.15 \times 10^{13}(\mathrm{He}) \\
2.17 \times 10^{12}(\mathrm{Kr})\end{array}$ & $\begin{array}{c}1 \times 10^{17}(\mathrm{He})[\sim 4.5] \\
2.5 \times 10^{14}(\mathrm{Kr})\end{array}$ & \\
\hline
\end{tabular}




\begin{tabular}{|c|c|c|c|c|}
\hline $\begin{array}{c}(873-973 \mathrm{~K}) \\
+600 \mathrm{keV} \mathrm{Kr} \\
(\text { at } 295 \mathrm{~K})\end{array}$ & & & {$\left[^{\sim 0.6]}\right.$} & \\
\hline $20 \mathrm{keV} \mathrm{He}$ & 143 & $2.1 \times 10^{13}$ & $1.2 \times 10^{17}[\sim 3.4]$ & No He bubbles \\
\hline $\begin{array}{c}20 \mathrm{keV} \mathrm{He} \\
{\left[\boldsymbol{S}_{\boldsymbol{e}}=0.12,\right.} \\
\left.S_{n}=0.011\right]\end{array}$ & 295 & $1.6 \times 10^{13}$ & $1.7 \times 10^{17}[\sim 4.8]$ & $\begin{array}{c}\text { He bubbles seen } \\
\text { at } 1.7 \times 10^{17}\end{array}$ \\
\hline $20 \mathrm{keV} \mathrm{He}$ & 363 & $2.4 \times 10^{13}$ & $1.2 \times 10^{17}[\sim 2.5]$ & No He bubbles \\
\hline
\end{tabular}

*1: One single $\mathrm{Kr}$ fluence of $5 \times 10^{14}$ for amorphisation. Then He implantation to form the He bubbles and then additional $\mathrm{Kr}$ irradiation post He bubble formation. Total Kr fluence $=1.48 \times 10^{15}$.

*2: One single Kr fluence for amorphisation and then He implantation to form the He bubbles in the amorphous ceramic phase.

\subsection{Experimental Methodology for In-Situ Irradiation}

This section gives a detailed overview of the methodologies employed for the experimentation, data analysis and calculations.

\subsubsection{Formation of He bubbles}

The microscope at the MIAMI-2 facility (Hitachi-9500) is equipped with a Gatan Imaging Filter (GIF quantum) permitting electron energy loss spectroscopy (EELS) and Energy Filtered Transmission Electron Microscopy (EFTEM). Besides the diffractograms of various grains for their identification, EELS spectra and EFTEM images of the grains of interest were captured to confirm the presence of the key elements such as $\mathrm{Ca}, \mathrm{Zr}, \mathrm{O}$ and $\mathrm{Ti}$ in the $\mathrm{Zr}$-GC to ensure that the correct material was being studied. A typical example of a Zr-GC is shown in Figure 2 (am). Figure 2 (a) shows a bright field (BF) TEM image showing two grains labelled as G1 and G2. The diffractograms taken from the regions indicated by the circles are shown in Figure 2(b) and Figure 2(c) respectively. Figure 2 (d) and Figure 2(f) (inverted and rotated) show blown up diffractograms of G1 before the irradiation to highlight the streaking seen along the c-axis (as indicated by the arrow in Figure 2(f)). The streaking is indicative of the presence of stacking fault defects (the streaking takes place along the thinnest direction of the diffracting element) in the grain G1 as has been previously reported by Rossell in his seminal work on zirconolite[26][27]. Throughout this study, grains with and without stacking faults along the c-axis were observed but they did not seem to play any observable role in the nucleation of He bubbles and are therefore omitted from any discussion.

Furthermore, in some cases, small nanoparticles (grains) of $\mathrm{ZrO}_{2}$ were found to be embedded inside the zirconolite grains. Because $\mathrm{ZrO}_{2}$ was used as one of the starting materials for the $\mathrm{Zr}$-GC they are essentially unreacted particles. Effects of heavy ion irradiation on these nanoparticles and their role in He precipitation was also studied. This aspect will be addressed separately in sections 3.3 .2 and 4.5. Figure 2 (e) shows the diffractogram of grain-G2 after amorphisation (details are given later). The grains were assumed to be fully 
135 amorphous when no diffraction spots were seen (TEM amorphous). These grains will be referred to as the 136 amorphous zirconolite. In the cases where some diffraction spots were visible either because of the partial 137 amorphisation of the specimen or because of the presence of some undamaged material present beyond the 138 projected range of the ions (such that the distinction between these two cases was not possible), we will use the 139 term damaged zirconolite instead. Figure $2(\mathrm{~g})$ and $(\mathrm{h})$ show typical low-resolution core-loss EELS spectra of G1 140 showing $\mathrm{Ca}(\sim 346,350 \mathrm{eV}), \mathrm{Ti}(\sim 456,460 \mathrm{eV})$ and $\operatorname{Zr}(\sim 2222,2306 \mathrm{eV})$ edges. Figure $2(\mathrm{i}-\mathrm{I})$ show EFTEM maps of $141 \mathrm{Ti}, \mathrm{Ca}, \mathrm{O}$ and $\mathrm{Zr}$ respectively captured using energy windows of $30 \mathrm{eV}$ for $\mathrm{Ca}$, $\mathrm{Ti}$ and $\mathrm{O}$ and $50 \mathrm{eV}$ for $\mathrm{Zr}$ (collection 142 angle $>100 \mathrm{mrad}$, the three-window method was used for elemental maps[28]). In the case of O, a jump-ratio 143 image is shown whereas for other elements direct elemental maps are shown (this was to prevent the Ti edges 144 at $460 \mathrm{eV}$ from affecting the background subtraction for $\mathrm{O}$ at $532 \mathrm{eV}$ ). Zirconium elemental maps were relatively 145 noisy and for speed and convenience EELS spectra of all the above-mentioned elements were captured whereas 146 EFTEM maps of $\mathrm{Ca}, \mathrm{Ti}$ and $\mathrm{O}$ only were captured for the majority of the grains (unless there was a specific need 147 to obtain better quality Zr EFTEM maps, as discussed later, to differentiate the $\mathrm{ZrO}_{2}$ particles from the zirconolite 148 matrix). These additional elemental maps are provided in the supplementary information (SI) and will be referred 149 to from time to time. Besides elemental maps, thickness maps in terms of the inelastic mean free path (IMFP, 150 written as $\lambda_{i}$ ) of the various grains were also captured so as to systematically follow any thickness related effects 151 (for instance, on amorphisation and presence/absence of He bubbles in thick/thin grains). Figure 1 ( $\mathrm{m}$ ) shows a 152 typical thickness map in terms of $\lambda_{\mathrm{i}}$. Due to a lack of studies on the conversion of $\lambda_{\mathrm{i}}$ to absolute specimen thickness 153 for the type of materials studied here, it is addressed separately in section 2.2.3 to allow the researchers to 154 convert $\lambda_{i}$ to absolute specimen thickness and a supplementary excel file is included to do that.

Throughout this study, grains with thicknesses ranging from about 0.2 to 1.2 IMFP were obtained using 156 the FIB. It is worth mentioning that no He bubbles were observed in grains with thicknesses $\leq 0.3 \lambda_{\mathrm{i}}$ for $10 \mathrm{keV}$ $157 \mathrm{He}$ (discussed in section 3.3). This is because the projected range of the $10 \mathrm{keV}$ He ions is greater than $0.3 \lambda_{\mathrm{i}}$ and 158 therefore there was minimal He implantation in these thin specimens. For this reason, the observation and the 159 analysis of He bubbles was restricted to grains with thicknesses between $0.5 \lambda_{\mathrm{i}}$ and $1.0 \lambda_{\mathrm{i}}$. 


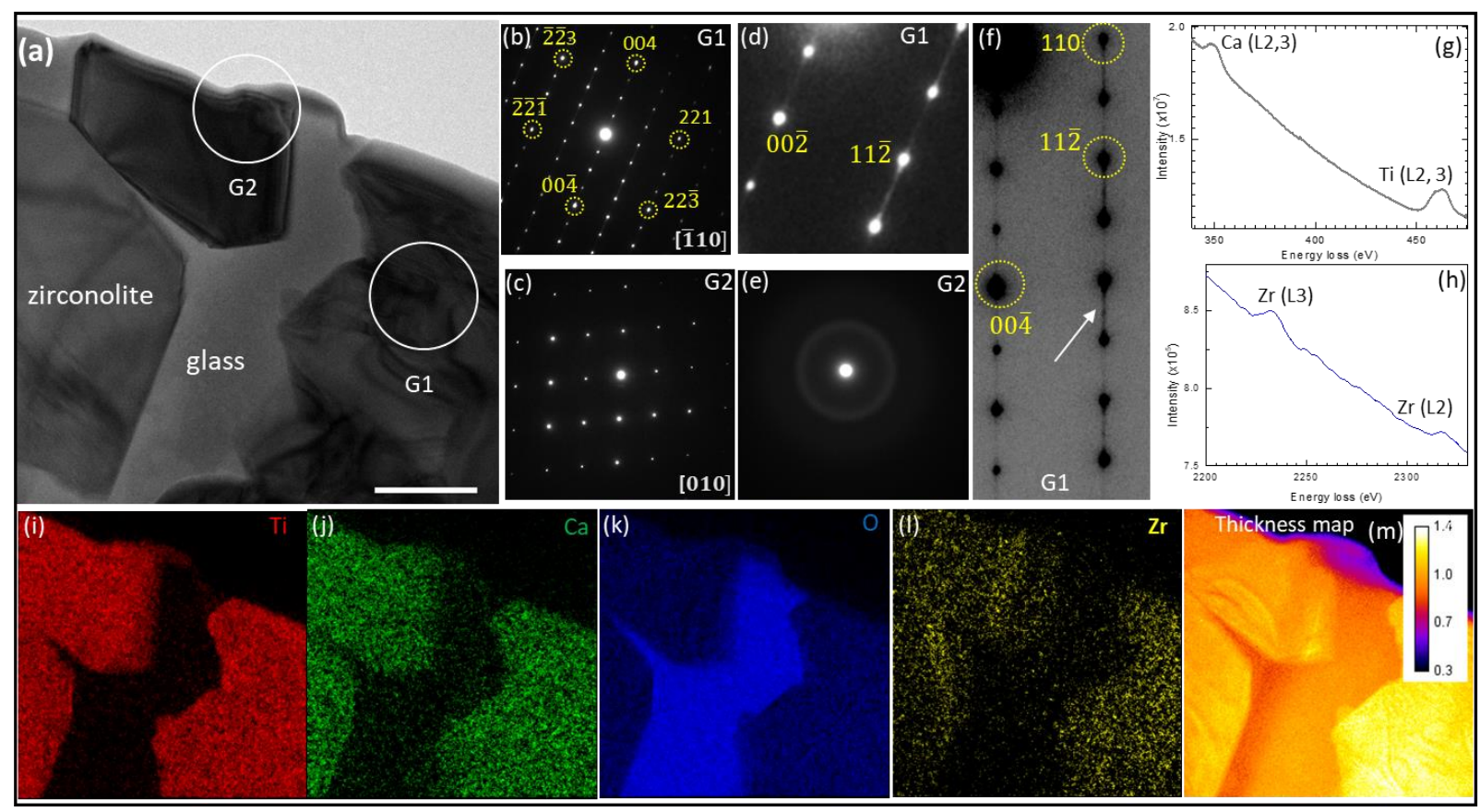

Figure 2: Typical bright-field TEM images (BF-TEM), diffractograms, EFTEM maps and EELS spectra of zirconolite-based glassceramics. (a) A BF-TEM image showing the glass and zirconolite phases. The circles indicate the regions from which the diffraction patterns shown in (b-f) were taken; (b-c) diffractograms of grains $G 1$ and G2 before any irradiation; (d) a magnified version of the diffractogram of G1 grain to highlight the streaking. This is further processed in image (f) which shows a rotated and inverted version of this diffractogram to highlight the streaking, as shown by the arrow, indicating the presence of stacking fault defects; (e) diffraction pattern of G2 grain after amorphisation; (g, h) core-loss EELS spectra showing Ca, Ti and Zr edges; (i-I) EFTEM elemental maps; and, (m) specimen thickness map shown in terms of the inelastic mean free path of electrons (note that one inelastic mean free path $=130 \mathrm{~nm}$. See section 2.2 .3 for more details). (Scale mark in $(a)=500 \mathrm{~nm})$.

\subsubsection{Amorphisation and disorder due to He irradiation}

In addition to studying the formation of He bubbles using $10 \mathrm{keV}$ He ions, separate studies specifically aimed at studying the amorphisation/disorder in zirconolite due to He irradiation were performed at three different temperatures (143, 295 and $363 \mathrm{~K})$ using $20 \mathrm{keV}$ He ions. The higher energy He ions were chosen primarily because $10 \mathrm{keV}$ He implantation studies at $143 \mathrm{~K}$ suggested that while He was able to induce amorphisation, a complete amorphisation was not observed due to the relatively small projected range of $10 \mathrm{keV} H e$ ions ( $65 \pm 30$ $\mathrm{nm}$ ) compared to the specimen thickness. This was indicated by the observation that the intensity of the amorphous rings and diffraction spots seemed to saturate after a certain fluence. $20 \mathrm{keV}$ energy was regarded as a good compromise between limiting the He implantation while maintaining a similar damage rate as with 10 $\mathrm{keV}$ ions. The studies were performed at the same/similar temperatures at which the He bubble formation was studied and therefore allowed a better understanding of the concurrent effects of He induced structural disorder and He bubble nucleation. For this study, crushed grains of zirconolite were used to completely avoid any FIB damage (even though the diffraction patterns of the FIBed specimen shown in Figure 2 (b, c) did not show any major signs of amorphisation) and therefore better follow the evolution of disorder/amorphisation due to He 
184 ions alone. The grains ranged in thickness from 0.2 to about $1.5 \lambda_{\mathrm{i}}$. To reliably compare the results obtained at 185 different temperatures and in various grains/specimens (at a given temperature) diffraction patterns were 186 captured from at least three pre-selected grains (which appeared thin in the TEM images) and then in various 187 regions of a given grain (by displacing the selected area aperture). This allowed better comparison of 188 amorphisation results at various temperatures by using similar specimen thicknesses and also enabled studying 189 the effect of specimen thickness on amorphisation dose (the studies on the kinetics of amorphisation will not be 190 addressed in this article). The methodology used to determine the "similar grains" is described in detail in section1912 of the SI.

\subsubsection{Relation between inelastic mean free path $\left(\lambda_{i}\right)$ and absolute specimen thickness}

Although there are several TEM studies of radiation damage and amorphisation of ceramics available in the literature, the absolute specimen thickness and its effects are rarely mentioned or addressed in these studies. This is despite the fact that it is one of the most important factors in accurately evaluating the critical dose for amorphisation. Perhaps the biggest reason for this is a lack of data on the inelastic mean free path $\left(\lambda_{i}\right)$ of electrons for these types of materials. To fill this void, two approaches, one theoretical and one experimental, are discussed in detail in section-3 of the SI and briefly below.

The theoretical approach is based on relativistic TPP-2M equation which is derived from a modified relativistic Bethe equation and other material-dependent parametric equations [29][30]. Given the flexibility, wide applicability, and availability of the data necessary for TPP-2M equation, it offers a fairly easy way of calculating $\lambda_{i}$ over a wide energy range covering most TEMs and are therefore of interest to the community. $A$ supplementary Excel sheet called "Inelastic Mean Free Path Calculator" along with the necessary data is provided with this article for the estimation of the mean free paths. The experimental approach is based on the KramersKronig analysis of the EELS spectra. Using this approach, the inelastic mean free path for $300 \mathrm{keV}$ electrons in zirconolite was evaluated to be 120 to $130 \mathrm{~nm}$ comparing reasonably well with the estimates from the TPP-2M equations ( $150 \mathrm{~nm}$ ). In this article $\lambda_{i}=130 \mathrm{~nm}$ for $300 \mathrm{keV}$ electrons will be used for electrons.

\subsubsection{Annealing, void formation and recrystallization}

The specimens implanted with either He to form the He bubbles or irradiated with heavy ions to form amorphous zirconolite were annealed using a Gatan double tilt heating holder to study the effects of annealing on He bubbles and recrystallization. The specimens were heated at a rate of $100 \mathrm{~K} /$ minute to the desired temperature and then imaged at regular intervals (isothermal annealing). Diffractograms and BF-TEM images were taken to follow the effects of annealing. The electron beam was switched off during the annealing and used only to capture the TEM images (within 1s). The pressure in the TEM column ranged from about $8 \times 10^{-8}$ to $6 \times 10^{-7} \mathrm{mbar}$.

\section{Results}




\subsubsection{He bubble formation at $143 \mathrm{~K}$}

218 During implantation with $10 \mathrm{keV}$ He ions, BF-TEM images in under and over-focus condition were captured after 219 regular fluence intervals of about $2 \times 10^{16}$ ions. $\mathrm{cm}^{-2}$ (or less). The first signs of He bubbles in the ceramic phase 220 were seen after $8 \times 10^{16} \mathrm{He} . \mathrm{cm}^{-2}$. BF-TEM images showing the evolution of He bubbles as a function of the fluence 221 up to $1.7 \times 10^{17} \mathrm{He} . \mathrm{cm}^{-2}$ are shown in Figure $3(\mathrm{a}-\mathrm{i})$ (The EELS spectra and EFTEM maps of these grains are shown 222 in Fig. S1 in the SI). The relatively bright region in the top left corner of the images is the glass phase whereas the 223 darker region is the ceramic phase (zirconolite). The He bubbles in the ceramic phase can be identified as small 224 bright features in the under-focus images (as indicated in (d)). The He bubbles grew in size and became more 225 easily visible for fluences $\geq 10^{17} \mathrm{He}_{\mathrm{cm}} \mathrm{cm}^{-2}$. Figure $3(\mathrm{~h}, \mathrm{i})$ show higher magnification images of the region indicated 226 by the rectangle in Figure $3(\mathrm{~g})$ in under and over-focus imaging condition to better visualize the He bubbles.

227 Typical bright/dark contrast for the bubbles in the under/over-focus imaging condition can be seen as indicated 228 for some of the encircled bubbles. No He bubbles were seen in the glass phase under current implantation 229 conditions.

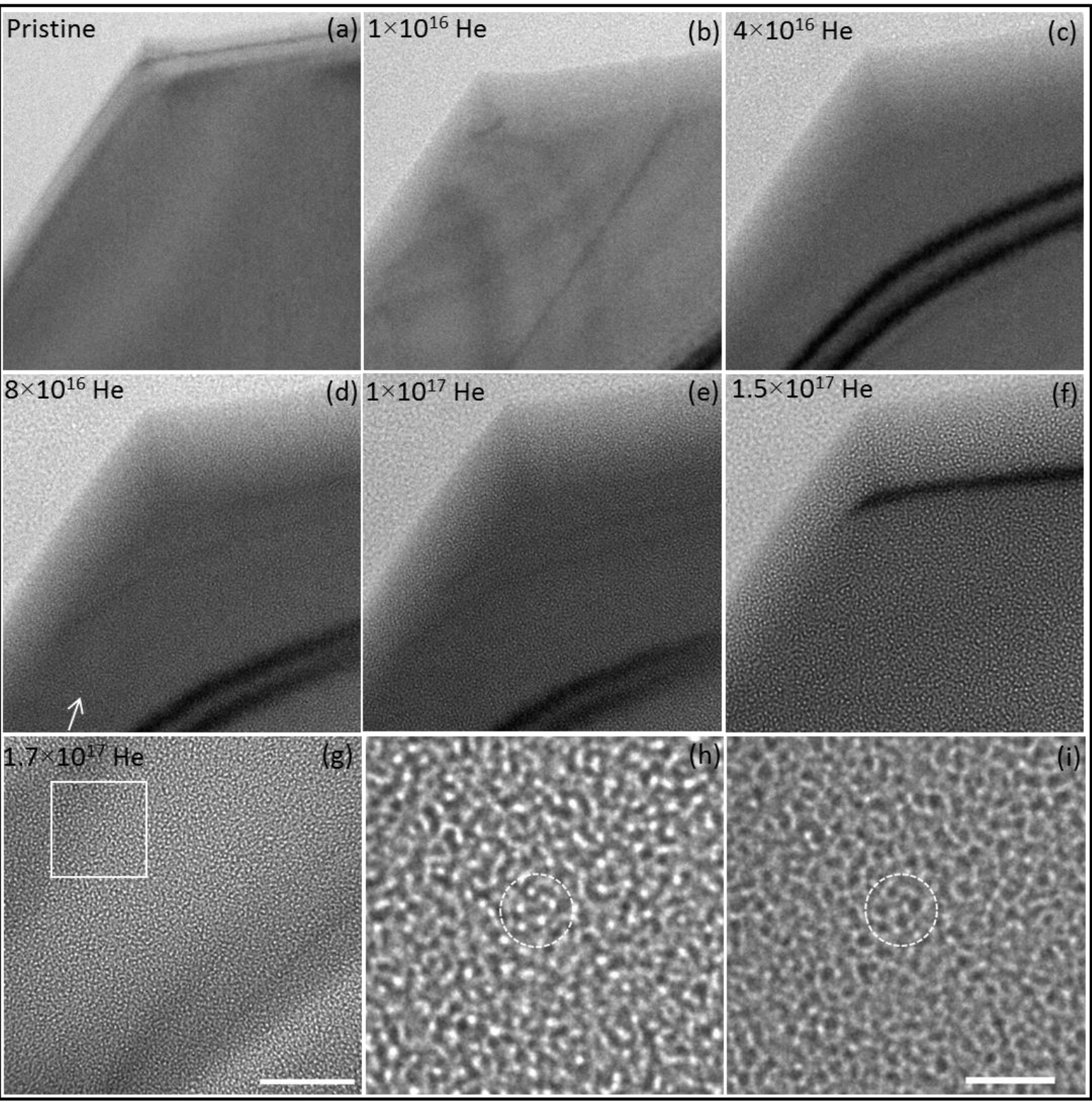


231 Figure 3: He bubbles in zirconolite phase of the glass-ceramic (Zr-GC) after implantation with $10 \mathrm{keV} \mathrm{He} \mathrm{ions} \mathrm{at} 143 \mathrm{~K}$. (a-g) 232 Evolution of He bubbles as a function of the He fluence (ions. $\mathrm{cm}^{-2}$ ). The first signs of He bubbles were seen after $8 \times 10^{16} \mathrm{He}^{\mathrm{cm}}$ 2. One such He bubble is indicated by the arrow in the image-(d). Higher magnification under and over-focus images of the region indicated by the rectangle in image-(g) are shown in (h)-(i) respectively (scale bar $=100 \mathrm{~nm}$ for (a)-(g) and $25 \mathrm{~nm}$ for $(g)-(i)$, image defocus $\left.\left(d_{f}\right) \sim 2 \mu m\right)$.

The evolution of He bubble size as a function of the He fluence is shown in Figure 4 (a). The distribution showed a shift towards a larger size at the expense of smaller bubbles with an increase in the fluence. This can directly be seen in Figure 4 (a) itself and also in Figure 4 (b); which shows an increase in the mean and maximum bubble size. The largest He bubbles seen at the highest fluence of $1.7 \times 10^{17} \mathrm{He}_{\mathrm{cm}} \mathrm{cm}^{-2}$ were just under $3 \mathrm{~nm}$ whereas the mean He bubble diameter was about $1 \mathrm{~nm}$. The total projected area of the bubbles is given in Figure 4 (c) which was fairly low ( $0.5 \%$ ) up to $1.5 \times 10^{17}{\mathrm{He} . \mathrm{cm}^{-}}^{2}$ and showed a very large increase after that $(\sim 2.5 \%)$. The He bubble sizes and the projected area were evaluated using the particle analysis tool of the Fiji software [31].
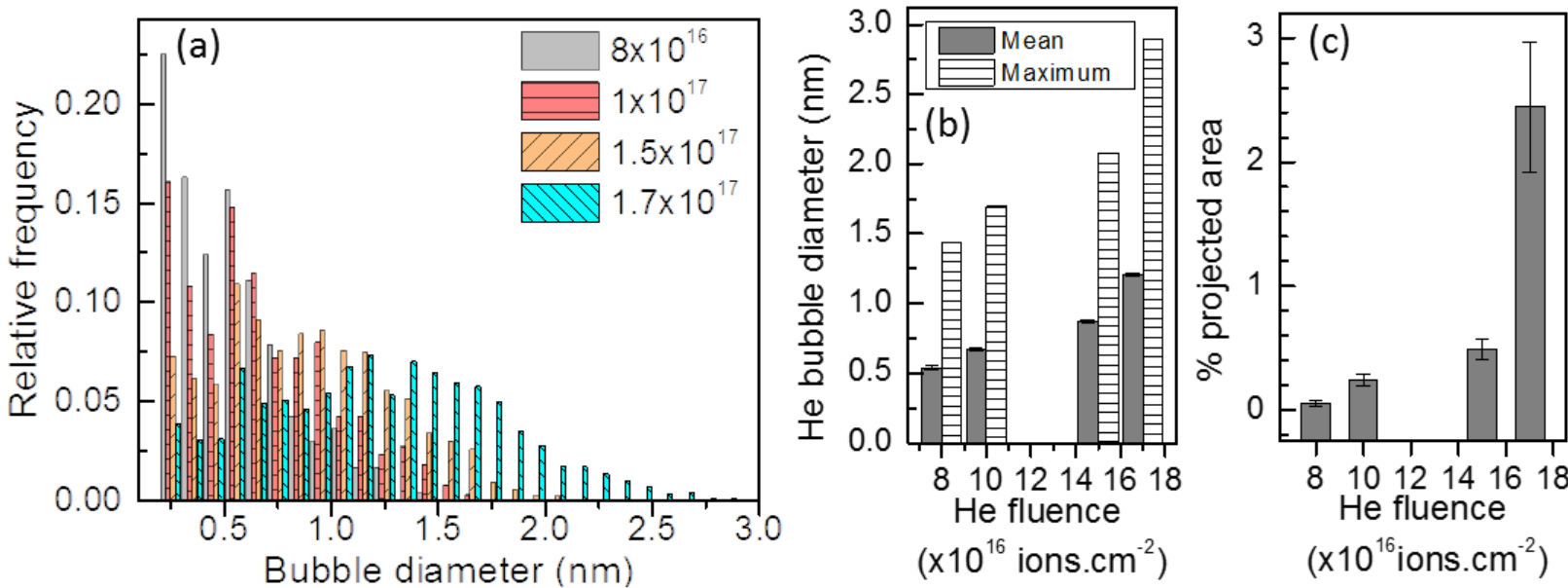

Bubble diameter $(\mathrm{nm})$

Figure 4: Evolution of He bubbles in zirconolite at $143 \mathrm{~K}$. (a) He bubble distributions at various fluences (ions. $\mathrm{cm}^{-2}$ ); (b) the evolution of the mean and the maximum bubble size with fluence (error bars are standard errors of the mean); and (c) the evolution of projected He bubble area as a function of the He fluence (the projected area was calculated in three different regions and the error bars show the standard error of the mean).

\subsubsection{He bubble formation at higher temperatures $(295,373$ and $473 \mathrm{~K})$}

The same procedure used for the implantation at $143 \mathrm{~K}$ was followed in all the cases. For the case of the He implantation at $295 \mathrm{~K}$, the first signs of He bubbles were seen at a fluence of $4 \times 10^{16} \mathrm{He}_{\mathrm{cm}} \mathrm{cm}^{-2}$ and an increase in bubble size was observed with an increase in the fluence up to the highest studied fluence of $1.5 \times 10^{17} \mathrm{He}^{-\mathrm{cm}^{-2}}$. Under-focus images for various fluences are shown in Figure 5 (a-c). The size distribution of He bubbles, mean size, maximum size and the projected area are shown in Fig. S2 in the SI. The largest He bubbles were just under $2.3 \mathrm{~nm}$ in diameter and the mean size was about $1.2 \mathrm{~nm}$ at $1.5 \times 10^{17} \mathrm{He}_{\mathrm{cm}} \mathrm{cm}^{-2}$. No He bubbles were observed in the glass phase. However, some oxygen bubbles in the glass phase as indicated by the arrow in Figure 5 (a) were observed at this temperature. The oxygen bubbles were formed due to electron beam exposure of the specimen before He implantation. The formation of oxygen bubbles at various temperatures is addressed separately in 
section 3.9 where we discuss the sensitivity of glass specimens to the electron beam. The formation of oxygen bubbles in the glass phase at temperatures greater than $295 \mathrm{~K}$ was a general observation in this study. More detailed studies on the formation of oxygen bubbles in glasses under electron beam exposure and its dependence on temperature and flux have been addressed by Ollier et al. elsewhere [32].

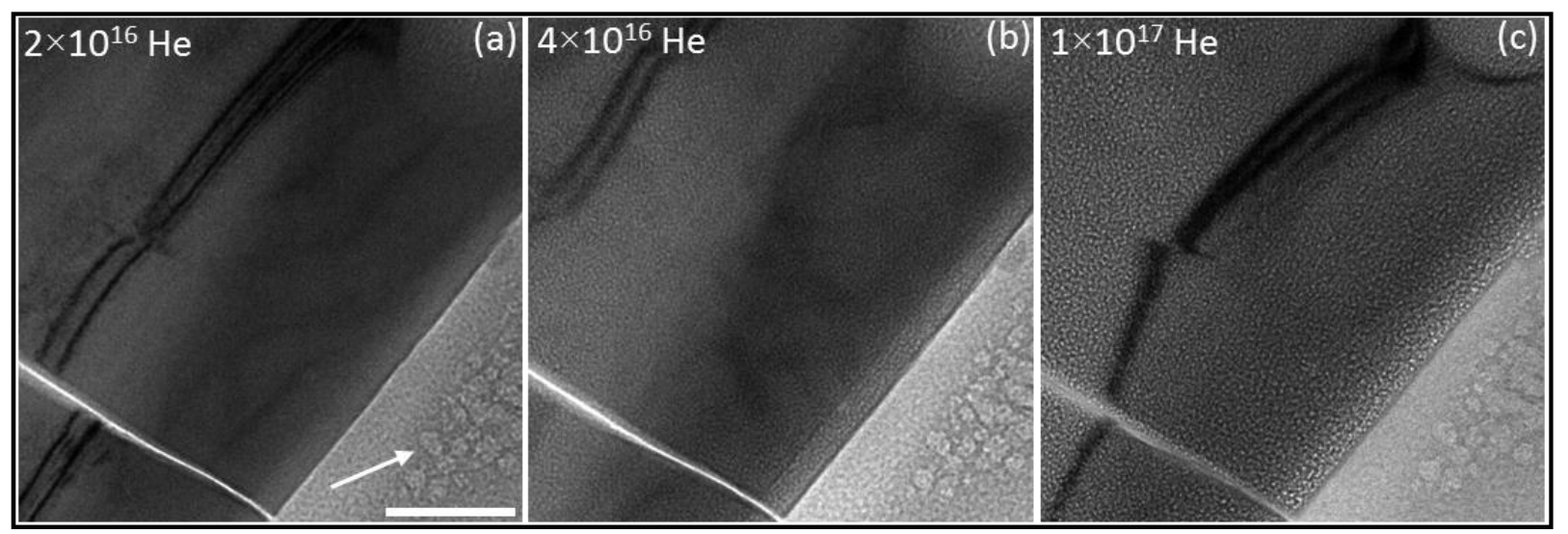

Figure 5: He bubbles in the ceramic phase of Zr-GC after implantation with $10 \mathrm{keV} H e$ ions at $295 \mathrm{~K}$. (a-c) Evolution of He bubbles as a function of He fluence (ions. $\mathrm{cm}^{-2}$ ). The size distribution is shown in Fig. S2 in the SI. The arrow in (a) indicates oxygen bubbles in the glass phase formed due to electron beam exposure (scale bar $=100 \mathrm{~nm}, d_{f} \sim 2 \mu \mathrm{m}$ under focus).

For the implantation at $373 \mathrm{~K}$, He bubbles in the ceramic phase were seen after implantation up to a fluence of $2.1 \times 10^{16} \mathrm{He}_{\mathrm{cm}} \mathrm{cm}^{-2}$. The implantation was further continued up to $2.5 \times 10^{16} \mathrm{He} \mathrm{cm}^{-2}$ to see the evolution of He bubbles. Under and over-focus images are shown in Fig. S3 in the SI. Except for the difference in the He fluence at which the bubbles were first observed, no major differences were observed in comparison to the studies at lower temperatures.

The implantation at $473 \mathrm{~K}$ was performed up to a fluence of $1 \times 10^{17} \mathrm{He}_{\mathrm{cm}} \mathrm{cm}^{-2}$ and the evolution of He bubbles as a function of the fluence was followed. The He bubbles in the ceramic phase were first observed at a

273 fluence of $2 \times 10^{16} \mathrm{He}_{\mathrm{cm}}{ }^{-2}$; which is essentially the same value as for the implantations at $373 \mathrm{~K}$. The He bubbles 274 at various fluences are shown in Figure 6 (a-f). The inset in (a) shows the size-distribution of He bubbles at various 75 fluences which followed the same trend as observed in the case of the implantation at $143 \mathrm{~K}$. 


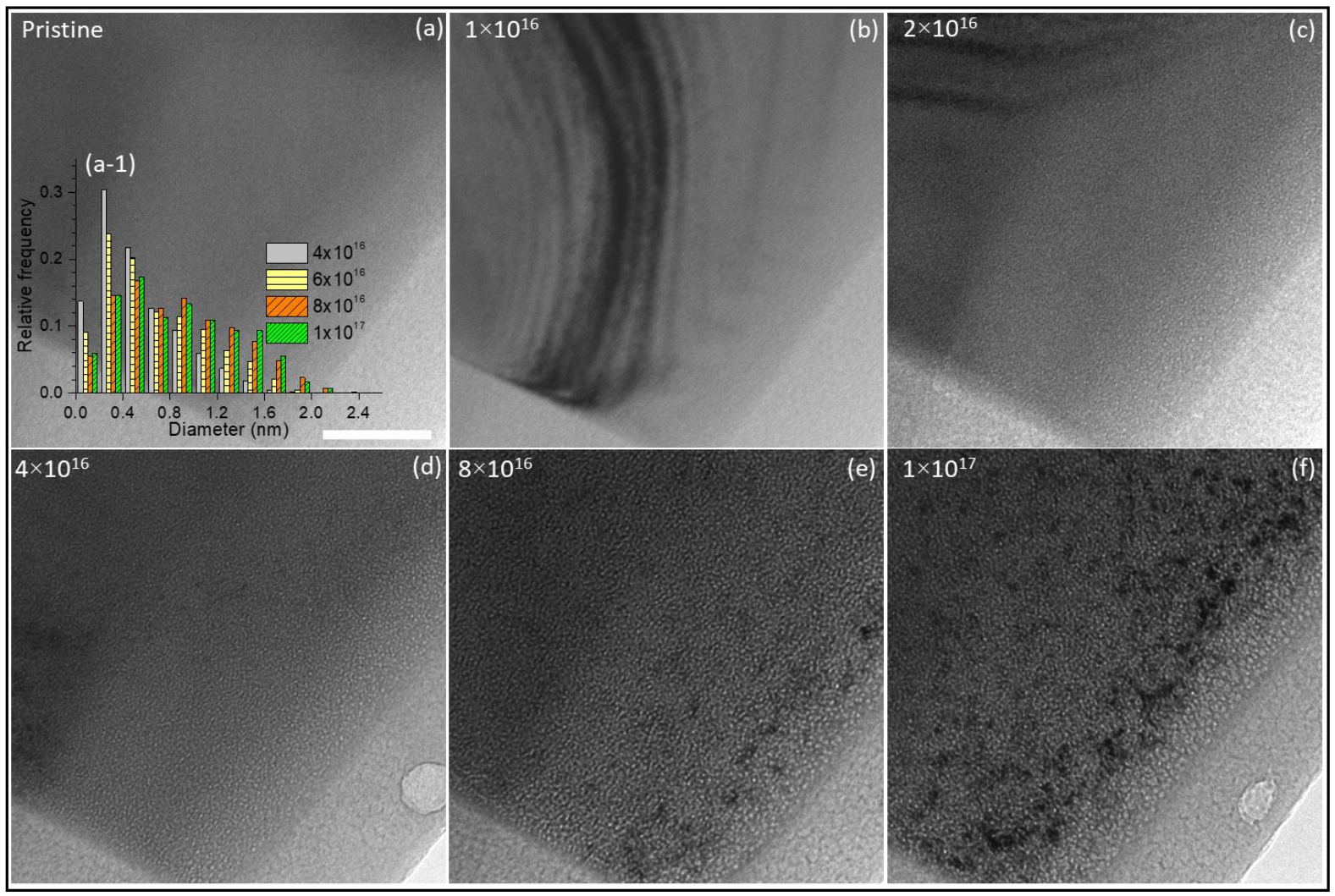

Figure 6: BF-TEM images showing the evolution of He bubbles in Zr-GC implanted with $10 \mathrm{keV}$ He at $473 \mathrm{~K}$. (a-f) Evolution of He bubbles as a function of the He fluence (ions. $\left.\mathrm{cm}^{-2}\right)$. The inset in (a) shows the size-distribution of He bubbles at various fluences (scale bar $=100 \mathrm{~nm}, d_{f} \sim 2 \mu m$ under-focus).

\subsection{He accumulation at interfaces}

\subsubsection{Glass-Ceramic interfaces}

No He bubbles were observed to preferentially nucleate at glass-ceramic interfaces in the specimens implanted with He ions under various implantation conditions. This is primarily because He bubbles did not nucleate in the glass phase itself due to the large He diffusion coefficient in both simple and complex glasses $\left(\sim 10^{-8}\right.$ for amorphous $\mathrm{SiO}_{2}$ to $>10^{-13} \mathrm{~cm}^{2} . \mathrm{s}^{-1}$ for more complex SON68 glass [33][34]) which allows the He to escape. Detailed studies of noble gas precipitation in simple and complex glasses have shown that diffusion coefficients of less than $10^{-17} \mathrm{~cm}^{2} \cdot \mathrm{s}^{-1}$ are needed to see bubble nucleation under this type of implantation conditions [35]. On the other hand, oxygen bubbles were readily formed in the glass phase at $295 \mathrm{~K}$ and higher temperatures within 5 to 10 minutes of normal TEM imaging due to electron beam damage (see Ref [32] for oxygen bubble formation in various glasses and the effect of temperature and electron flux). Based on the study of many specimens, we conclude that even in the case of oxygen bubbles there was no preferential nucleation at any specific sites or near the grains. However, in a few cases, a small glass region between the ceramic and the glass phase was found to be depleted of any large oxygen bubbles as shown in Figure 7 (a). In the majority of cases (almost always) oxygen bubbles were seen uniformly distributed in the glass phase and near the glass-ceramic interfaces as shown in Figure 7 (b). These observations are based on the analysis of multiple specimens that were studied and 
are highlighted here to caution about any misinterpretations that might arise from an isolated experiment. The potential reasons for the existence of the bubble denuded zone observed in certain cases are discussed later.

Furthermore, in the case of some wedge-shaped specimens with the thin wedges protruding into the glass phase (with the wedge being covered by the glass phase on top and/or bottom side), two different observations were made. In certain cases, relatively larger He bubbles were seen near the edges as shown in Figure 7 (c, d). Figure 7 (c) shows a glass region and the thin wedge-shaped zirconolite grain. The He bubbles near the thin wedge appear relatively larger compared to the He bubbles present inside the grain. This is highlighted in Figure 7 (d) which shows a larger portion of the ceramic phase in addition to the wedge to visually compare the He bubbles present near the wedge with the ones deeper inside (the bubbles are indicated by the arrows). In the case of the grains with sharp boundaries (no wedges), no such phenomenon was observed. This observation is attributed to the effect of specimen thickness such that He bubbles in very thin wedges appear slightly bigger whereas due to potentially multiple scattering in a thicker region the He bubbles appear smaller.

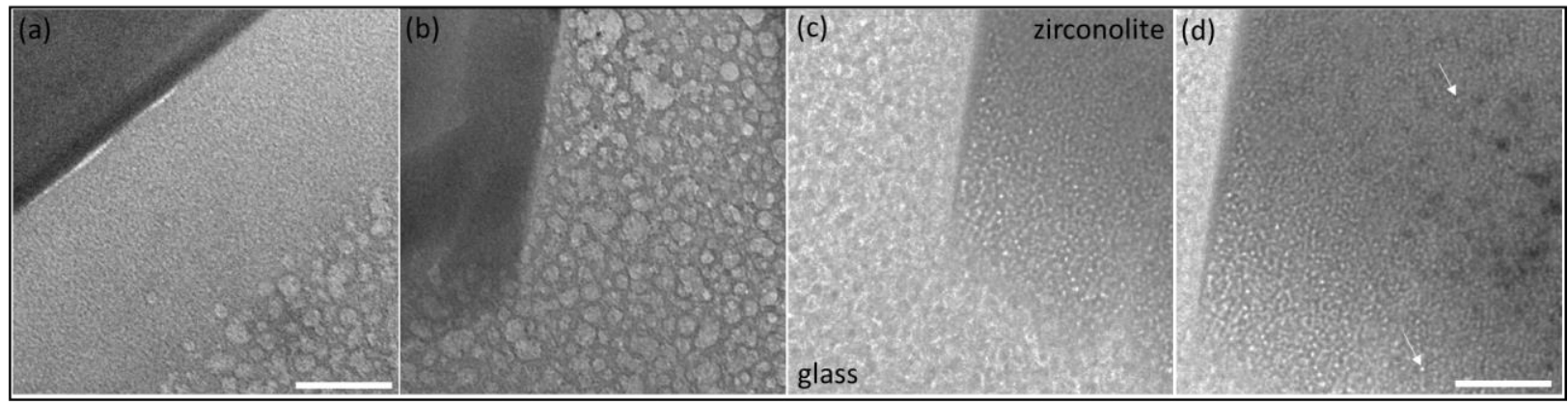

Figure 7. Formation of oxygen and He bubbles. (a) Formation of oxygen bubbles in the glass phase at $295 \mathrm{~K}$ during normal TEM imaging. Note a bubble denuded zone near the zirconolite grain which was seen in a few cases; (b) uniformly distributed oxygen bubbles in the glass phase as observed in the majority of the cases; $(c, d)$ appearance of relatively larger He bubbles near the edges of zirconolite grain. The image in (d) shows more of the zirconolite grain to compare the edge with the inside region (He fluence $\sim 2.5 \times 10^{16} \mathrm{He} . \mathrm{cm}^{-2}, T=373 \mathrm{~K}$, scale bar $=150 \mathrm{~nm}, \mathrm{df}=2 \mu \mathrm{m}$ under-focus).

In the second case, some of the thin wedges were found to be depleted of He bubbles altogether as shown in Figure $8(a-d)$. Figure $8(a)$ shows a wedge-shaped zirconolite grain implanted with $10 \mathrm{keV}$ He ions up to $9 \times 10^{16} \mathrm{He}_{\mathrm{cm}} \mathrm{cm}^{-2}$ at $143 \mathrm{~K}$. The thickness map is shown in Figure $8(\mathrm{~b})$ showing that the outer region is thinner than $0.4 \lambda_{i}$ (bluish region). Magnified images in the thicker region $\left(\lambda_{i}>0.5\right)$ showing the presence of He bubbles and near the thin wedge lacking any He bubbles are shown in Figure 8 (c) and Figure 8 (d) respectively. In this case, the He ions are completely traversing the thin wedge and therefore the He concentration needed to form the He bubbles is not reached. 


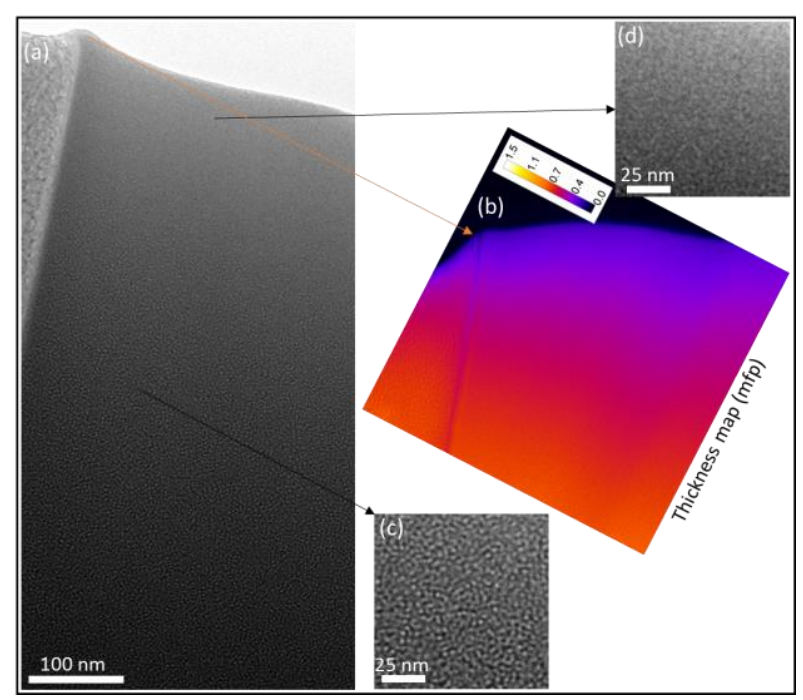

322 Figure 8: He bubbles in a wedge-shaped specimen of Zirconolite based glass-ceramic implanted with $10 \mathrm{keV}$ He ions. (a) He 323 bubbles in a wedge-shaped zirconolite grain implanted with $10 \mathrm{keV} \mathrm{He}$ at $143 \mathrm{~K}$ up to $9 \times 10^{16} \mathrm{He}_{\mathrm{cm}} \mathrm{cm}^{-2}$; (b) thickness map in 324 terms of $\lambda_{i}$; and, $(c, d)$ two regions (thick and thin) as indicated by the arrows with and without He bubbles respectively.

\subsubsection{Ceramic-Ceramic interface (grain boundaries and particle-matrix interface boundaries)}

326 In the majority of the cases, relatively larger He bubbles were seen to nucleate along the grain boundaries. Two 327 such examples showing the evolution of He bubbles at grain boundaries as a function of the He fluence are shown 328 in Figure 9 and Figure 10. These experiments were performed at $143 \mathrm{~K}$ (10 keV He). Figure 9 (a-d) shows low 329 magnification images to highlight the evolution of He bubbles at the grain boundary in Zr-GC. Higher 330 magnification images to highlight the intra-grain He bubbles are shown in Figure 9 (e-f) in the under and over331 focus condition respectively. Multiple such examples where significantly larger He bubbles were seen along the 332 grain boundaries are shown in Fig. S4 in the SI. 


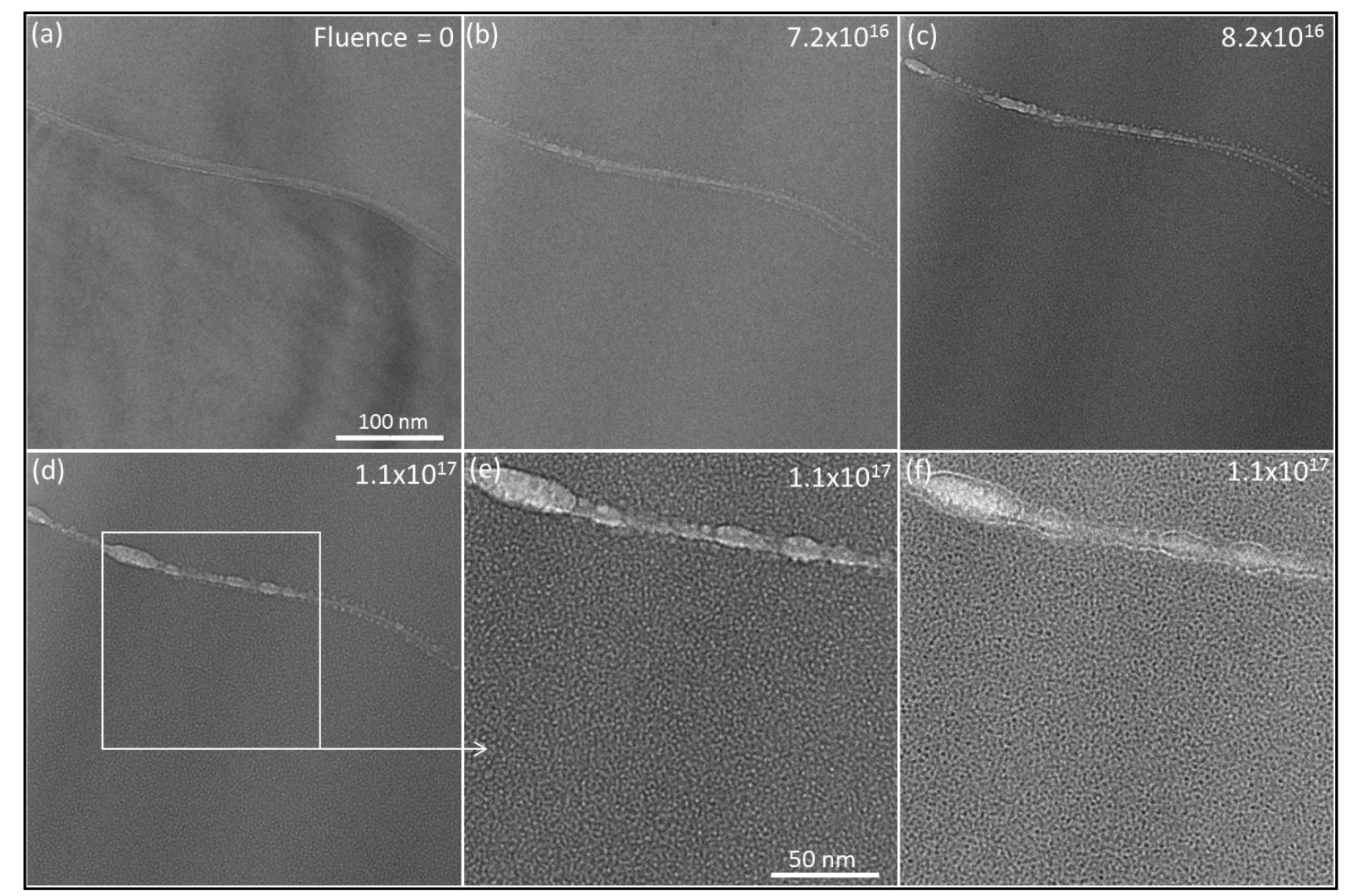

Figure 9: Implantation of zirconolite-based GC with $10 \mathrm{keV}$ He ions at $143 \mathrm{~K}$. (a) Before He implantation; (b-d) after implantation with He for various fluences as shown on the images (in ions. $\mathrm{cm}^{-2}$ ); and, (e-f) higher magnification images in under and over-focus condition of the region indicated by the rectangle showing small intra grain He bubbles relative to the large inter-grain He bubbles (scale bar $=100 \mathrm{~nm}, \mathrm{D}_{\mathrm{f}}=2 \mu \mathrm{m}$ under-focus for images $a$ - $d$ and, scale bar $=50 \mathrm{~nm}, D_{\mathrm{f}}=1 \mu \mathrm{m}$ for images e-f).

Another example and the one most commonly observed, of the He bubble nucleation at grain boundaries is shown in Figure 10 for various fluences (10 keV He at $143 \mathrm{~K})$. At $4 \times 10^{16} \mathrm{He}^{-\mathrm{cm}^{-2}}$ no intra-grain He bubbles were visible in the zirconolite but He bubbles were potentially present at grain boundaries (see Fig. S5 in the SI for the images of the pristine and some images at lower fluences). However, very small intra-grain He bubbles could be seen after $8 \times 10^{16} \mathrm{He} . \mathrm{cm}^{-2}$ whereas the inter-grain He bubbles were more distinct and larger. In all the cases, the inter-grain He bubbles were relatively prominent as compared to the intra-grain He bubbles especially at low He fluences. Because the size of He bubbles does not vary significantly at higher fluences, the distinction between inter and intra grain He bubbles is less obvious at high fluences (this is essentially because the maximum He bubble size seems to saturate after $3 \mathrm{~nm}$ and intra grain He bubbles catch up with the inter grain He bubbles at high fluences even though inter grain He bubbles appear more prominent at low fluences and attain the maximum size first). 


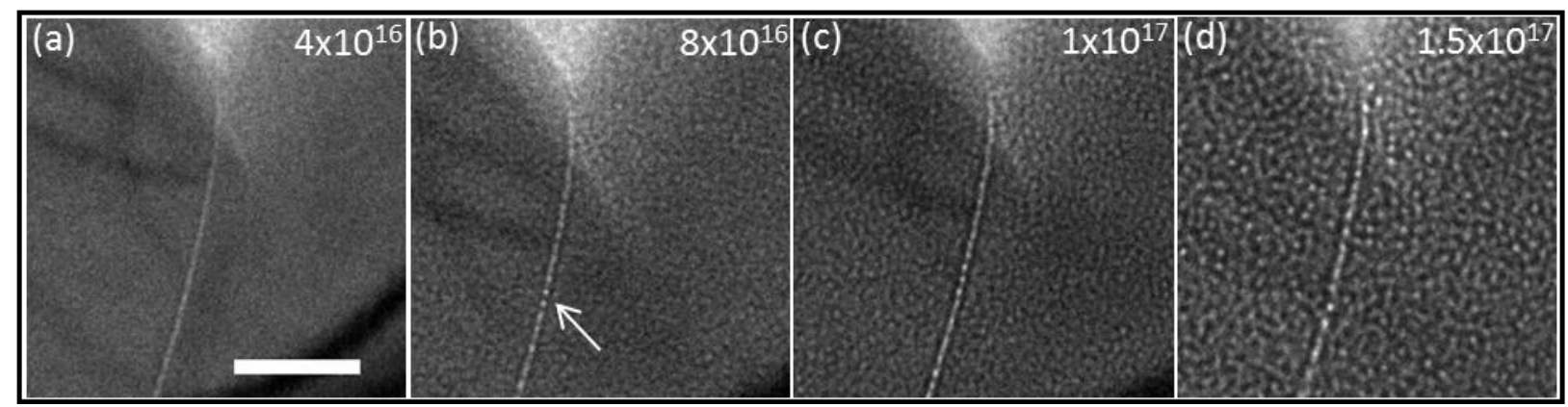

351 Figure 10: Evolution of He bubbles at grain boundaries at $143 \mathrm{~K}$ as a function of the He fluence (in ions.cm ${ }^{-2}$ ). The arrow in (b) 352 indicates inter-grain He bubbles (scale marker $=50 \mathrm{~nm}$ for all the images, $D_{f}=2 \mu \mathrm{m}$ under-focus).

353 Also, in many cases, small particles of $\mathrm{ZrO}_{2}$ (from tens to a few hundreds of nanometres big) were found 354 embedded in the zirconolite grains. These particles retained their crystallinity both during He and heavy ion 355 irradiations $\left(\mathrm{ZrO}_{2}\right.$ is known to be radiation resistant [36][37]). Furthermore, no cracks were formed in the 356 zirconolite grains or in/around the inclusions either due to amorphisation of the zirconolite grains or due to He 357 bubble formation. A typical example showing several $\mathrm{ZrO}_{2}$ particles (darker) in now amorphous zirconolite matrix 358 is shown in Figure 11. Figure 11 (a) shows a low magnification BF-TEM in which the dark appearing particles are $359 \mathrm{ZrO}_{2}$. EFTEM maps showing the distribution of $\mathrm{Ti}, \mathrm{Ca}$ and $\mathrm{Zr}$ are shown in Figure $11(\mathrm{~b}-\mathrm{d})$ respectively showing $\mathrm{Ca}$ 360 and Ti depleted and $\mathrm{Zr}$ enriched particles (zirconia is denser than zirconolite and contains about 33 at. \% of $\mathrm{Zr}$ 361 compared to zirconolite which contains only about 9 at. \% of $\mathrm{Zr}$. That is why $\mathrm{ZrO}_{2}$ particles show higher $\mathrm{Zr}$ signal 362 in Figure 11 (d) compared to the zirconolite matrix). Higher magnification images to highlight the presence of He 363 bubbles at the interface of the $\mathrm{ZrO}_{2}$ particles and the zirconolite matrix are shown in Figure 12 (a-e) whereas the 364 EFTEM maps to show the distribution of various elements and diffraction pattern of the particle to show its 365 crystalline nature are shown in Figure $12(f-i)$. In all the cases, He bubbles were observed to accumulate at the 366 particle-matrix interface (at times uniformly around the particles as seen in Figure 12 (d) and at times less 367 uniformly as in Figure 12 (e)) 


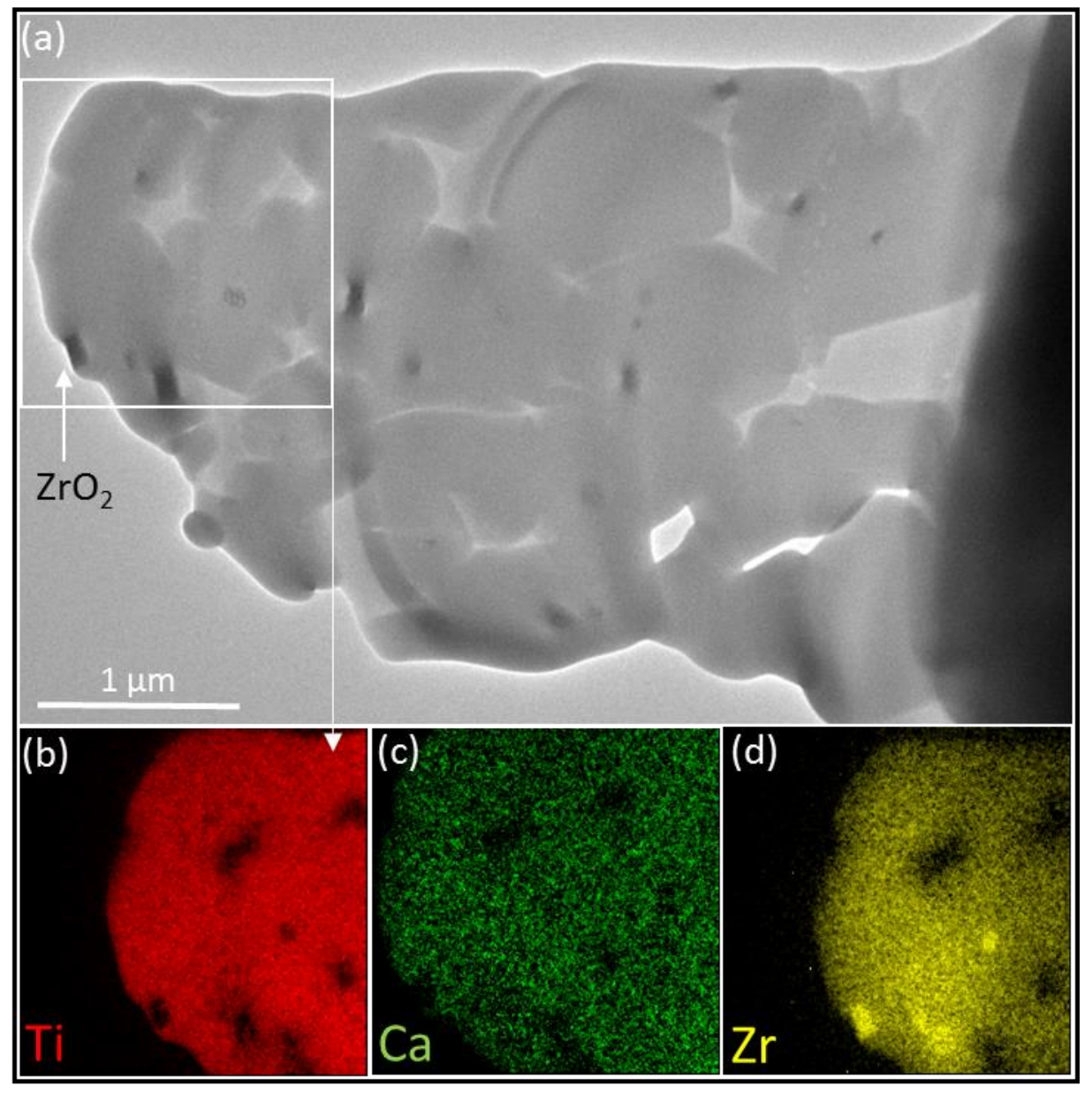

369 Figure 11: Presence of crystalline $\mathrm{ZrO}_{2}$ particles in zirconolite matrix. (a) A low magnification BF-TEM image showing dark appearing ZrO 370 particles; $(\boldsymbol{b}-\boldsymbol{d})$ distribution of $\mathrm{Ti}, \mathrm{Ca}$ and $\mathrm{Zr}$ in the region indicated by the rectangle in (a) (the specimen was first irradiated with $350 \mathrm{keV}$ $371 \mathrm{Kr}$ ions up to $5 \times 10^{14}$ ions. $\mathrm{cm}^{-2}$ and then with $10 \mathrm{keV}$ He ions up to $4.1 \times 10^{16} \mathrm{He}_{\mathrm{cm}} \mathrm{cm}^{-2}$ at $143 \mathrm{~K}$ ).

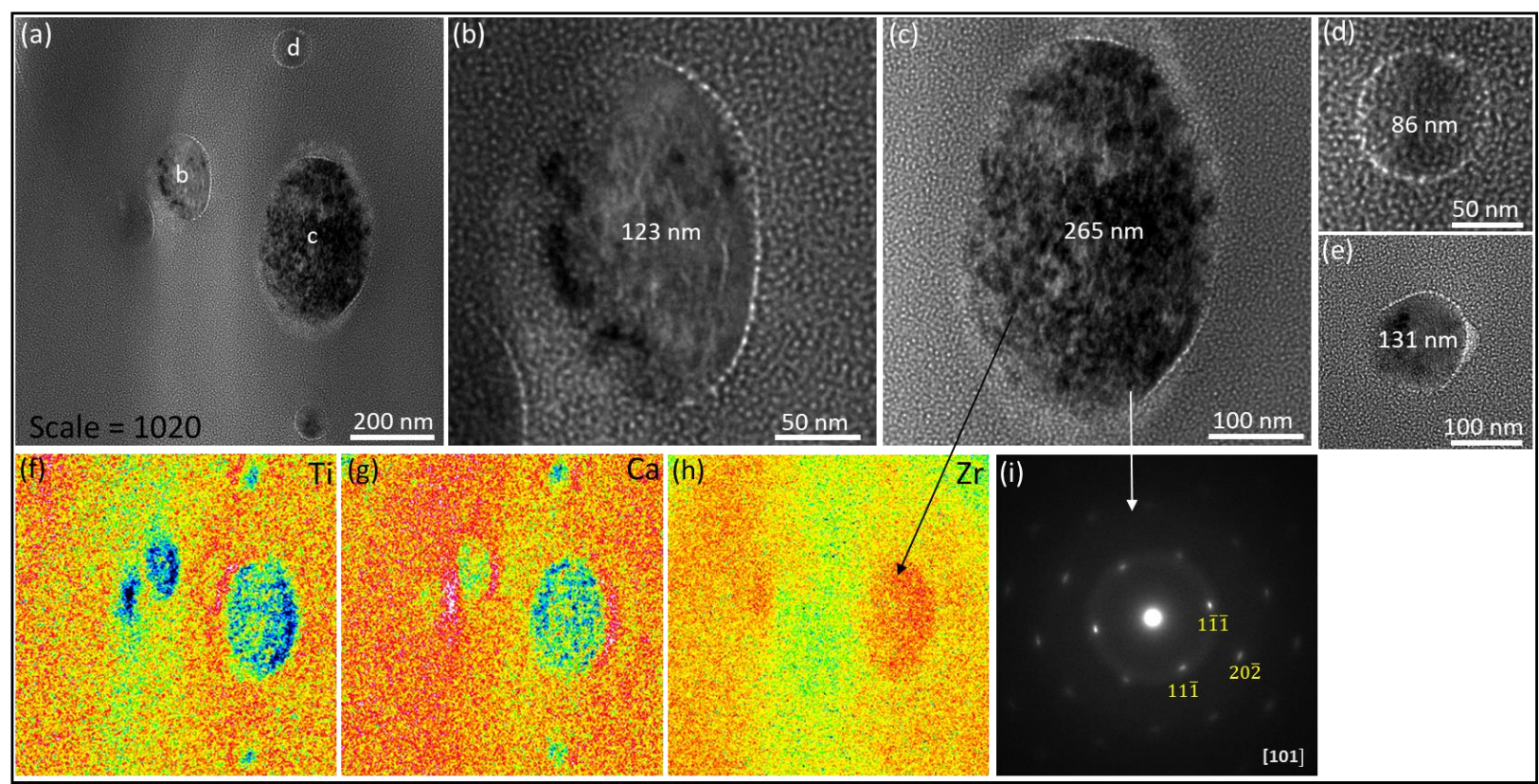

373 Figure 12: BF-TEM images showing the presence of He bubbles at the particle-matrix interface. (a) A low magnification image showing 374 several crystalline $\mathrm{ZrO}_{2}$ particles in an amorphous zirconolite matrix. Various labelled particles are shown in subsequent figures under the 
375

376

377

378

same label; (b-d) higher magnification images of the particles labelled in (a) showing He bubbles at the interface; (e) a particle from a different region not shown in (a); (f-h) EFTEM maps showing the distribution of Ti, Ca and $\mathrm{Zr}$; and, (i) a diffraction pattern from the $\mathrm{ZrO}_{2}$ particle shown in (c) (the specimen was first irradiated with $350 \mathrm{keV} \mathrm{Kr}$ ions up to $3.8 \times 10^{14} \mathrm{Kr}^{-\mathrm{cm}^{-2}}$ and then with $10 \mathrm{keV}$ He ions up to

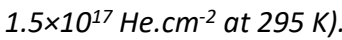

\subsection{Amorphisation/disorder due to He and $\mathrm{Kr}$ ion irradiations}

During implantation with $10 \mathrm{keV}$ He ions, signs of amorphisation simultaneously with He bubble formation were observed (especially at $143 \mathrm{~K}$ and to a lesser extent at higher temperatures). Because the projected range of 10 keV He ions ( $~ 60 \mathrm{~nm})$ was in most cases less than the specimen thickness, it was not possible to achieve full amorphisation throughout the specimen. This prevented us from accurately calculating the fluence/dpa required for full amorphisation or to ascertain whether He ions could induce full amorphisation at all. Furthermore, it also prevented us from confirming whether He bubbles were nucleating in an amorphous phase or a crystalline/disordered phase during the He implantation. For this reason, amorphisation studies were separately performed with $20 \mathrm{keV} \mathrm{He}$ ions (range $120 \mathrm{~nm}$ ). Although, a higher He energy could have been chosen to lessen the chances of He implantation, but then the damage rate would have been significantly less (i.e. higher He per dpa). To maintain almost a similar damage rate as with $10 \mathrm{keV}$ He ions, $20 \mathrm{keV}$ was regarded as a good compromise between limiting the implantation and retaining a similar damage rate.

The specimens were irradiated with $20 \mathrm{keV}$ He ions at least up to a fluence at which He bubbles were seen during $10 \mathrm{keV} \mathrm{He} \mathrm{implantation.} \mathrm{A} \mathrm{typical} \mathrm{example} \mathrm{showing} \mathrm{the} \mathrm{evolution} \mathrm{of} \mathrm{diffraction} \mathrm{patterns} \mathrm{(specimen}$ thickness $\sim 0.6 \lambda_{\mathrm{i}} \sim 80 \mathrm{~nm}$ ) at $295 \mathrm{~K}$ under $20 \mathrm{keV}$ He ion irradiation is shown in Figure 13. No visible change in the DPs was observed at a fluence of $2.3 \times 10^{15} \mathrm{He}_{\mathrm{cm}} \mathrm{cm}^{-2}(\mathrm{dpa} \sim 0.06)$ whereas a diffuse intensity background was observed at about $1.8 \times 10^{16} \mathrm{He} . \mathrm{cm}^{-2}(\mathrm{dpa} \sim 0.5)$. An amorphous ring was observed after $1.5 \times 10^{17} \mathrm{He}_{\mathrm{cm}} \mathrm{cm}^{-2}(\mathrm{dpa} \sim$ 4.2) the intensity of which was observed to have increased at the highest studied fluence of $1.7 \times 10^{17} \mathrm{He}_{\mathrm{cm}} \mathrm{cm}^{-2}$ (dpa 4.8). These data show that while He ions can induce disorder at room temperature, full amorphisation may require significantly larger fluences. Note that with $10 \mathrm{keV}$ He implantation at $295 \mathrm{~K}$, the He bubbles were observed only after about $4 \times 10^{16} \mathrm{He}_{\mathrm{cm}} \mathrm{cm}^{-2}$ (dpa $~ 1.8$ ). With $20 \mathrm{keV} \mathrm{He}$ ions, the damage level of $1.8 \mathrm{dpa}$ corresponds to about $6.4 \times 10^{16} \mathrm{He} . \mathrm{cm}^{-2}$ which is somewhat between images (e) and (f) in Figure 13. These results show that He bubbles at room temperature essentially nucleate in a disordered zirconolite structure. 


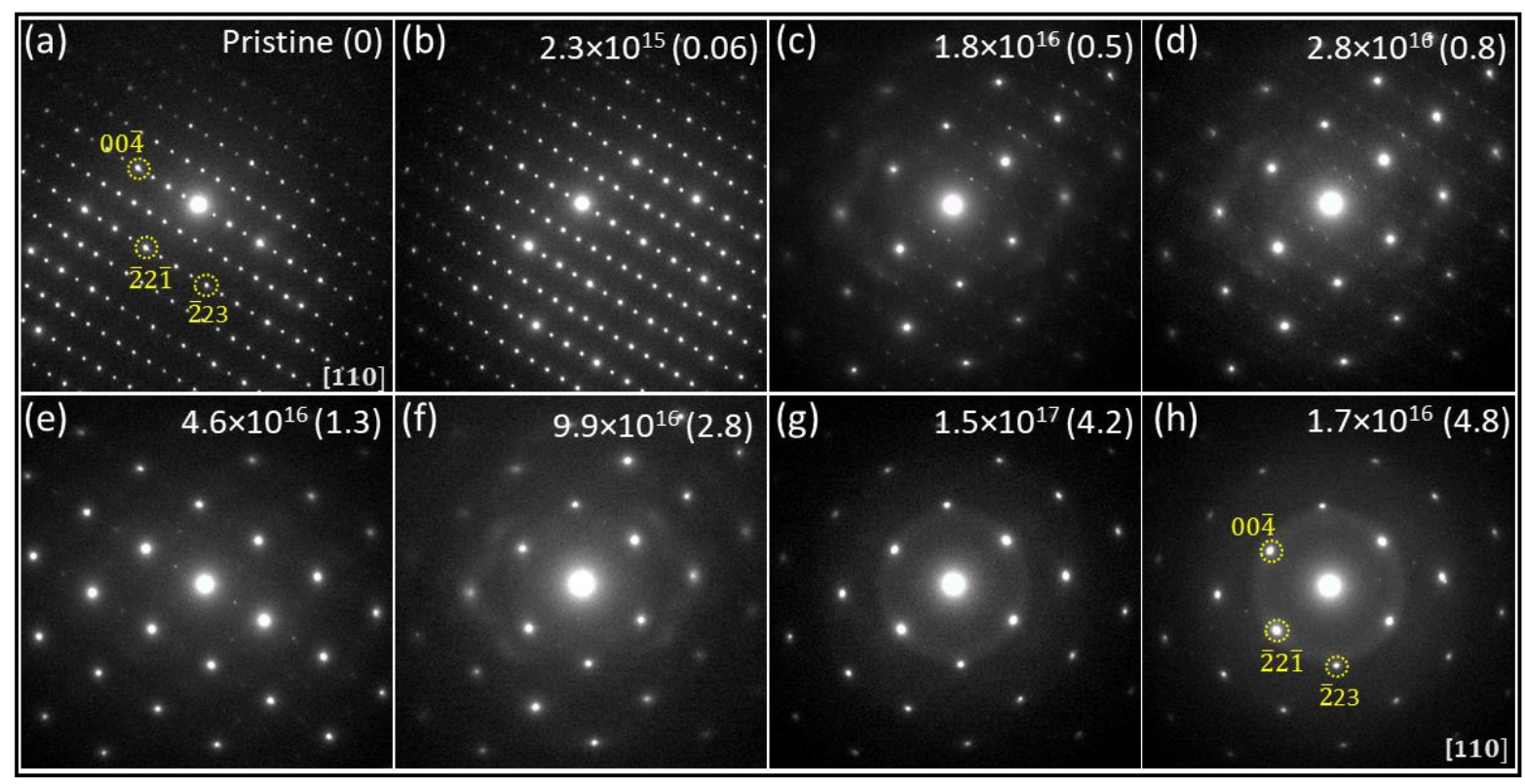

Figure 13: Evolution of diffraction patterns of zirconolite as a function of He fluence (20 keV He) at $295 \mathrm{~K}$. The number in brackets next to the fluence are dpa values.

Similar experiments were performed at $143 \mathrm{~K}$ and $363 \mathrm{~K}$. A comparison of the diffraction patterns at three different temperatures at comparable fluences is shown in Figure 14. The behaviour at $363 \mathrm{~K}$ was similar to the one observed at $295 \mathrm{~K}$ with no major differences in terms of the degree of amorphisation (judging by the intensity of the diffuse background and the presence of diffraction spots). However, a significant degree of amorphisation was observed at $143 \mathrm{~K}$ already after $8 \times 10^{16} \mathrm{He}_{\mathrm{cm}}{ }^{-2}$ as shown in Figure 14 (a). Complete amorphisation at $143 \mathrm{~K}$, as shown in Figure 14 (b), was obtained after $1.2 \times 10^{17} \mathrm{He}^{-\mathrm{cm}^{-2}}(\sim 3.4 \mathrm{dpa}$ ). The square root of the intensity of the amorphous diffraction pattern (to enhance the low-intensity values) shown in Figure 14 (b), along with its radial intensity profile are shown in Figure $14(\mathrm{~b}-\mathrm{I}, \mathrm{b}-\mathrm{II})$. The $\mathrm{x}$-axis of the radial intensity profile in Figure 14 (b-II) was calibrated against evaporated Al spacings. The radii of the two prominent amorphous peaks were about 3.4 and $2 \mathrm{~A}^{\circ}$. They correspond to average metal-metal and metal-oxygen distances in the amorphous zirconolite structure [15]. The values of extremities of the amorphous rings are indicated by vertical dashed lines in Figure $14(b-1)$.

These results show that He bubbles during He implantation essentially nucleated in a disordered zirconolite structure, especially at temperatures $>295 \mathrm{~K}$, and not in its defect-free crystalline or amorphous form. There are currently no studies on whether He bubbles nucleate in the crystalline zirconolite and therefore it remains a subject of further investigation (He implantation at temperatures $>650 \mathrm{~K}$ could be interesting from this perspective). 


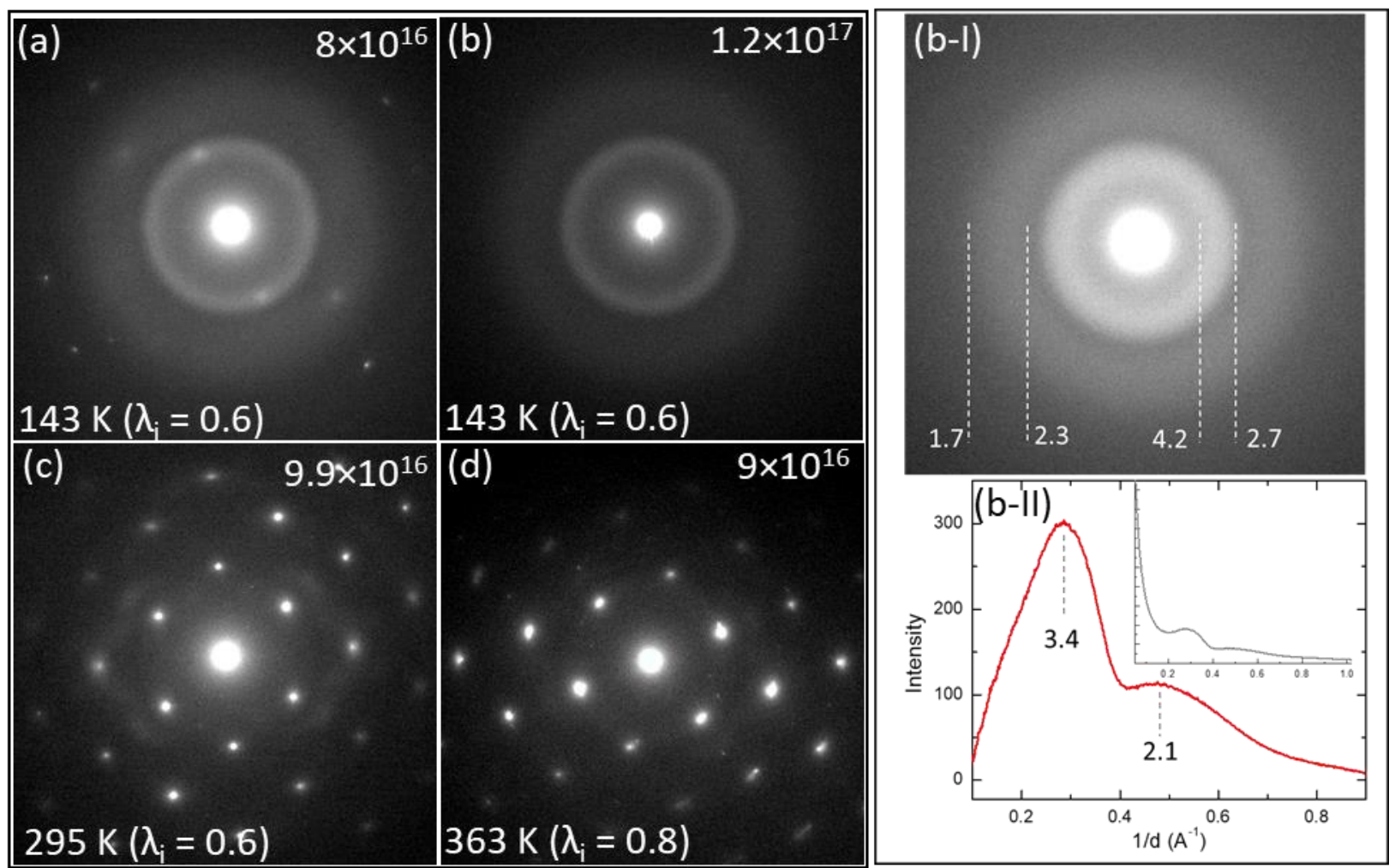

Figure 14: A comparison of diffraction patterns of zirconolite irradiated with $20 \mathrm{keV}$ He at various irradiation temperatures.

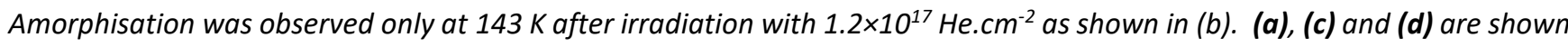
at similar fluences for a direct comparison; (b-I) square root of the DP intensity shown in (b). The vertical lines and the values (in angstroms) indicate the extremities of the amorphous rings; and, (b-II) azimuthally integrated radial intensity profile of the DP shown in (b-I) (background subtracted). The vertical dashed lines and the associated values are the average metalmetal (3.4 $\left.A^{\circ}\right)$ and metal-oxygen $\left(2.1 A^{\circ}\right)$ distances in amorphous zirconolite. The inset shows a raw intensity profile without background subtraction.

In addition to He induced amorphisation, amorphisation due to $\mathrm{Kr}$ ions was also studied. The focus of this study was not to study the temperature dependence or kinetics of amorphisation but rather to obtain amorphous zirconolite specimens which could then be implanted with He ions to unambiguously study the nucleation of He bubbles in the amorphous phase of zirconolite. The specimens were irradiated with $350 \mathrm{keV} \mathrm{Kr}$ ions until full amorphisation was attained (lack of any diffraction spots in the DP's). Unlike the case of He irradiation, amorphisation was obtained at 143, 295 and $473 \mathrm{~K}$ in under $0.5 \mathrm{dpa}$. This is in line with the studies already available in the literature showing that the critical temperature for amorphisation of zirconolite is about $750 \mathrm{~K}$ for Kr ions (1 MeV) [16].

The effect of amorphisation on one of the $\mathrm{Zr}$-GC specimens irradiated with $\mathrm{Kr}$ ions up to $1.5 \times 10^{15} \mathrm{ions}^{-\mathrm{cm}^{-}}$ 2 is shown in Figure 15. The images before the amorphisation are shown in (a-c) and the images after the amorphisation are shown in (d-f). A general effect of the amorphisation was a loss of the sharpness at glassceramic interfaces and blurring of the interfaces/grain boundaries. In fact, the demarcation of individual grains was no longer possible after amorphisation. However, no cracks or tears along the grain boundaries or glass- 
ceramic interfaces were observed showing that the integrity of the composite matrix was not compromised as a result of the amorphisation.

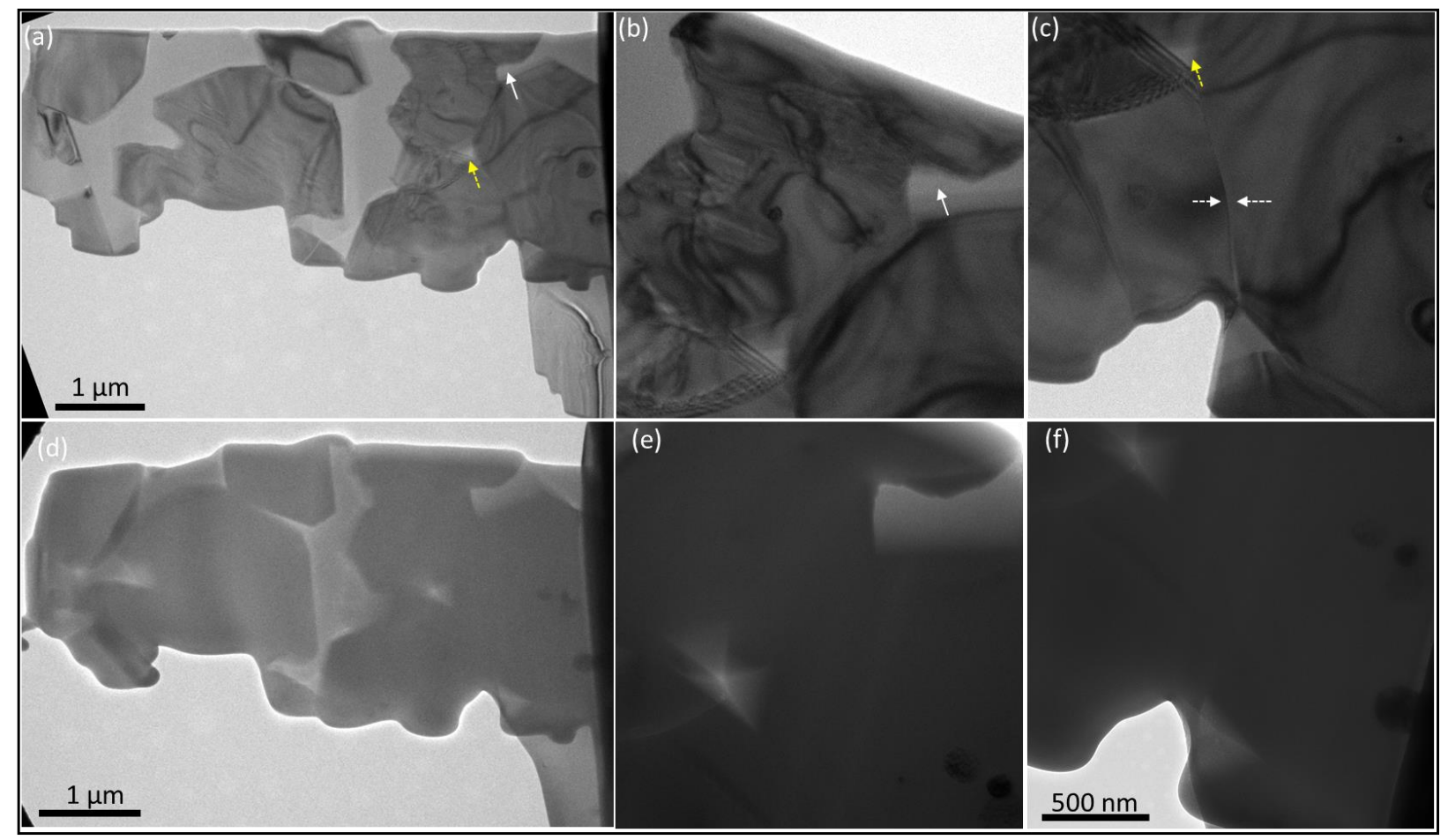

Figure 15: Effect of amorphisation on interfaces. (a) A low magnification view of a Zr-GC specimen before irradiation; (b, c) magnified images of the regions indicated by the arrows in (a). The fiducial marks between $a$, and $b, c$ are indicated by the arrows. The two dashed arrows in (c) indicate a grain boundary; (d) a fully amorphous specimen after irradiation with $1.5 \times 10^{15} \mathrm{Kr} \mathrm{cm}^{-2} ;(e, f)$ images after irradiation corresponding to the regions shown in $(b, c)$. Note that the grain boundaries after amorphisation are not visible.

\subsection{He bubble formation in amorphous zirconolite and the effect of ballistic collisions}

This study aims to investigate the formation of He bubbles in amorphous zirconolite and the behaviour of He bubbles under subsequent heavy ion irradiation. These studies were conducted at different temperatures and some of the examples are discussed below. As a general observation, He bubbles in amorphous zirconolite were observed to nucleate at a lower He concentration compared to disordered zirconolite. A general discussion on the effect of temperature and amorphisation on He bubble nucleation is presented later in section 4.1.

In the first case, the $\mathrm{Zr}-\mathrm{GC}$ specimens were first irradiated with $350 \mathrm{keV} \mathrm{Kr}$ ions at $143 \mathrm{~K}$ to form amorphous zirconolite and then they were implanted with $10 \mathrm{keV} H e$ ions at the same temperature (these experiments were performed sequentially without having to take the specimens out of the TEM). Formation of He bubbles after implantation with $4 \times 10^{16} \mathrm{He}^{-\mathrm{cm}^{-2}}$ is shown in Figure 16 (a). Note that the He bubbles were observed after implantation with about $8 \times 10^{16} \mathrm{He}_{\mathrm{cm}} \mathrm{cm}^{-2}$ in non-amorphous (defective) zirconolite (section 3.1.1). The He-containing zirconolite was then subjected to $\mathrm{Kr}$ irradiation in small fluence increments to follow the evolution of He bubbles. Figure 16 (b-d) show the impact of the incremental $\mathrm{Kr}$ irradiation on the He bubbles 
after fluences of $3.3 \times 10^{14}, 6.6 \times 10^{14}$ and $1.1 \times 10^{15} \mathrm{Kr} \mathrm{cm}^{-2}$ respectively. The distribution of $\mathrm{He}$ bubbles before and after $\mathrm{Kr}$ irradiation with $1.1 \times 10^{15} \mathrm{Kr}_{\mathrm{cm}} \mathrm{cm}^{-2}$ is shown in Figure 16 (f). The distribution showed a decrease in the fraction of small He bubbles and an increase in the fraction of larger He bubbles, effectively, shifting the distribution towards a larger size. A lower magnification image to better visualize the He bubbles in the ceramic particle is shown in Figure 16 (e). It highlights that the glass-ceramic interface did not play any important role with regards to He bubble nucleation or growth as a result of the ballistic collisions.

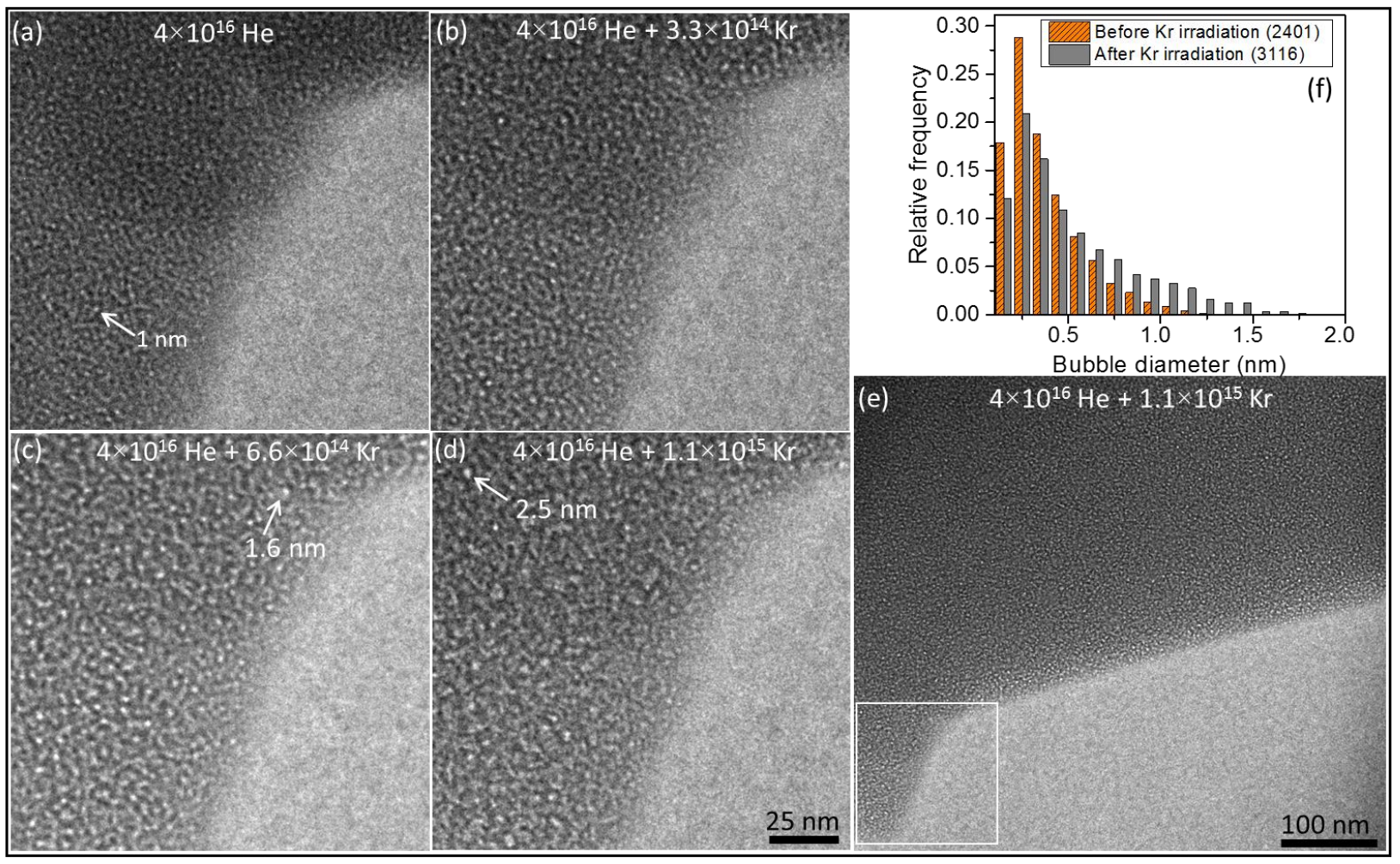

Figure 16: Effect of $350 \mathrm{keV} \mathrm{Kr}$ irradiation on He bubbles in amorphous zirconolite-based glass-ceramic at $143 \mathrm{~K}$. (a) He bubbles in amorphous zirconolite after implantation with $10 \mathrm{keV}$ He ions up to $4 \times 10^{16} \mathrm{He}_{\mathrm{cm}} \mathrm{cm}^{-2}$ at $143 \mathrm{~K}$; (b-d) effect of 350 $\mathrm{keV} \mathrm{Kr}$ ion irradiation on the evolution of He bubbles. The arrows indicate the He bubbles; (e) a larger field of view showing glass-ceramic interface does not play any significant role. The rectangle indicates the region shown in images a-d; and, (f)

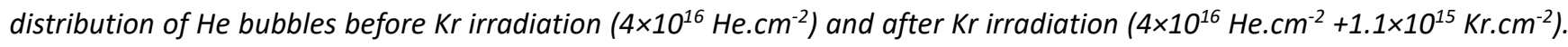
The numbers in brackets are the number of He bubbles counted to calculate the distributions $\left(D_{f}=2 \mu \mathrm{m}\right.$ under-focus, scale $=$ $25 \mathrm{~nm}$ for images $a-d)$.

To better follow the dynamics of He bubbles under the effect of ballistic collisions, higher magnification images of individual He bubbles are shown in Figure 17 for small $\mathrm{Kr}$ fluence increments. The first set of images (A1 - E5) show potential growth/coalescence of two He bubbles. The Frame A1 shows two He bubbles as indicated by the arrows. The evolution of these two He bubbles is then shown in various frames until one relatively large He bubble in frame A4 can be seen replacing the two He bubbles. However, in between these frames, the two He bubbles are less evident, for instance in frames A2 - B3. After B3, a small He bubble emerges which progressively grows in size until A4. Subsequently, this He bubble seems to have completely disappeared in frame E5. Similarly, possible He bubble re-solution is shown in images F1-J5. The arrows in frame F1 indicate three small He bubbles which can no longer be seen in frame J5 indicating their re-solution. Thus, the behaviour 
490 of He bubbles under ballistic collisions is very dynamic showing evidence of growth as well as re-solution at the 491 same time.

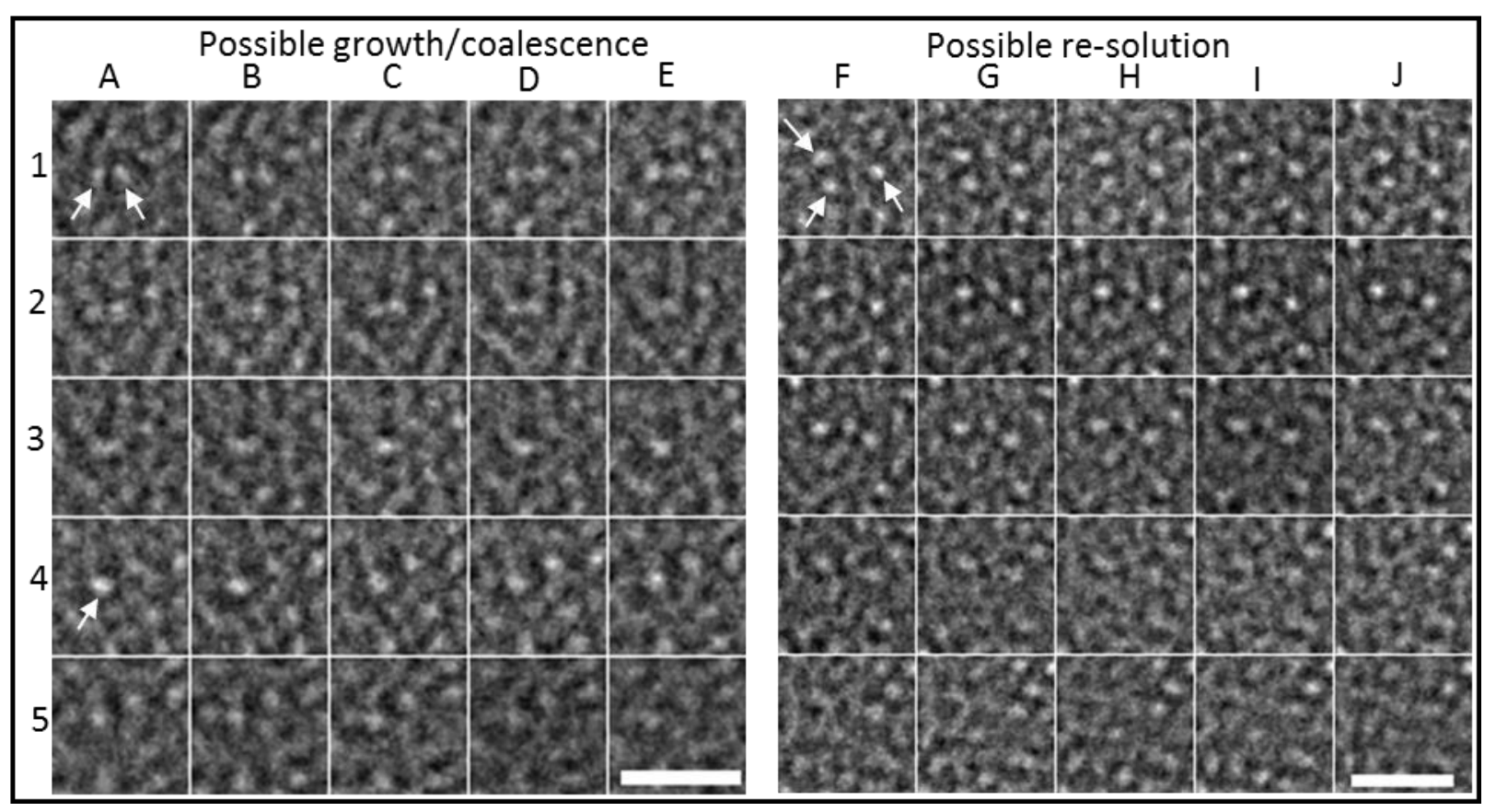

Figure 17: Growth and re-solution of He bubbles in zirconolite under the influence of ballistic collisions shown in sequential images in the same region. Frames A1-E5 show the growth of He bubbles. Some of the He bubbles are indicated by the arrows. Two He bubbles seen in frame A1 as indicated by the arrows seem to have been replaced by one large He bubble in frame A4. Frames F1-J5 show re-solution of He bubbles. Bubbles indicated by the arrows in frame F1 cannot be seen any more in frame J5. Irradiation conditions: Ion $=350 \mathrm{keV} \mathrm{Kr}, T=143 \mathrm{~K}$, flux $=4.6 \times 10^{12}$ ions. $\mathrm{cm}^{-2} . \mathrm{s}^{-1}$, fluence increment per frame $=4.6 \times 10^{12}$ ions. $\mathrm{cm}^{-2}$ (scale marker $=10 \mathrm{~nm}$ for each group of images).

Besides the behaviour of small intra-grain He bubbles, the effect of $\mathrm{Kr}$ ion irradiation on large inter-grain He bubbles (as shown in Figure 9) was also studied. In stark contrast to the behaviour of small intra-grain He bubbles, which showed an overall shift towards larger size, a consistent shrinkage of large He bubbles was observed as shown in Figure 18.

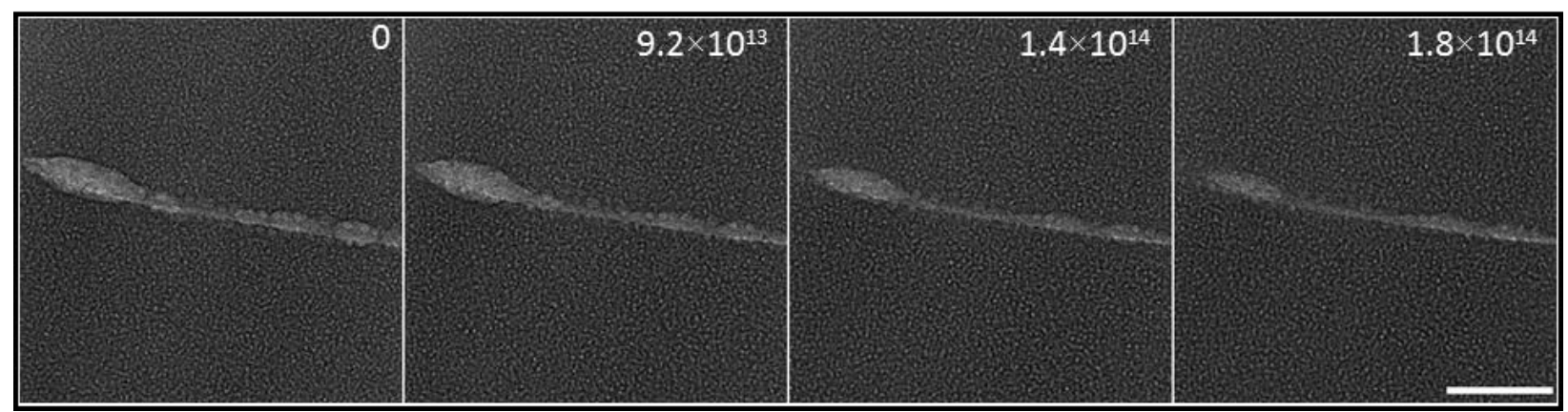

Figure 18: Evolution of He bubbles at grain boundaries shown in Figure 9 after irradiation with $350 \mathrm{keV} \mathrm{Kr}$ ions at $143 \mathrm{~K}$ for various fluences (fluences are in ions. $\mathrm{cm}^{-2}$, scale bar $=50 \mathrm{~nm}, D_{f}=2 \mu \mathrm{m}$ under-focus).

A similar study was performed on a specimen first implanted with He ions up to $2.5 \times 10^{16} \mathrm{He}_{\mathrm{cm}} \mathrm{cm}^{-2}$ at 373 $\mathrm{K}$ to form the He bubbles and then with $350 \mathrm{keV} \mathrm{Kr}$ ions up to $1.2 \times 10^{15} \mathrm{Kr}_{\mathrm{cm}} \mathrm{cm}^{-2}$ to study the response of He bubbles to ballistic collisions. With respect to the previous case, there are two major differences. Firstly, this 
509 temperature is more relevant for long-term geological disposal and, secondly, He bubbles, in this case, are 510 present in a slightly disordered zirconolite, unlike the previous case where they were present in a fully amorphous 511 zirconolite. Therefore, He bubbles are affected by the phase change (transformation to amorphous state) as well 512 as directly by ballistic collisions. Under-focus images of the He bubbles before and after $\mathrm{Kr}$ ion irradiation (350 $513 \mathrm{keV}$ ) are shown in Figure 19 (a-b) and the distribution of He bubbles is shown in Figure 19 (c). As observed earlier, 514 the distribution shifted towards larger size at the expense of smaller He bubbles. Also, growth, as well as re515 solution of He bubbles, was observed as discussed in the previous section. Compared to the behaviour at $143 \mathrm{~K}$, 516 no major differences were observed in terms of the growth of He bubbles. This shows that phase transformation 517 does not have a drastic effect on pre-existing He bubbles (amorphisation of zirconolite is known to cause a 518 decrease in the density by about 6\%). Examples like the ones shown in Figure 17 of bubble growth and re-solution 519 at this temperature are shown in Fig. S6 and S7 in the SI.

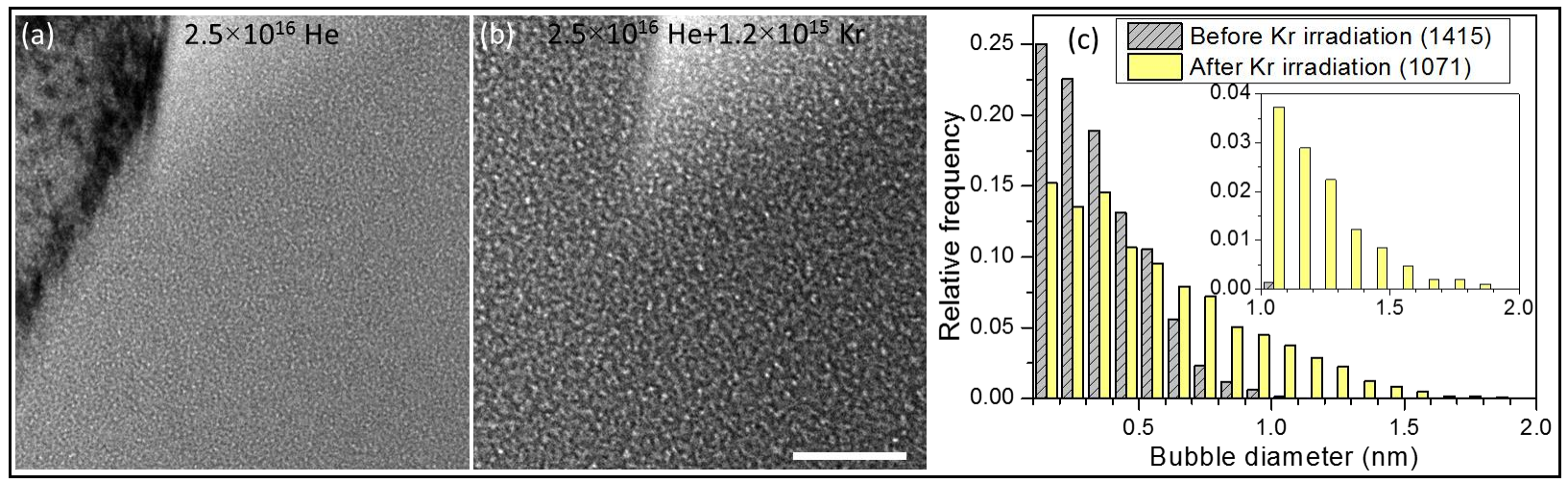

521 Figure 19: Effect of Kr irradiation on pre-existing He bubbles at $373 \mathrm{~K}$ in zirconolite based glass-ceramic. (a) He bubbles after

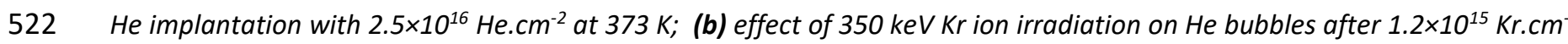
5232 ; (c) the distribution of He bubbles before and after Kr irradiation. The numbers in brackets are the number of He bubbles $524(N)$ used to evaluate the distributions (scale marker $=100 \mathrm{~nm}, D_{f}=1 \mu \mathrm{m}$ ).

\subsection{Effect of annealing on He bubbles and the effect of ballistic collisions on voids}

The experiments and the results presented in this section have a twofold aim. Firstly, we are interested in studying the thermal stability of He bubbles and any changes in their size distribution as a result of the heating/annealing because of its relevance for geological disposal and, secondly, by holding the specimen at high temperature for a sufficiently long time (keeping in mind the He diffusion coefficients in zirconolite [38] at such temperatures) we aim to drive all the He out of the bubbles to create unambiguous voids and then study the stability of these voids to ballistic collisions. This is similar to the experiments presented in our earlier article [39] on glasses where the temperature was used to pressurize or depressurize Xe precipitates to study the effect of internal pressure on their radiation stability. These experiments then allow us to compare and contrast the behaviour of He bubbles and voids as discussed below. bubbles. The specimen was then heated to $873 \mathrm{~K}$ at a rate of $100 \mathrm{~K} /$ minute and annealed isothermally for 200 
538 minutes in-situ in the TEM. The electron beam was switched off during this time and used only to capture the 539 TEM images after regular intervals. The specimen was then further heated to $973 \mathrm{~K}$ and held at this temperature 540 for 60 minutes. TEM images of He bubbles/voids and the distribution of He bubbles/voids at various 541 temperatures and time intervals are shown in Figure 20 (typical TEM images and He bubble size distributions for 542 this specimen just after implantation at $473 \mathrm{~K}$ are shown in Figure 6). Some of the He bubbles/voids are indicated 543 by the arrows and circles. The major change seen after about 40 minutes of annealing at $873 \mathrm{~K}$ was a shift of the 544 distribution to larger sizes as shown in Figure 20 (e) (formation of larger He bubbles at the expense of smaller 545 ones). Further annealing for up to 200 minutes caused only a minor additional shift of the distribution. In fact, 546 based on the He diffusion coefficient at $873 \mathrm{~K}$ in zirconolite $\left(\sim 4 \times 10^{-11} \mathrm{~cm}^{2} . \mathrm{s}^{-1}\right.$ based on the data in [38]), no He is 547 expected to be present in the bubbles or the specimen at the end of 200 minutes of annealing (see section 4.3 548 for a detailed discussion). Therefore, it is now appropriate to use the term void for the remaining features. 549 Further increasing the temperature up to $973 \mathrm{~K}$ and annealing for 60 minutes did not have any major/measurable 550 effect on the voids. In terms of the projected areal density of the He bubbles/voids, it dropped from about $5511.8 \times 10^{12} \mathrm{~cm}^{-2}$ at $473 \mathrm{~K}$ to about $1 \times 10^{12} \mathrm{~cm}^{-2}$ at $873 \mathrm{~K}$ after 40 minutes of annealing without any further measurable 552 changes until the end of annealing (200 minutes). After 60 minutes of annealing at $973 \mathrm{~K}$, the projected areal 553 density further dropped to about $7 \times 10^{11} \mathrm{~cm}^{-2}$. These results highlight that voids in zirconolite have fairly high 554 thermal stability, surviving temperatures as high as $973 \mathrm{~K}$ whereas the He bubbles for temperatures $\geq 873 \mathrm{~K}$ do 555 not have long-term thermal stability (due to the fast He diffusion). Furthermore, it is worth mentioning here that 556 a few zirconolite specimens containing He bubbles and stored at room temperature ( $295 \mathrm{~K})$ were imaged again 557 after about 13 months of implantation and no changes were seen in the He bubble sizes (comparing same regions 558 after 13 months). These observations show that He bubbles themselves are stable at room temperature (room 559 temperature He diffusion coefficient in zirconolite is $\sim 5 \times 10^{-23} \mathrm{~cm}^{2} \cdot \mathrm{s}^{-1}$ ).

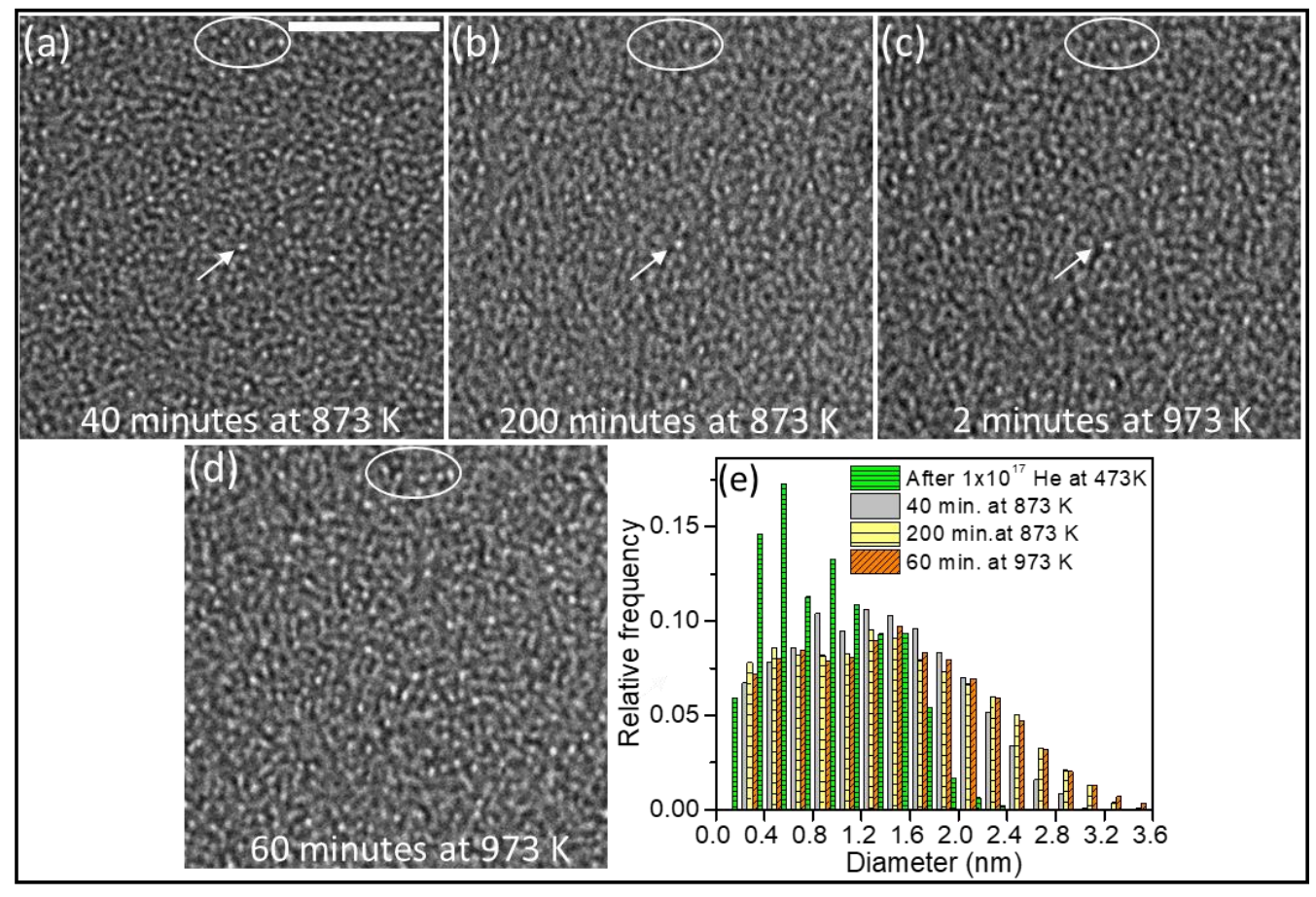


561 Figure 20: BF-TEM images showing the effect of annealing on He bubbles in zirconolite. (a) He bubbles after 40 minutes of 562 annealing at $873 \mathrm{~K}$. The arrows and circles indicate some of the He bubbles to visually follow their evolution as a function of 563 annealing time and temperature; (b) He bubbles after 200 minutes of annealing at $873 \mathrm{~K}$; (c) He bubbles/voids at the 564 beginning of annealing at $973 \mathrm{~K}$; (d) He bubbles/voids after 60 minutes of annealing at $973 \mathrm{~K}$ and, (e) distribution of He 565 bubbles/voids before and after annealing at various times and temperatures. $N=2993,4097,4106,3584$ from top to bottom 566 in the legend (scale marker $=50 \mathrm{~nm}$ for images $a-d, D_{f}=2 \mu \mathrm{m}$ under-focus).

567 568 569 570

At the end of the annealing, the specimen was cooled to $295 \mathrm{~K}$ and irradiated with $600 \mathrm{keV} \mathrm{Kr}$ ions to follow the evolution of the voids left in the specimen as a result of the annealing. BF-TEM images, the changes in void size distribution and, the diffraction patterns as a function of the $\mathrm{Kr}$ irradiation fluence are shown in Figure 21 (a-k). One can see in the TEM images progressive shrinking and eventual disappearance of all the voids after $1.6 \times 10^{14}$ ions. $\mathrm{cm}^{-2}$. This is clearly reflected in the size-distributions shown in Figure 21 (e) which show the size distribution after 60 minutes of annealing at $973 \mathrm{~K}$ and at various fluences (no change was observed on cooling the specimen to $295 \mathrm{~K}$ ). It shows a progressive shrinkage of larger voids and a shift of the distribution towards smaller size. This is a complete reverse behaviour when compared to the He bubbles - which showed a global growth rather than a shrinkage. At a fluence of $1.6 \times 10^{14}$ ions. $\mathrm{cm}^{-2}$, only faint diffraction spots were seen in the diffraction pattern (Figure $21(\mathrm{j})$ ) indicating almost complete amorphisation of the specimen. Irradiation was then further continued up to $2.6 \times 10^{14}$ ions. $\mathrm{cm}^{-2}(\sim 0.5 \mathrm{dpa})$ to induce complete amorphisation in all the grains (Figure $21(\mathrm{k}))$.
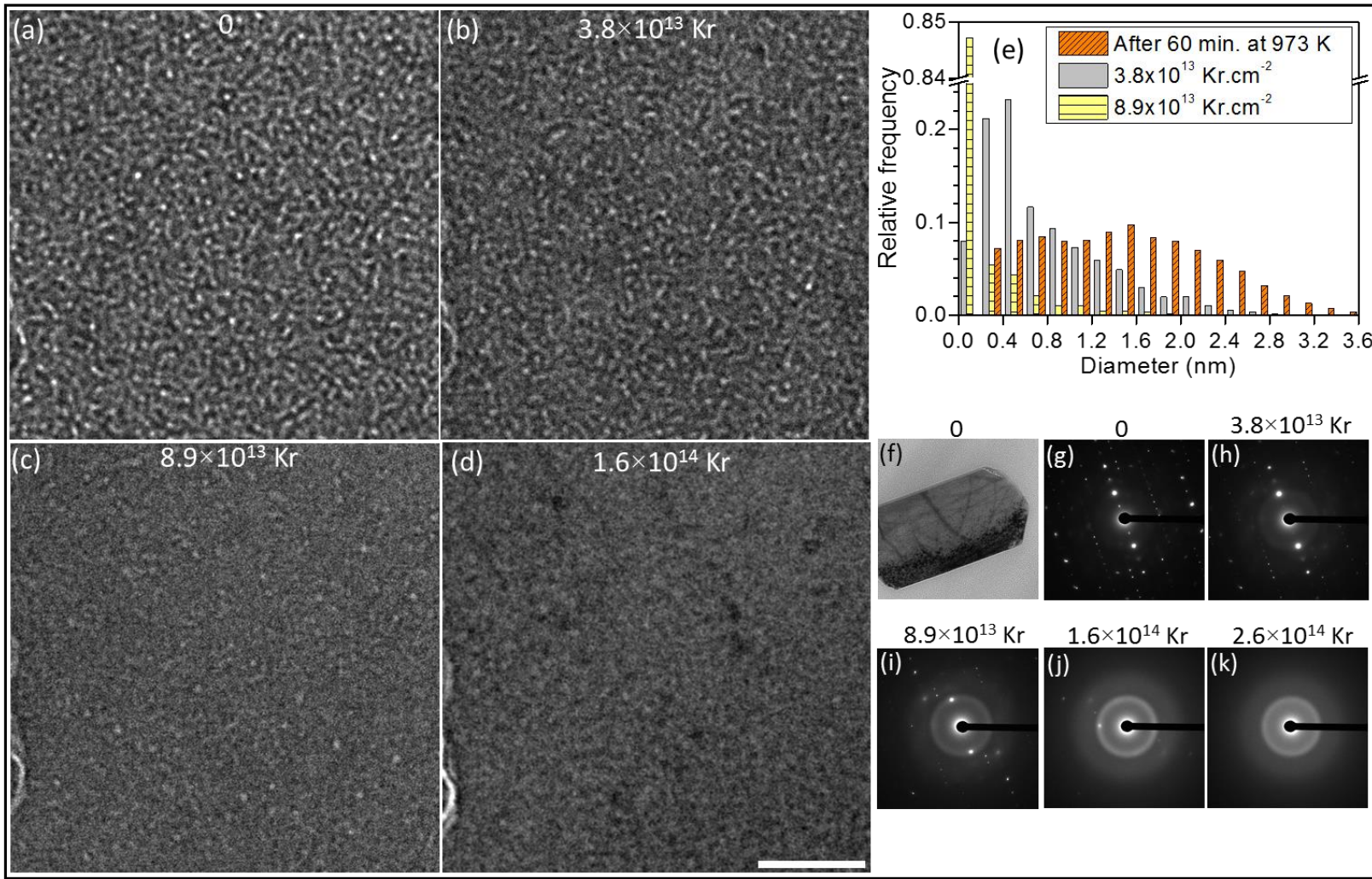

$3.8 \times 10^{13} \mathrm{Kr}$
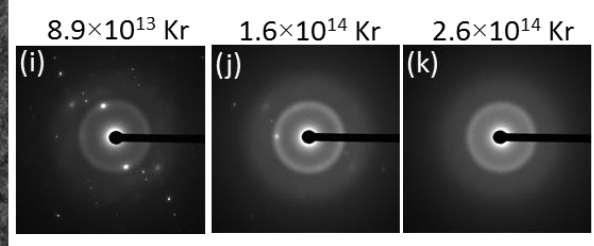

Figure 21: Voids in a Zirconolite specimen left behind after annealing the specimen. (a) Voids at $295 \mathrm{~K}$ before irradiation with $600 \mathrm{keV} \mathrm{Krions}$ ( $(b-d)$ voids after irradiation with $600 \mathrm{keV} \mathrm{Krions} \mathrm{up} \mathrm{to} \mathrm{various} \mathrm{fluences} \mathrm{(in} \mathrm{ions.} \mathrm{cm}^{-2}$ ); (e) the size distribution of voids before irradiation and after irradiation for various fluences ( $N=3584,2114,2114$ from top to bottom in the legend); 
583 (f) low magnification image of one of the grains at $295 \mathrm{~K}$ before $\mathrm{Kr}$ irradiation and, $(\boldsymbol{g}-\boldsymbol{k})$ diffraction patterns of the grain 584 shown in (f) as a function of the fluence (scale marker $=50 \mathrm{~nm}$ for images (a)-(d), $D_{f}=2 \mu \mathrm{m}$ under-focus).

A separate annealing experiment focussing mainly on the behaviour of inter-grain He bubbles/voids was also performed. As already mentioned, relatively larger He bubbles were observed at grain boundaries at all the implantation temperatures. This distinction was retained even when annealing the specimens at high temperature. Furthermore, the He bubbles/voids were found to be thermally stable at least up to $873 \mathrm{~K}$ whether present in the grains or at the grain boundaries. As shown earlier, the general effect of annealing was to decrease the population of smaller bubbles and increase the population of larger ones in the grains. However, some visible differences were found when comparing the intra and inter grain behaviour. The effect of annealing on a Heimplanted Zr-GC at 773 and $923 \mathrm{~K}$ is shown in Figure 22 (a-i). The bubbles/voids at the grain boundary grew slightly in size after annealing for 1.5 hours at $773 \mathrm{~K}$ as can be seen visually on comparing Figure 22 (a) and Figure 22 (b). On further raising the temperature to $923 \mathrm{~K}$, a larger void was seen to form as shown in Figure 22 (c) potentially due to the coalescence of the smaller voids visible in Figure $\mathbf{2 2}$ (b) (indicated by the arrows). This transformation occurred within 5 minutes of annealing at $923 \mathrm{~K}$ and then no further evolution up to 1.5 hours was seen. Another example showing relatively larger voids at the grain boundary after annealing for 1.5 hours at $923 \mathrm{~K}$ is shown in Figure 22 (d). Another similar example is shown in Figure $22(e, f)$ showing the presence of cavies at the grain boundaries after annealing for about 1 hour at $923 \mathrm{~K}$. A magnified image of the region indicated by the rectangle is shown in Figure $\mathbf{2 2}(\mathrm{f})$ to highlight the presence of intra and inter-grain voids after annealing. All these results show that inter grain bubbles and voids are relatively larger and that this trend is retained even upon annealing. Furthermore, the results highlight that the voids at grain boundaries can grow to a larger size than anywhere inside the grains. 


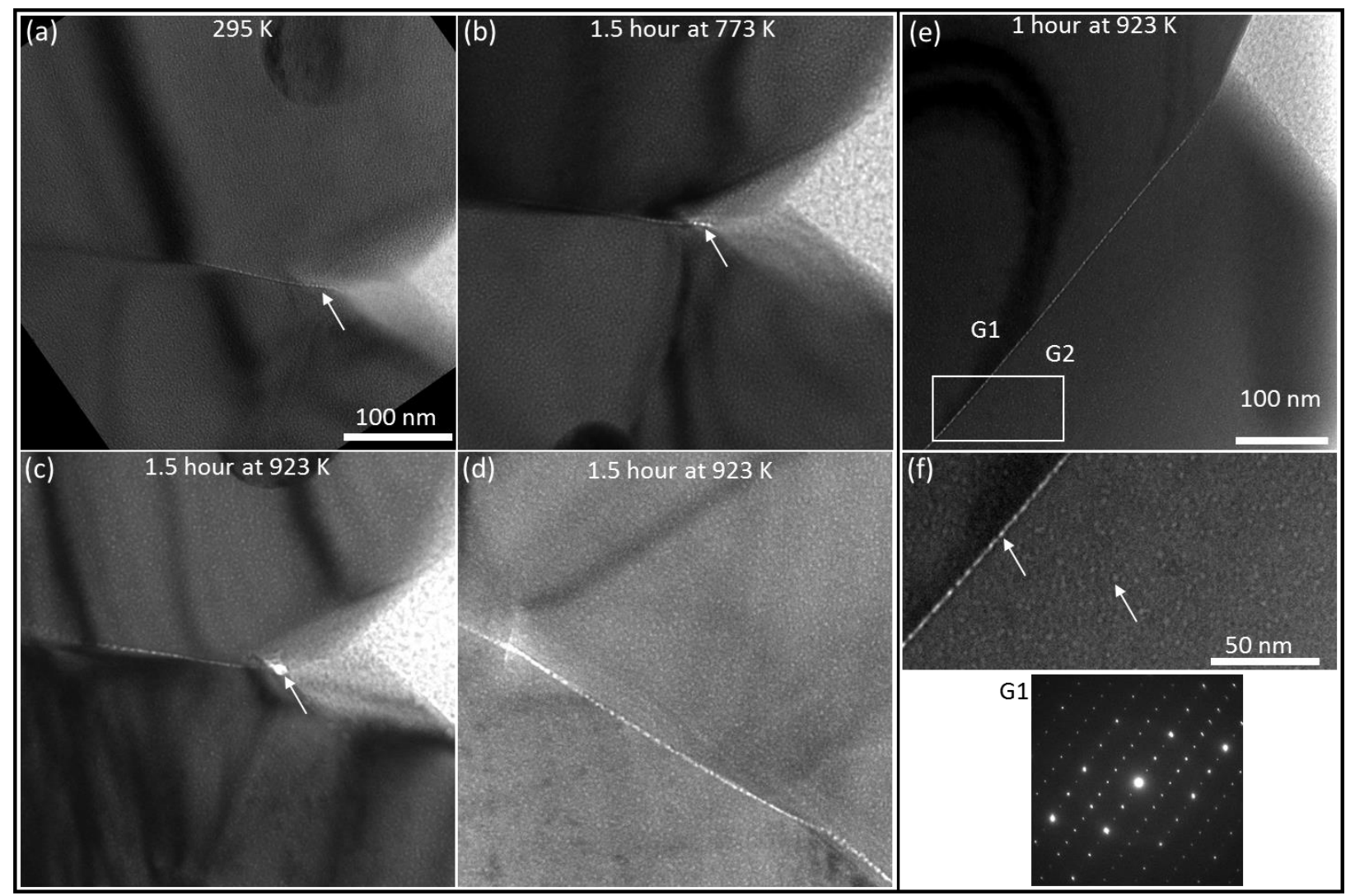

Figure 22: Effect of annealing on He bubbles. (a) A low magnification image showing the He bubbles at grain boundaries before annealing; (b) voids after isothermal annealing at $773 \mathrm{~K}$ for 1.5 hours; (c) voids after isothermal annealing at $923 \mathrm{~K}$ for 1.5 hours. Note the formation of a large void, as indicated by the arrow, potentially as a result of the coalescence of smaller voids; (d) voids at grain boundaries in a different region; (e-f) low and high magnification images showing intra and inter grain voids. In this case, the diffraction pattern of grain G1([-110]) showing it is essentially crystalline is also shown (scale marker in (e) applies to (a)-(d).

\subsection{Effect of annealing and recrystallization of amorphous zirconolite}

612 From a geological disposal perspective, understanding the effect of annealing on ceramic waste forms is an 613 element of understanding their behaviour under normal heating due to the decay heat and due to other 614 accidental thermal transients. The specimen for this study was the amorphised Zr-GC left behind at the end of 615 the $600 \mathrm{keV} \mathrm{Kr}$ irradiation experiment described above (shown in Figure 21). The specimen was heated at a rate 616 of $100 \mathrm{~K} /$ minute up to $973 \mathrm{~K}$ where it was annealed for 80 minutes. A small degree of recrystallization of the 617 grains was observed as indicated by the emergence of some diffraction spots in Figure 23 (c, d) (the diffraction contrast can be seen in Figure 23 (e) as indicated by the arrow). The temperature was then raised to $1073 \mathrm{~K}$ where further annealing for 60 minutes was performed. The grain recrystallized within the first 5 minutes of annealing at this temperature as shown in Fig $25(\mathrm{~g})$, which reveals extensive diffraction contrast in the BF image recorded at this stage. No further changes were observed during the rest of the 60 minutes anneal. However, in

622 the majority of the grains, the recrystallization process resulted in the development of many nano-crystals (not necessarily zirconolite) varying in size from about 10 to $50 \mathrm{~nm}$. Some typical examples of such nano-grains are 
624 shown in Figure 24. More detailed studies on the subject of annealing and recrystallization of amorphous 625 zirconolite have been addressed elsewhere[40].

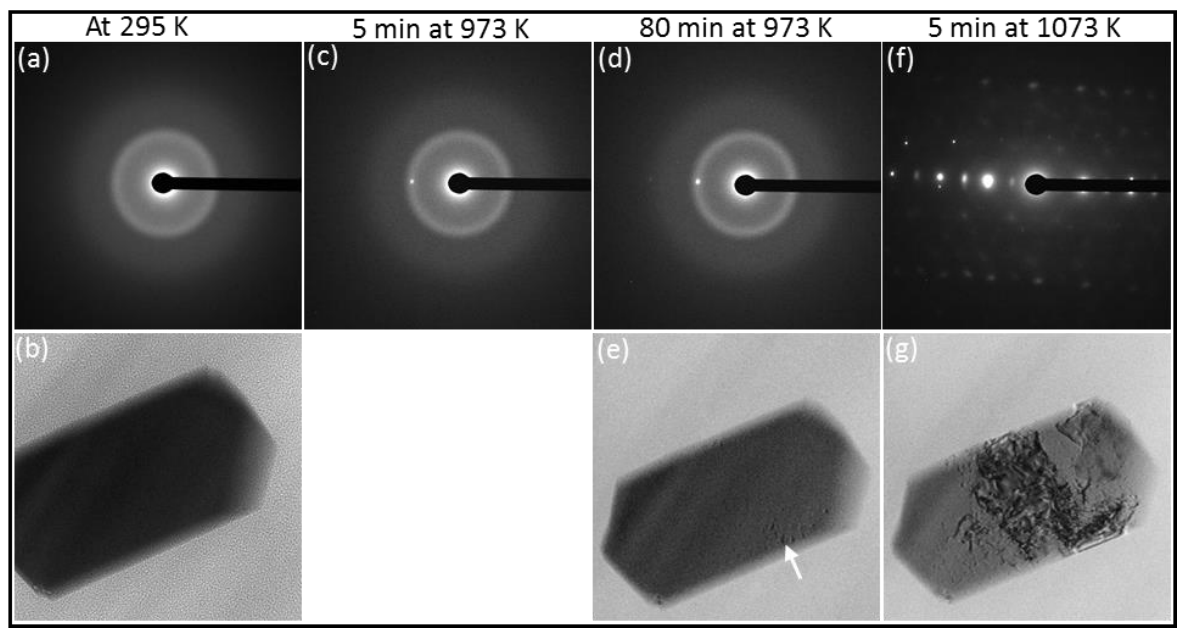

Figure 23: Effect of annealing on amorphous zirconolite grains. $(\boldsymbol{a}, \boldsymbol{b})$ diffraction patterns and BF-TEM images of a grain after amorphisation at $295 \mathrm{~K}$; (c) diffraction pattern after 5 minutes of annealing at $973 \mathrm{~K}$; (d, e) diffraction pattern and a BF-TEM image after 80 minutes of annealing at $973 \mathrm{~K}$. The arrow indicates a small crystalline region; and, $(\boldsymbol{f}, \boldsymbol{g})$ diffraction pattern and a BF-TEM image after 5 minutes of annealing at $1073 \mathrm{~K}$.

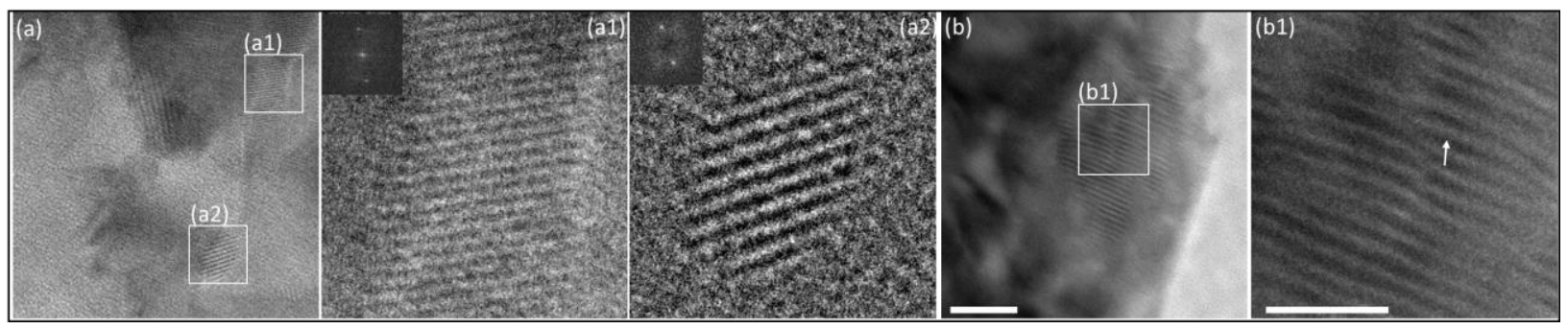

Figure 24: High-resolution images showing small crystals formed after annealing at $973 \mathrm{~K}$ and then at $1073 \mathrm{~K} .(\boldsymbol{a}, \boldsymbol{a 1}, \boldsymbol{a 2}) \mathrm{A}$ low magnification image and two crystalline grains indicated by the rectangles and shown in high magnification images in $a 1$ and $a 2 ; a n d,(b, b 1)$ another grain showing small crystals with a dislocation type defect visible in (b1) as indicated by the arrow (scale marker in $(b)=20 \mathrm{~nm}$ and applies to (a) as well. Scale marker in (b1) $=10 \mathrm{~nm}$ and applies to a1, a2 as well).

It is worth highlighting that recrystallization resulted in the formation of voids in all the new grains although to varying extents in terms of the size and spatial homogeneity. Some of the examples showing the voids in the recrystallized grains are shown in Figure 25. This is potentially because zirconolite is known to swell by about 5-6 \% due to amorphisation and recrystallization into denser crystalline zirconolite or other dense crystalline phases will lead to compaction and formation of voids in the recrystallized grains. Attempts to measure dimensional changes in the grains as a result of amorphisation and recrystallization did not provide any conclusive results because slight specimen bending/tilting complicated such measurements. 


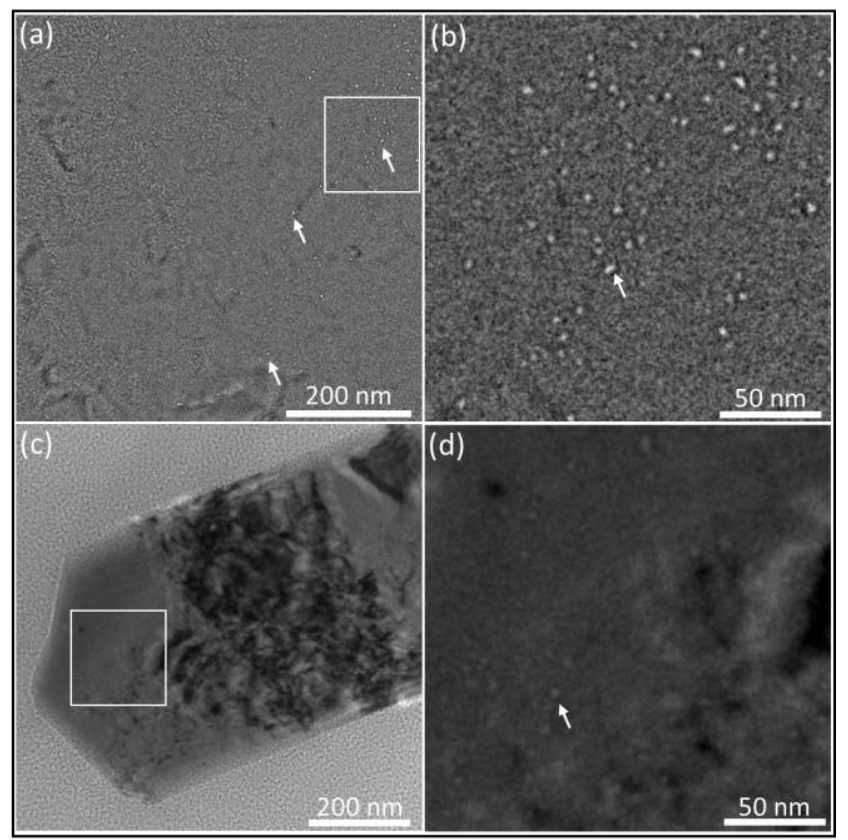

Figure 25: BF-TEM images showing the formation of voids after recrystallization of amorphous zirconolite grains. (a) A low magnification image showing the inhomogeneous distribution of the voids in a recrystallized grain. The arrows indicate some of the voids; (b) a higher magnification image of the region indicated by the rectangle in (a); (c) a low magnification image showing the inhomogeneous distribution of voids in a different recrystallized grain; and, (d) a higher magnification image of the region indicated by the rectangle in (c).

\subsection{Formation of $\mathrm{Kr}$ bubbles}

In addition to He bubble formation, the specimens were also implanted with low energy $\mathrm{Kr}$ ions to evaluate the concentration needed to form the $\mathrm{Kr}$ bubbles. The main aim was to demonstrate that the $\mathrm{Kr}$ fluences used in the studies presented thus far (to study the amorphisation and the effects of ballistic collisions on He bubbles) were low enough to not have resulted in any $\mathrm{Kr}$ bubble formation in the ceramic phase. Furthermore, it also provides a useful reference for many other studies available in the literature on $\mathrm{Kr}$ irradiation of various nuclear waste ceramics especially zirconolite. A Zr-GC specimen was implanted with $80 \mathrm{keV} \mathrm{Kr}$ ions (projected range $30 \pm 12$ $\mathrm{nm}$ ) at $295 \mathrm{~K}$ and imaged after regular fluence increments. The first signs of $\mathrm{Kr}$ bubbles (diameter $1 \mathrm{~nm}$ ) in the ceramic phase were observed at $6.7 \times 10^{15}$ ions. $\mathrm{cm}^{-2}$ whereas large $\mathrm{Kr}$ bubbles were already observed in the glass phase at this fluence. Further evolution of $\mathrm{Kr}$ bubbles as a function of the fluence is shown in Figure 26 (a-c). It is noteworthy that unlike He bubbles, large irregular $\mathrm{Kr}$ bubbles were seen at high fluences as a result of the coalescence. Figure 26 (d) shows large $\mathrm{Kr}$ bubbles in the glass phase after $1 \times 10^{16}$ ions. $\mathrm{cm}^{-2}$ whereas only small $\mathrm{Kr}$ bubbles were observed in the ceramic phase at this fluence (as shown in Figure 26 (a)). Like oxygen bubble formation, no preferential $\mathrm{Kr}$ bubble nucleation was observed anywhere in the specimen. In any case, these results show that the $\mathrm{Kr}$ fluences used in previous experiments to study the effect of ballistic collisions and amorphisation were too low to have induced any bubble formation. 

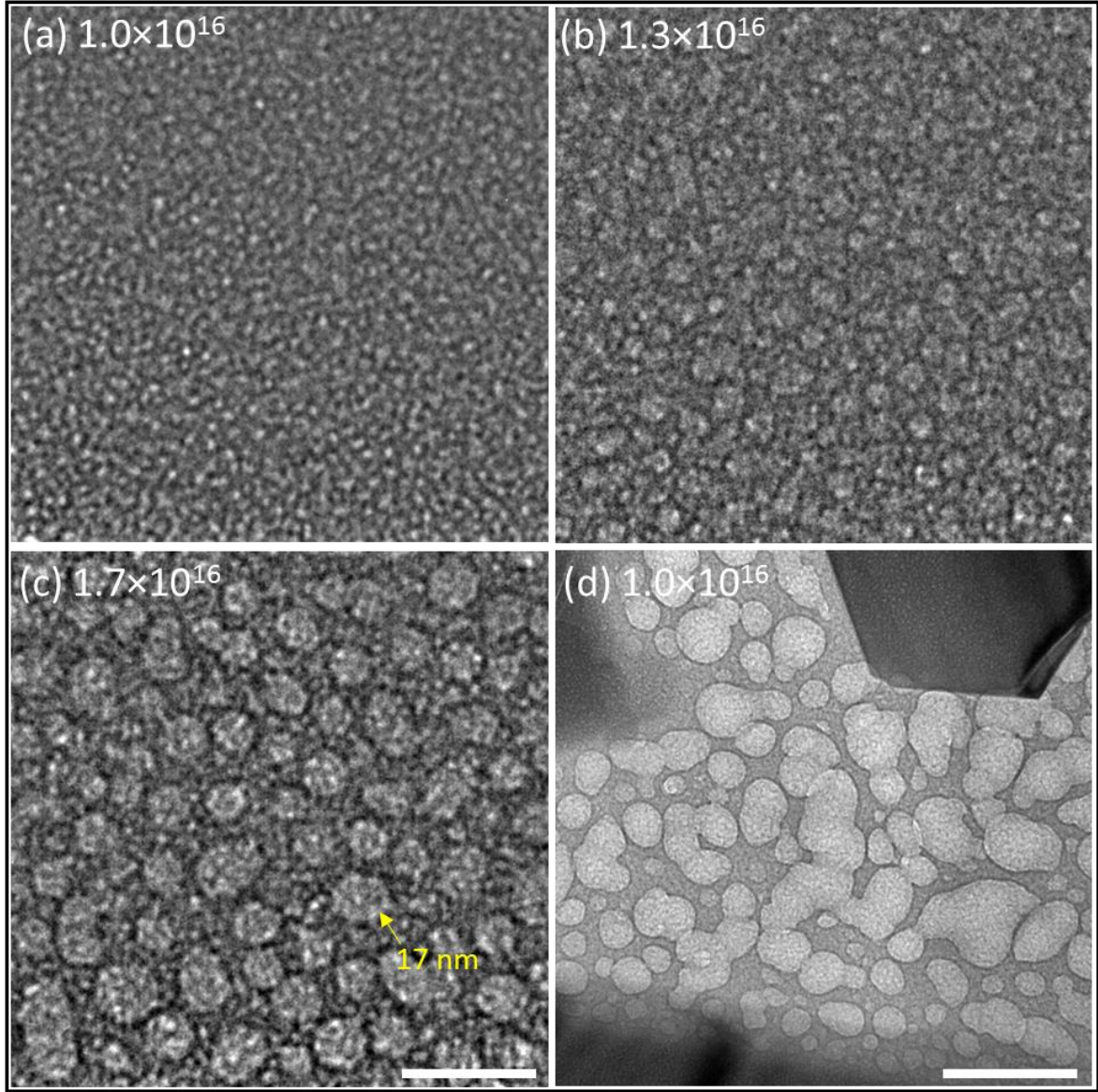

Figure 26: Implantation of $80 \mathrm{keV} \mathrm{Kr} \mathrm{into} \mathrm{Zr}$-GC and formation of Kr bubbles at $295 \mathrm{~K}$. (a-c) Kr bubbles in the zirconolite phase at various Kr fluences; and, (d) Kr bubbles in the glass phase after $1 \times 10^{16}$ ions. $\mathrm{cm}^{-2}$ (scale marker $=50 \mathrm{~nm}$ for (a-c) and 150 $n m$ for $(d))$.

It is worth highlighting that the He bubble formation required about $4 \times 10^{16}$ ions. $\mathrm{cm}^{-2}$, which is about 6 times the $\mathrm{Kr}$ fluence needed to form the $\mathrm{Kr}$ bubbles. In terms of the peak atomic concentration needed for bubble

671 formation, the values are about 2.5 and 6 atomic \% for $\mathrm{Kr}$ and He respectively. $\mathrm{Kr}$ precipitates in the zirconolite 672 were observed to first grow and eventually lose the gas to vacuum transforming into voids. The voids when 673 subjected to further ballistic collisions shrank and closed, as observed previously in the case of noble gas 674 precipitates in glasses [39].

\subsection{Sensitivity to the electron beam and the formation of oxygen bubbles in the glass phase}

677 This study is not intended to present a detailed study of electron beam induced bubble formation in glassceramics but rather highlight the various observations made during this study. The glass-ceramics in this work were studied at temperatures ranging from 143 to $473 \mathrm{~K}$. Compared to the TEM observation at $295 \mathrm{~K}$, the formation of oxygen bubbles was significantly suppressed at $143 \mathrm{~K}$. Either no or only a few small oxygen bubbles 681 (usually by the end of the ion irradiation due to the cumulative exposure to electron beam) in certain regions 682 were observed in the glass phase during the course of ion irradiation experiments. The experiments typically 683 lasted for up to 1 - 2 hours and the electron beam was switched on only intermittently to capture the images in 684 different regions of the specimen. When switched on, the electron beam flux was kept less than $5 \times 10^{17}$ 
685

electrons.cm $\mathrm{cm}^{-2} \cdot \mathrm{s}^{-1}$ and typical image exposure times ranged from 0.5 to $1 \mathrm{~s}$. In comparison, oxygen bubbles were seen within a matter of few minutes at $295 \mathrm{~K}$ when imaging the specimen before the ion irradiation (to avoid excessive oxygen bubble formation at $295 \mathrm{~K}$, the specimens were not extensively scanned at this temperature before the ion irradiation whereas it was not a significant issue at $143 \mathrm{~K}$ ). Some typical examples of oxygen bubbles formed at 143 and $295 \mathrm{~K}$ are shown in Figure $27(\mathrm{a}, \mathrm{b})$. He ion irradiation did not seem to have a major effect on the oxygen bubbles whenever they were present. Furthermore, the oxygen bubble formation seemed to be relatively suppressed at $473 \mathrm{~K}$ (judging by the areal density of the oxygen bubbles formed at $295 \mathrm{~K}$ and 473K) but detailed studies were not performed. However, this is in agreement with the earlier studies of oxygen bubble formation in lithium borosilicate glasses under electron beam at various temperatures and fluxes showing that oxygen bubble formation at high temperatures can be suppressed under certain conditions[32].

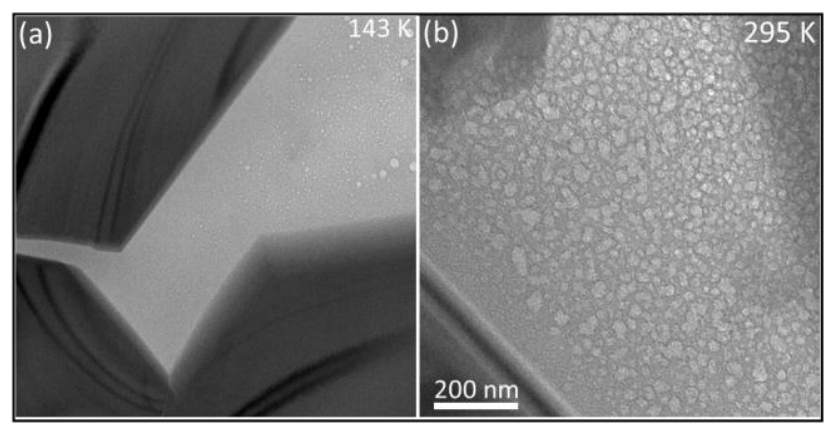

Figure 27: Formation of oxygen bubbles in the glass phase due to electron beam exposure. (a) oxygen bubbles at 143 K; and, (b) oxygen bubbles at $295 \mathrm{~K}$.

\section{Discussion}

The results showed that He bubbles precipitated in a disordered zirconolite. An increase in either the implantation temperature or the degree of disorder both favoured He nucleation at lower concentrations. It was also shown that while zirconolite was amorphised under He irradiation at low temperature, requiring about 3.4 dpa for amorphisation at $143 \mathrm{~K}$, amorphisation at higher temperatures $(>295 \mathrm{~K})$ required fluences $>2 \times 10^{17} \mathrm{He} . \mathrm{cm}^{-}$ ${ }^{2}$ (> $6 \mathrm{dpa}$ ). In contrast, amorphisation under heavy ion irradiation was attained in less than $0.5 \mathrm{dpa}$ over a wide temperature range.

The He bubbles were observed to preferentially nucleate at grain boundaries, but no such preferential nucleation was observed along the glass-ceramic interfaces. The bubble size distribution was observed to shift towards larger size due to ballistic collisions/amorphisation, but such a shift was not very drastic. The He bubbles in all the cases were $\leq 3 \mathrm{~nm}$ in diameter. In contrast to the behaviour of He bubbles, voids were unstable under ballistic collisions which progressively shrank and were eliminated. In the rest of the article, we will consider the relevance of the important aspects of these findings for the long-term geological disposal of nuclear waste.

\subsection{Effect of implantation temperature and amorphisation on threshold He concentration}


714 Two important parameters that affected the He concentration at which the He bubbles were formed (threshold 715 concentration) were implantation temperature and the defect state of the zirconolite grains. Increase in the 716 implantation temperature and structural disorder/amorphisation both decreased the threshold He 717 concentration needed for the formation of visible bubbles. The effect of both these parameters is shown in Figure $71828(\mathrm{a}, \mathrm{b})$. The threshold He fluence dropped from about $8 \times 10^{16} \mathrm{He}_{\mathrm{cm}} \mathrm{cm}^{-2} \sim 5$ at. \%) at $143 \mathrm{~K}$ to about $4 \times 10^{16} \mathrm{He} . \mathrm{cm}^{-}$ $7192^{2}$ at $295 \mathrm{~K}$ and, to $2 \times 10^{16} \mathrm{He} . \mathrm{cm}^{-2}(\sim 1$ at. \%) for temperatures greater than $373 \mathrm{~K}$ for defective zirconolite. 720 Amorphisation also had a similar effect leading to a decrease in the threshold He concentration for bubble 721 formation from about 5 at. \% to about 2 at. \% at $143 \mathrm{~K}$ but higher temperatures did not play a significant role in 722 the amorphous zirconolite. When comparing the projected He bubble areas at various temperatures (Figure 28 723 (b)), there were no major changes for temperatures up to $373 \mathrm{~K}$ and for fluences up to $1.5 \times 10^{17} \mathrm{He} . \mathrm{cm}^{-2}$ with 724 projected bubble area remaining less than $1 \%$. However, for higher fluence $\left(1.7 \times 10^{17} \mathrm{He} . \mathrm{cm}^{-2}\right)$ or higher 725 temperature $(473 \mathrm{~K})$ the projected He bubble area showed a clear increase due to an increase in the size of the 726 He bubbles. In any case, the projected He bubble area remained less than about $2.5 \%$. This is in stark contrast 727 to $\mathrm{Kr}$ implantation where significantly larger $\mathrm{Kr}$ bubbles (10 to $20 \mathrm{~nm}$ ) and a higher projected bubble area ( 50\%) 728 were observed.

729 For geological disposal of nuclear waste, temperatures of up to $373 \mathrm{~K}$ are most relevant in the long730 term (after a few hundred years). Based on our results, it is reasonable to propose that He concentration of about 7311 to about 2.5 atomic \% would be needed to precipitate the He bubbles in a typical zirconolite matrix. To put 732 these numbers in context, Figure 28 (c) shows the accumulated number of alpha decays (per unit volume) as a 733 function of the time in zirconolite for ${ }^{239} \mathrm{Pu}$ loading contents ranging from $1 \mathrm{wt}$. \% to $20 \mathrm{wt}$. \%. If 1 at. \% He ( $7349 \times 10^{20}{\mathrm{He} . \mathrm{cm}^{-3}}^{-3}$ was taken as the critical He concentration for bubble formation, it would then take about twenty 735 thousand years for $20 \mathrm{wt} . \%{ }^{239} \mathrm{Pu}$ loading to result in He bubble formation and about sixty thousand years for 10 736 wt. \% loading. Furthermore, zirconolite amorphises after about $0.5 \mathrm{dpa}$, requiring only about 500 years to 737 amorphise for $20 \mathrm{wt} . \%{ }^{239} \mathrm{Pu}$ loading (He concentration would be around 0.05 at. \% after 500 years). Therefore, 738 He bubbles will essentially nucleate in the amorphous zirconolite. Assuming that the typical lifetime of a waste 739 package over-pack (carbon steel) is about 5000 years ( 0.2 at. \% He for 20 wt. \% loading at this time), the waste 740 package should already be exposed to surrounding geological formation by the time He bubbles are formed. 741 Therefore, any swelling/stresses as a result of the He bubble nucleation will have no impact on the packaging 742 itself simply because it is unlikely to exist at this time. Also, if the He diffusion coefficient in zirconolite is assumed 743 to follow Arrhenius behaviour down to room temperature (the experimental data exists up to $620 \mathrm{~K}$ ), then the 744 data in [38] shows that the He diffusion coefficient (D) under disposal conditions should be less than $1 \times 10^{-19}$ $745 \mathrm{~cm}^{2} . \mathrm{s}^{-1}$. With this value, the typical He diffusion length $(\sim \sqrt{D . t})$ would be less than $5 \mu \mathrm{m}$ in twenty thousand years $746(t)$. This shows that He will essentially be retained inside large grains (provided that the grains are large compared 747 to the range of the alpha particles or there is a high density of grains in the case of glass-ceramics as discussed 748 later). On the other hand, small grains (well separated from each other) can be expected to be depleted in He 749 and they are unlikely to show any He bubble formation. 

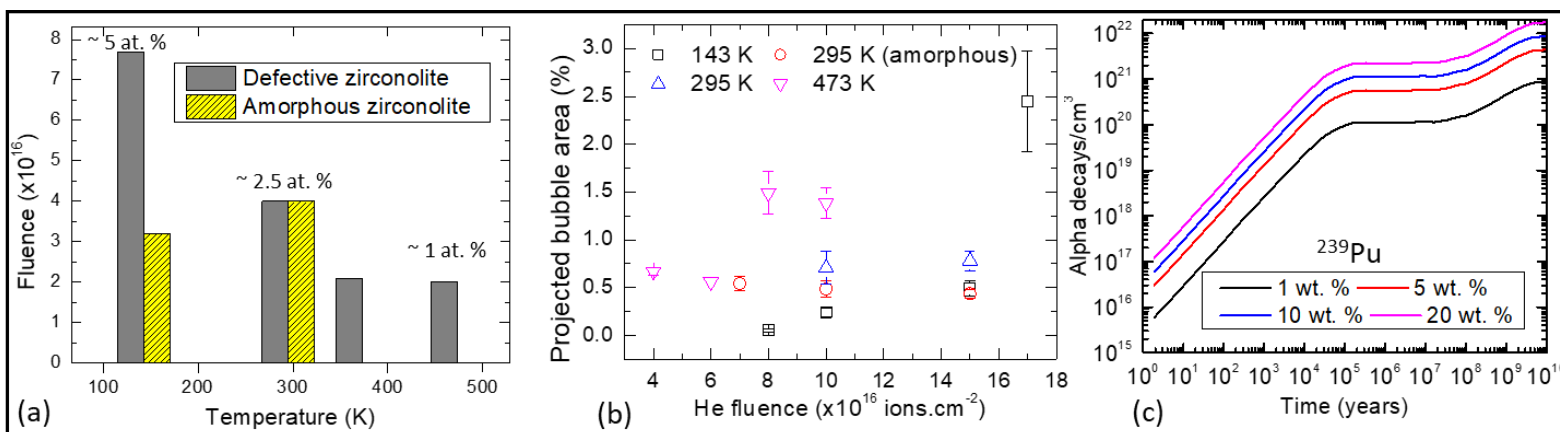

Figure 28: Effect of temperature and amorphisation on He bubble formation in zirconolite. (a) Effect of temperature on the critical He concentration needed to form the He bubbles in defective zirconolite (non-amorphous) and amorphous zirconolite; (b) Effect of helium fluence and temperature on the projected He bubble area (the data at 143, 195 and $473 \mathrm{~K}$ is for defective zirconolite); and, (c) accumulation of alpha decays in zirconolite for various ${ }^{239} \mathrm{Pu}$ loading contents as a function of time.

It is worth discussing here the results of the only study on natural radioactive zirconolite that has raised the possibility of He bubble formation in natural samples under geological conditions (at He concentrations of about 0.1 at. \%) [2]. In this study, the authors observed some porosity in the specimens with pore sizes ranging from a few tens to thousands of $\mathrm{nm}$. The authors raised the possibility of the pores being He bubbles but no other concrete evidence of this could be provided except mentioning the fact that He is usually desorbed from natural radioactive specimens under annealing. Whether the desorbed He is trapped as interstitial atoms or in large clusters and bubbles is not clear. Therefore, it would be interesting in the future to utilize EELS on such natural specimens to verify the contents of the pores, as done for instance for He bubbles in silicon [41], and unambiguously address whether He bubbles precipitate in natural analogues.

Also, converting the data from the number of alpha decays per gram in a given time to damage rate in dpa.s ${ }^{-1}$, one obtains from the data in [8] $\left(4.5 \times 10^{18} \mathrm{\alpha} / \mathrm{g}\right.$ in 200 days $)$ a damage rate of about $2 \times 10^{-8} \mathrm{dpa}^{-1}$ $\left(\sim 1.5 \times 10^{12}\right.$ disintegrations per second per cubic centimetre). This is about $10^{6}$ times smaller than the typical dose rates in ion irradiation experiments used for studying such materials (e.g. $\sim 10^{-2}$ dpa.s ${ }^{-1}$ in our experiments and those of others) and yet the amorphisation takes place in under $0.5 \mathrm{dpa}$ in both the cases. These results highlight a negligible role of the dose rate in the amorphisation process at least in the range of $10^{-2}$ to $10^{-8} \mathrm{dpa} \cdot \mathrm{s}^{-1}$. This indicates that it is rather the temperature that would play the dominant role in controlling the amorphisation dose and not the dose rate under disposal conditions. Therefore, external ion irradiations quite well capture the kinetics of amorphisation despite the large dose rates employed in such experiments.

The results highlight that to better investigate the release of radioelements from the waste package under disposal conditions, it is important to investigate the leaching behaviour of amorphous zirconolite containing He bubbles rather than study the behaviour of the crystalline or amorphous phase without any He bubbles. In general, this is true for a single-phase, multi-phase or a glass-ceramic composite matrix where zirconolite is a major phase. It is worth bearing in mind that the distinction between various adjoining grains was 
780 lost after the amorphisation due to the loss of the grain boundaries (Figure 15). Since grain boundaries offer fast 781 transport pathways, their role in the amorphous phase is perhaps irrelevant and could prove to be a positive 782 aspect of amorphisation. It, however, needs to be investigated further.

783

Nevertheless, it is important to highlight that the alpha decay of ${ }^{239} \mathrm{Pu}$ will result in an alpha particle of about $5.2 \mathrm{MeV}$ and a ${ }^{235} \mathrm{U}$ recoil nucleus of about $86 \mathrm{keV}$. The typical range of the alpha particle in zirconolite is about $15 \mu \mathrm{m}$ and that of the recoil nucleus is about $20 \mathrm{~nm}$ (these are about twice as much in the glass phase). For zirconolite grains smaller than $15 \mu \mathrm{m}$ in size and grain separation of the same order, most of the He atoms would end up in the glass matrix where they will diffuse out. A typical He diffusion coefficient in simple and complex oxide glasses at about $373 \mathrm{~K}$ is in the range of $10^{-7}$ to $>10^{-12} \mathrm{~cm}^{2} \cdot \mathrm{s}^{-1}$ whereas it is about $3 \times 10^{-19} \mathrm{~cm}^{2} \cdot \mathrm{s}^{-1}$ for zirconolite. This large difference in the He diffusion coefficients makes the glass phase an easy escape route for He atoms. It is very likely that for fine-grained glass-ceramic composites (grain sizes $<15 \mu \mathrm{m}$ ) with glass as the major phase the critical He concentration for He bubble formation would either take significantly longer than the above-mentioned times or would never be attained. If a spherical grain of $15 \mu \mathrm{m}$ diameter was assumed to be surrounded by a glass shell of about $15 \mu \mathrm{m}$ thickness, this would yield a glass to ceramic volume ratio of about 27 (for an isolated particle). Note that it was about 0.4 in the specimens studied here and values close to or smaller than this would be implemented in the actual glass-ceramic waste form. In any case, given that a small fraction of He would still end up in the glass phase in the actual glass-ceramic waste form with ceramic particles as the major phase, the numbers quoted above for He bubble nucleation only represent the earliest possible time scale because no He loss was assumed in estimating these numbers. Issues such as these need to be addressed in the future studies and would be best tackled by a combination of Monte-Carlo methods for alpha decay and alpha particle transport (e.g. by MCNP code) and then finite-element simulations of He diffusion in glass-ceramic composites consisting of amorphous zirconolite phase and the glass phase with varying grain sizes and volume fractions of the two.

Furthermore, studies on radioactive specimens of zircon and monazite, containing moderate levels of Pu isotopes ( 5 mass \% or less) have shown that due to the emission of charged particles during radioactive decays electric fields high enough to cause a dielectric breakdown or shape change driven by the electrostatic fields can lead to cracks and fracturing of radioactive particles. This strongly depends on the half-life of the radioisotope and the size of the radioactive particles with critical particle radii ranging from about a micrometre to hundreds of micrometres [42]. Therefore, in addition to the importance of the grain size in He retention, it also plays an important role in the electrostatic stability of the waste forms. For these reasons, it is not only the glass to ceramic volume ratio that is important but engineering appropriate grain sizes should also be an integral part of the waste form design. 
As far as the effect of temperature is concerned, the studies showed that higher implantation temperature favoured He nucleation at lower concentrations. One plausible explanation for this would be that the vacancies and He atoms diffuse faster at higher temperatures potentially favouring the nucleation and precipitation of He bubbles. This is a common observation made in many other ceramics and metals. To understand the impact of amorphisation, some insights can be gained from atomistic simulations of $\mathrm{He}$ diffusion/He Trapping in crystalline zirconolite [43] and solid state diffusion in amorphous zirconolite [44]. MD simulations have shown that for a given density, solid state diffusion is relatively faster in amorphous zirconolite than in the crystalline zirconolite [44] and that faster and slower diffusion pathways exist in the crystalline zirconolite with energy barriers ranging from $1.4 \mathrm{eV}(<010\rangle$ channels in zirconolite) to $1.7 \mathrm{eV}$ (along <110 $>$ channels in zirconolite) [43]. In general, faster diffusion channels seem to dominate after amorphisation. This is in addition to the already well-known fact that lower density favours faster diffusion [45] and zirconolite is known to swell by about $5 \%$ due to amorphisation. Unfortunately, no studies on the mobility of vacancies in amorphous zirconolite are available but it is plausible to propose that higher He diffusion coefficient combined with a higher concentration of vacancies in the amorphised phase (each $350 \mathrm{keV} \mathrm{Kr}$ ion would create about 1700 vacancies within a $100 \mathrm{~nm}$ thick zirconolite grain) would favour the precipitation of He bubbles at lower He concentration than in a crystalline or less damaged zirconolite.

\subsection{Effect of fluence and temperature/annealing on He bubble size distributions}

Increasing both fluence and/or temperature resulted in the formation of larger He bubbles. In general, both these parameters shifted the bubble size distributions towards larger size (formation of large bubbles and an increase in their population) and caused a decrease in the population of smaller bubbles. This can be explained on the basis that the implanted He atoms diffused towards the existing bubbles leading to their growth. During implantation, newly implanted He atoms and He atoms re-solved from the existing He bubbles due to radiation damage are the driving forces for He bubble growth whereas during annealing it is essentially the diffusion of He atoms from the matrix and smaller bubbles that drive the He bubble growth (note that the population of smaller bubbles drops at the expense of the larger ones). From the analysis of various images, there is no concrete evidence that the He bubble growth in the ceramic phase was driven by coalescence whereas coalescence is one of the main causes of the formation of large irregular $\mathrm{Kr}$ bubbles in the ceramic as well as in the glass phase as observed here and also addressed previously [21]. In general, coalescence happens when inter-bubble spacing (measured from the bubble centre) approaches the bubble size itself [46]. With an aerial coverage of less than $1 \%$ for the He bubbles, it is plausible to propose that coalescence should not be a dominant process for He bubble growth at the He fluences studied in this work.

\subsection{Effect of annealing on He bubbles and the formation of voids}

The He diffusion coefficient in zirconolite has been measured using He implantation and Rutherford Back Scattering (RBS) in the temperature range of 350 to $830^{\circ} \mathrm{C}$ [38]. The He diffusion coefficient in this temperature 
849 range has been given as $5.1 \times 10^{-9} \cdot \exp (-1.05 / \mathrm{k} . \mathrm{T})\left(\mathrm{m}^{2} . \mathrm{s}^{-1}\right)$, where $\mathrm{k}$ is the Boltzmann's constant $\left(8.61 \times 10^{-5} \mathrm{eV} \cdot \mathrm{K}^{-1}\right)$ 850 and $\mathrm{T}$ is the absolute temperature. Assuming the validity of Arrhenius behaviour down to room temperature, the 851 room temperature diffusion coefficient is about $5 \times 10^{-23} \mathrm{~cm}^{2} . \mathrm{s}^{-1}$. The He-implanted specimen was stored for about

85248 hours at $295 \mathrm{~K}$ before the annealing at high temperature was performed. The He diffusion length during this 853 time is less than $0.05 \mathrm{~nm}$. Therefore, it is reasonable to assume that no He was lost from the specimen during 854 this time and that it was retained in the matrix and/or in the He bubbles. The He diffusion coefficient at $873 \mathrm{~K}$ is 855 however significantly higher $\left(\sim 4 \times 10^{-11} \mathrm{~cm}^{2} . \mathrm{s}^{-1}\right)$ yielding a He diffusion length of $1.4 \times 10^{4} \mathrm{~nm}$ during annealing at $856873 \mathrm{~K}$ (diffusion length $130 \mathrm{~nm}$ during the first one second of annealing alone). This is significantly larger than 857 the specimen thickness ( $100 \mathrm{~nm}$ ) and it is plausible to assume that voids were left behind at the end of this 858 annealing step. This is the reason why the He bubbles were observed to grow in the very initial phase of annealing 859 and no further change was observed afterwards (Figure 19 (e)). Subsequent annealing at $973 \mathrm{~K}$ did not have any additional measurable effect on the void distribution for this reason.

These results highlight that annealing at high temperatures does not lead to any significant increase in He bubble sizes and that the voids in zirconolite are thermally stable at least up to $873 \mathrm{~K}$. This is an important observation from the standpoint of the safety of nuclear waste forms showing that the presence of any He bubbles is not detrimental to the stability of the waste forms under accidental thermal transients. The thermal stability of voids observed here is very similar to the observation made in amorphous $\mathrm{SiO}_{2}$ where we found that the voids were stable at least up to $1073 \mathrm{~K}$ [47]. It should also be noted that the formation of voids upon annealing offers one possible way of designing nano-porous zirconolite/ceramic lamellae with a well-defined pore size distribution which could find applications in durable ceramic-based nano-filters.

\subsection{Effect of ballistic collisions on the Voids and He bubbles}

Based on the results of heavy ion irradiation of the specimens containing He bubbles it was shown that

He bubbles under ballistic collisions tend to grow as indicated by the changes in their size distribution. However, beyond this macroscopic observation, when one focusses on the individual He bubbles, it was also shown that mechanisms such as growth, coalescence and re-solution can be present at the same time during ballistic collisions and the overall change in the size distributions was only a simplified picture coming to fruition as a result of these multiple processes. However, it should also be noted that what we have been referring to as He bubbles could also be voids (or a mixture of He bubbles and voids). Therefore, when following the evolution of the so-called He bubbles as a function of the heavy ion irradiation, as shown in Figure 16 and Figure 19, it is in fact, impossible to differentiate the voids and He bubbles and identify their individual behaviour. For this reason, one cannot with certainty determine whether the shift in size distribution was a result of the formation of larger voids or due to the formation of larger He bubbles at the expense of smaller ones (or a combination of both). Furthermore, it makes it impossible to distinguish between He bubble re-solution and void closure (although we deliberately used the term re-solution in Figure 17 without actually providing much evidence in its support). One of the issues in dealing with He bubbles is the fact that it is not possible to distinguish He bubbles from voids in 
BF-TEM images due to the very low electron scattering cross-section and mass density of He. This aspect has been discussed at length in our earlier article focussed on the identification and dynamics of noble gas precipitates and voids in glasses [21]. The fact that they were referred to as He bubbles is due to their continuous evolution as a function of the He fluence indicating the role of He in the development of these features. Irradiation with $20 \mathrm{keV}$ He ions to even higher fluences did not result in He bubble formation showing that they could not just be He induced voids and void clusters but that He implantation was a necessary condition for these features/bubbles to grow. Furthermore, one of the important points that was highlighted in our earlier work [21] that is highly relevant here was that the voids irrespective of their size are unstable under ballistic collisions. Voids when subjected to ballistic collisions shrink and eventually close. This was subsequently also observed in micro-porous glasses (created as a result of the leaching) where voids ranging in size from a few hundreds of nanometres to less than a nanometre when subjected to heavy ion irradiation were observed to shrink and close [48]. This is essentially due to a mass flow from the regions of high density (matrix) towards the regions of low density (voids) under ballistic collisions that leads to their closure. MD simulations on the effects of ballistic collisions on voids in Si [49] (using 0.2 to $2 \mathrm{keV} \mathrm{Xe} \mathrm{ions)} \mathrm{and} \mathrm{mesoporous} \mathrm{silica} \mathrm{[50]} \mathrm{(using} 1.2 \mathrm{keV} \mathrm{U}$ ) also show that the cumulative effect of the collision cascades is essentially to induce a slow migration of surface atoms towards the void centre leading to its closure. It is worth highlighting that MD studies on voids in Si [49] show that the shrinkage is more efficient under isotropic irradiation conditions compared to unidirectional irradiation. This is something to bear in mind when comparing unidirectional ion irradiation studies such as ours with recoil nucleus effects in nuclear waste forms which will be irradiated isotopically. Also, MD studies with higher energies which are more representative of the ion irradiation conditions used herein and that of the recoil nucleus would be worth investigating, especially, in zirconolite.

With this behaviour of voids in mind, annealing experiments were performed to form unambiguous voids from He bubbles (by driving the He out) and their behaviour to ballistic collisions was studied. The results again confirmed the unstable nature of the voids (as shown in Figure 20), in contrast to He bubbles, which is in excellent agreement with our earlier results on noble gas precipitates/bubbles and voids in glasses [21]. Therefore, voids can be distinguished from He bubbles by following their dynamics rather than their appearance. It is worth mentioning here that voids in glasses and amorphous ceramics do not survive the intense ballistic damage. This is in stark contrast to ordered materials such as metals where random or regular arrays of voids can be formed purely due to ballistic collisions.

In the present case, all the voids were eliminated (void shrinkage and elimination) by $600 \mathrm{keV} \mathrm{Kr}$ ions at a fluence of about $1.6 \times 10^{14}$ ions. $\mathrm{cm}^{-2}\left(1.6\right.$ ions. $\mathrm{nm}^{-2} \sim 0.2 \mathrm{dpa}$ ). This means that a void with an initial diameter of about $3.2 \mathrm{~nm}\left(v=17 \mathrm{~nm}^{3}\right)$, would on average receive about 3 ion impacts (note that the voids shrink linearly as a function of the fluence and therefore the number of the ion impacts received by a continuously shrinking void is less than what one might calculate from its initial area). This corresponds to a volume recovery of about $5 \mathrm{~nm}^{3}$ 
920 per ion impact. Therefore, voids of diameter up to $2 \mathrm{~nm}$ can be destroyed by a single ion impact. Although the

921 ballistic collisions shifted the He distribution towards larger size it was not a very drastic change. Within the

922 context of nuclear waste disposal, it means that ballistic collisions of recoil nuclei will not have a significant impact

923 on the distribution of He bubbles. Thus, the study of He bubbles in amorphous zirconolite alone is a sufficient

924 indicator of the potential He bubble distribution in the waste forms in the long-term and the effect of recoil

925 nuclei need not be considered

\subsection{The role of glass-ceramic interfaces and grain boundaries}

927 The He implantation experiments were performed at various temperatures and in no case were He bubbles 928 observed in the glass phase. This is consistent with our studies of noble gases in simple and complex glasses at 929 various temperatures showing that for a combination of the glass composition and noble gas atom, gas diffusion 930 coefficients of less than $10^{-17} \mathrm{~cm}^{2} \cdot \mathrm{s}^{-1}$ are required to precipitate the bubbles under such conditions. The He 931 diffusion coefficient in oxide glasses of nuclear waste interest is generally $>10^{-13} \mathrm{~cm}^{2} \cdot \mathrm{s}^{-1}$ [35] and therefore it was 932 not surprising that no He bubbles were formed in the glass phase in the current case. Even for a complex glass 933 system such as the French SON68 glass (which contains about 30 different elements), the He diffusion coefficient 934 at room temperature is about $2 \times 10^{-13} \mathrm{~cm}^{2} \cdot \mathrm{s}^{-1}$ [34] and no He bubbles were observed in this glass at room 935 temperature in our studies. In fact, He bubbles in the SON68 glass form only at temperatures below $180 \mathrm{~K}$. 936 Therefore, when investigating the glass-ceramic interfaces in the present case no He bubbles were expected to 937 form in the simple sodium aluminosilicate glass a priori and, this was indeed the case throughout our 938 experiments. The main reason is simply the fact that the He diffusion in the glass phase is too fast and any He 939 implanted directly into the glass phase or diffusing out of the ceramic phase into the glass phase is lost (note that 940 there is practically no He diffusion out of the ceramic phase due to the very low He diffusion coefficient in it). On 941 the other hand, diffusion of He from the glass phase into the ceramic phase would be significantly limited due to 942 the very small He diffusion coefficient in the ceramic phase $\left(5 \times 10^{-23}\right.$ in zirconolite compared to $10^{-13} \mathrm{~cm}^{2} . \mathrm{s}^{-1}$ in the 943 glass phase at $295 \mathrm{~K}$ ). In any case, even if He were to diffuse into the ceramic phase, there would be no 944 measurable changes in the He bubble distribution in the ceramic particles because the results showed that the 945 bubble sizes do not change significantly for He fluence range of $2 \times 10^{16}$ to $1.5 \times 10^{17} \mathrm{~cm}^{-2} . \mathrm{s}^{-1}$. Furthermore, in the 946 actual nuclear waste forms, helium will mainly be generated in the ceramic phase rather than in the glass phase, 947 and as discussed earlier, the degree of He retention would depend on factors such as the size of ceramic particles 948 (microstructure) and glass to ceramic volume fraction. Therefore, for all the practical reasons, the glass-ceramic 949 interfaces should not introduce any detrimental effects with regards to He precipitation. When comparing glass950 ceramic composite waste forms to glass waste forms, He precipitation under geological disposal conditions is 951 only an issue in the ceramic phase and not in the glass phase or at the glass-ceramic interfaces.

As far as the diffusion along grain boundaries is concerned, several studies of diffusion of various 
954 be significantly greater than that in the lattice $\left(D_{1}\right)$. Although dependent on annealing conditions, microstructure, pressure, temperature and water content, the studies show that the ratio $D_{g h} / D_{l}$ for O and Ca in calcite is $\sim 10^{6}-$ $10^{7} ; D_{g h} / D_{l}$ for Ca in anorthite is $\sim 10^{4} ; D_{g h} / D_{l}$ for K and O in feldspars is $\sim 10^{4}-10^{5} ; D_{g h} / D_{l}$ for O in quartz is $\sim 10^{4}-$ $10^{5} ; D_{g h} / D_{l}$ for Si in quartz $10^{12}$ and so on for many other elements and minerals [51] (see pages 954 to 964 in this reference for the data). To the best of our knowledge, there is no such data on zirconolite but it is plausible to assume because of the structural similarity among these minerals that diffusion along grain boundaries can be expected to be greater for He as well as for other elements making up the waste form. Generally speaking, this will have a significant impact on the transport of water and other elements including He but the relevance of grain boundaries in the long-term is questionable in light of the results presented in Figure 15 showing that grain boundaries after amorphisation did not exist as distinctly. Probably the role of grain boundary diffusion in amorphous ceramic waste forms is very limited (or ambiguous) in the long-term but it needs to be investigated and compared with the behaviour of crystalline waste forms. From this perspective, amorphisation is not entirely a negative aspect.

Besides studying He bubbles, oxygen bubbles were observed to form in the glass phase due to the electron beam exposure. One particular aspect of this that is worth discussing here was the observation of bubble denuded zones in certain cases. In the majority of the cases, the glass phase in the denuded zones showed slightly higher brightness compared to the rest of the glass where oxygen bubbles were formed (in BF-TEM images). One such example is shown in Figure 29 (a, b). Figure 29 (a) shows a low magnification image of one of the specimens

972 and a magnified image of the region indicated by the rectangle is shown in Figure 29 (b). The intensity profile 973 superimposed on Figure 29 (b) shows that the region demarcated by two vertical lines ( $150 \mathrm{~nm}$ wide region) has 974 slightly lower mass thickness (higher transmission) than the rest of the glass region (this can also be seen in Figure 9755 (a) and Figure 7 (a) where regions next to the grains have higher brightness and are denuded). This would 976 indicate an inhomogeneity of glass composition and depletion of heavier elements like sodium and aluminium 977 from this region, such that the region would be silica-rich with a lower mass density. A lack of alkali elements 978 would automatically suppress oxygen release and bubble formation under the electron beam as is generally 979 known with regards to the behaviour of alkali bearing glasses under electron beam [52]. Therefore, the oxygen bubble denuded zones could be a result of local compositional inhomogeneity. Whether such an inhomogeneity can be seen in the TEM images would primarily depend on the extent of the inhomogeneity and the atomic number of the depleted element. TEM studies of simple alkali borosilicate glasses leached in water clearly show the alkali depleted regions as higher intensity regions compared to non-leached regions [53] in agreement with the observations made in the present case. Furthermore, when looking at the formation of $\mathrm{Kr}$ bubbles in the glass phase, no such denuded zones were observed indicating local compositional differences affecting the release of oxygen could be behind the origin of oxygen bubble denuded zones. In any case, such compositional 
inhomogeneity would not affect He precipitation near glass-ceramic interfaces because it does not have a major impact on the local He diffusion coefficient due to the already large He diffusion coefficient in glasses.

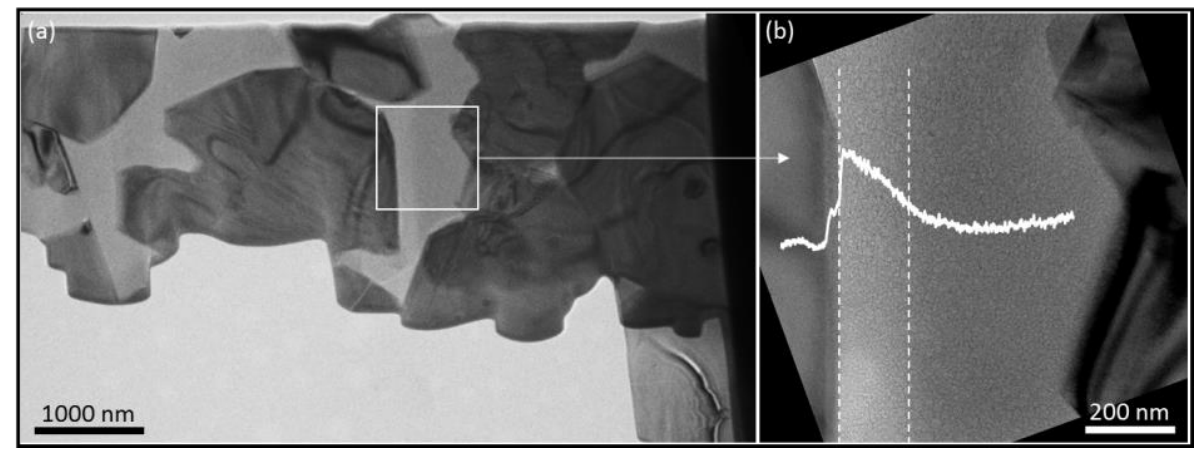

Figure 29: A low and high magnification image of one of the Zr-GC specimens. The intensity profile on the magnified image in (b) shows that the region demarcated by two vertical lines has a lower mass thickness. Such regions are usually oxygen bubble denuded zones.

\section{Summary and Conclusion}

Zirconolite $\left(\mathrm{CaZrTi}_{2} \mathrm{O}_{7}\right)$ based glass-ceramics were subjected to heavy ion irradiation and $\mathrm{He}$ implantation using a TEM with in-situ ion irradiation. The role of the implantation temperature, structural disorder/amorphisation, He concentration, grain boundaries and glass-ceramic interfaces in He bubble nucleation was studied. Under heavy ion irradiation ( 350 and $600 \mathrm{keV} \mathrm{Kr}$ ), zirconolite amorphised in less than 0.5 dpa whereas amorphisation with $20 \mathrm{keV} \mathrm{He}$ irradiation was observed at $143 \mathrm{~K}$ after $1.2 \times 10^{17} \mathrm{He}_{\mathrm{cm}}{ }^{-2}(\sim 3.4 \mathrm{dpa})$. He Irradiation at higher temperatures $\left(295,363 \mathrm{~K}\right.$ ) even up to $1.7 \times 10^{17} \mathrm{He}^{-\mathrm{cm}^{-2}}$ ( $4.8 \mathrm{dpa}$ ) did not lead to amorphisation but only to some structural disorder.

Implantation of crystalline zirconolite with $10 \mathrm{keV} \mathrm{He}$ ions essentially lead to the nucleation of He bubbles in a disordered zirconolite - the disorder being introduced by He ions themselves. An increase in the bubble sizes was observed when the disordered zirconolite containing He bubbles was subsequently subjected to ballistic collisions and amorphisation using heavy ions. The minimum He concentration required to nucleate the He bubbles was observed to depend on the implantation temperature and on the degree of the structural disorder/amorphisation. An increase in either of these favoured He bubble nucleation at a lower concentration. For instance, a peak He concentration of about 5 atomic \% was needed to nucleate the He bubbles in disordered zirconolite at $143 \mathrm{~K}$ whereas only about 1 at. \% was needed at $473 \mathrm{~K}$. Similarly, the He concentration needed to nucleate the He bubbles in amorphous zirconolite at $143 \mathrm{~K}$ was only about $50 \%$ of that needed for the disordered zirconolite.

In all the cases, He implantation at different temperatures was accompanied by some lattice disorder but amorphisation was not attained by the time He bubbles nucleated. These results highlight that He bubbles essentially nucleate in a disordered zirconolite and not in a defect-free crystalline or amorphous state when an 
1016 initially crystalline zirconolite is implanted with He ions. Irradiation of the specimens containing He bubbles with 1017 heavy ions showed that ballistic collisions shifted the He bubble size distribution towards larger size at the 1018 expense of the smaller ones (ballistic collisions increased the average He bubble size and the maximum size limit 1019 of the distribution). In any case, the maximum and mean diameter of intra-grain He bubbles was less than about $10203.5 \mathrm{~nm}$ and $1.2 \mathrm{~nm}$ respectively. Unlike He bubbles, which showed an overall growth under ballistic collisions, 1021 voids were found to be unstable under ballistic collisions showing a rapid shrinkage and closure.

1022

1023

1024

1025

1026

1027

1028

1029

1030

1031

1032

1033

1034

1035

1036

1037

1038

1039

1040

1041

1042

1043

1044

1045

1046

1047

1048

1049

Also, He bubbles did not nucleate in the glass phase at any of the studied temperatures. This is in line with the fast He diffusion coefficient in simple glasses leading to a rapid He loss from the specimens during the course of the implantation. Also, no preferential He nucleation was observed at glass-ceramic interfaces and this is again because He is quickly lost from the glass phase. However, preferential He bubble nucleation was observed along grain boundaries. Relatively larger He bubbles were observed at grain boundaries compared to the intra-grain He bubbles. Furthermore, neither amorphisation nor He bubble nucleation resulted in the formation of any cracks at any interfaces highlighting the high mechanical stability of this type of waste form against such factors. Also, although He was observed to accumulate at the interfaces between crystalline inclusions such as $\mathrm{ZrO}_{2}$ embedded within the zirconolite grains, no cracks or fracturing was observed.

These results when projected to actual nuclear waste forms show that the formation of He bubbles under disposal conditions would require about 1 to 2.5 atomic \% of $\mathrm{He}$ and that the bubbles would essentially nucleate in the amorphous phase of zirconolite. This corresponds to about twenty thousand years for a 20 weight \% Pu loading in zirconolite. Therefore, the leaching would be expected to take place from an amorphous, He bubble bearing zirconolite waste form. The results show that leaching tests on amorphous He bubble bearing specimens would be most representative of the long-term leaching behaviour under disposal conditions. Besides the effect of amorphisation, it is also crucial to understand the role of intra and inter-grain He bubbles in the transport of the water and radionuclides in the ceramic phase of the waste form.

\section{Data Availability}

The raw/processed data required to reproduce these findings cannot be shared at this time due to technical or time limitations. However, it can be made available upon request.

\section{Declaration of Competing Interests}

The authors declare no competing interest.

\section{CRedit Author Contribution Statement}

A H Mir: Conceptualization; Methodology, Formal analysis; Investigation; Visualization; Data curation; Validation; Funding acquisition, Writing - original draft writing. 
1050 N Hyatt: Resources, Writing - review \& editing.

1051 S E Donnelly: Resources, Funding acquisition, Writing - review \& editing,

\section{Acknowledgements}

1053 The in-situ experiments were carried out at the MIAMI Irradiation Facility which forms part of the EPSRC-funded 1054 UK National Ion-Beam Centre (UKNIBC). The authors are thankful to the Engineering and Physical Sciences 1055 Research Council for funding under grants, EP/ T012811/1, EP/ M011135/1 and EP/M028283/1. A H Mir is also 1056 thankful to Stephanie Thornber who prepared the bulk glass-ceramics using the HIP. 
1058

1059

1060

1061

1062

1063

1064

1065

1066

1067

1068

1069

1070

1071

1072

1073

1074

1075

1076

1077

1078

1079

1080

1081

1082

1083

1084

1085

1086

1087

1088

1089

1090

1091

1092

1093

1094

1095

1096

1097

1098

1099

1100

1101

1102

1103

1104

1105

1106

1107

1108

1109

1110

1111

1112

1113

1114

1115

1116

\section{References}

[1] Radioactive Wastes in the UK: A summary of the 2016 inventory, 2016. https://ukinventory.nda.gov.uk/wpcontent/uploads/sites/18/2017/03/High-Level-Summary-UK-Radwaste-Inventory-2016.pdf.

[2] C. Ewing, I. Headley, Alpa-recoil damage in natural zirconolite, J. Nucl. Mater. 119 (1983) 102-109.

[3] Y. Eyal, R.L. Fleischer, Timescale of natural annealing in radioactive minerals affects retardation of radiation damage induced leaching, Nature. 314 (1985) 518-520.

[4] G.R. Lumpkin, R.C. Ewing, Y. Eyal, Preferential leaching and natural annealing of alpha-recoil tracks in metamict betaflte and samarskite, J. Mater. Res. 3 (1988) 357-368. doi:10.1557/JMR.1988.0357.

[5] R.C. Ewing, W. Lutze, High-level nuclear waste immobilization with ceramics, Ceram. Int. 17 (1991) 287-293. doi:10.1016/0272-8842(91)90024-T.

[6] W.J. Weber, R.C. Ewing, C.R.A. Catlow, T.D. De La Rubia, L.W. Hobbs, C. Kinoshita, H.J. Matzke, A.T. Motta, M. Nastasi, E.K.H. Salje, E.R. Vance, S.J. Zinkle, Radiation Effects In Crystalline Ceramics For The Immobilization Of High-level Nuclear Waste And Plutonium, J. Mater. Res. 13 (1998) 1434-1484. doi:10.1557/JMR.1998.0205.

[7] A.E. Ringwood, V.M. Oversby, S.E. Kesson, W. Sinclair, N. Ware, W. Hibberson, A. Major, Immobilization of highlevel nuclear reactor wastes in SYNROC: A current appraisal, Nucl. Chem. Waste Manag. 2 (1981) 287-305. doi:10.1016/0191-815X(81)90055-3.

[8] F.W. Clinard, L.W. Hobbs, C.C. Land, D.E. Peterson, D.L. Rohr, R.B. Roof, Alpha decay self-irradiation damage in 238Pu-substituted zirconolite, J. Nucl. Mater. 105 (1982) 248-256. doi:10.1016/0022-3115(82)90381-6.

[9] F.W. Clinard, D.E. Peterson, D.L. Rohr, L.W. Hobbs, Self-irradiation effects in 238Pu-substituted zirconolite. I. Temperature dependence of damage, J. Nucl. Mater. 126 (1984) 245-254. doi:10.1016/0022-3115(84)90036-9.

[10] G.R. Lumpkin, K.L. Smith, M.G. Blackford, R. Giere, C.T. Williams, The crystalline-Amorphous transformation in natural zirconolite:Evidence for long-term annealing, in: Mat. Res. Soc.Symp. Proc, 1998: pp. 215-222.

[11] D.M. Strachan, R.D. Scheele, E.C. Buck, A.E. Kozelisky, R.L. Sell, R.J. Elovich, W.C. Buchmiller, Radiation damage effects in candidate titanates for Pu disposition: Zirconolite, J. Nucl. Mater. 372 (2008) 16-31. doi:10.1016/j.jnucmat.2007.01.278.

[12] G.R. Lumpkin, B.D. Begg, K.L. Smith, Radiation Damage Effects in Pyrochlore and Zirconolite Ceramic Matrices for the Immobilization of Actinide-Rich Wastes, (n.d.).

https://www.academia.edu/38099110/Radiation_Damage_Effects_in_Pyrochlore_and_Zirconolite_Ceramic_Matri ces_for_the_Immobilization_of_Actinide-Rich_Wastes.

[13] X. Deschanels, V. Picot, B. Glorieux, F. Jorion, S. Peuget, D. Roudil, C. J??gou, V. Broudic, J.N. Cachia, T. Advocat, C. Den Auwer, C. Fillet, J.P. Coutures, C. Hennig, A. Scheinost, Plutonium incorporation in phosphate and titanate ceramics for minor actinide containment, J. Nucl. Mater. 352 (2006) 233-240. doi:10.1016/j.jnucmat.2006.02.059.

[14] D.M. Strachan, R.D. Scheele, J.P.Icenhower, I.C.Buck, A.E.Kozelisky, R.L. Sell, R.J. Elovich, W.C.Buckmiller, Radiation Damage Effects in Candidate Ceramics for Plutonium Immobilization : Final Report (PNNL-14588), 2004. https://www.osti.gov/biblio/15007189.

[15] G.R. Lumpkin, Alpha-decay damage and aqueous durability of actinide host phases in natural systems, J. Nucl. Mater. 289 (2001) 136-166. doi:10.1016/S0022-3115(00)00693-0.

[16] S.. Wang, L.. Wang, R.. Ewing, G.. Was, G.. Lumpkin, Ion irradiation-induced phase transformation of pyrochlore and zirconolite, Nucl. Instruments Methods Phys. Res. Sect. B Beam Interact. with Mater. Atoms. 148 (1999) 704709. doi:10.1016/s0168-583X(98)00847-7.

[17] S.X. Wang, G.R. Lumpkin, L.M. Wang, R.C. Ewing, lon irradiation-induced amorphization of six zirconolite compositions, Nucl. Inst. Methods Phys. Res. B. 167 (2000) 293-298.

[18] T.J. Headley, G.W. Arnold, C.J.M. Northrup, Dose dependence of Pb ion implantation damage in zirconolite, holandite and zircon, in: Sci. Basis Nucl. Waste Manag. V, 1981: p. 371.

https://www.cambridge.org/core/journals/mrs-online-proceedings-library-archive/article/dosedependence-ofpbion-implantation-damage-in-zirconolite-hollandite-and-zircon/4D3996FD14EDB26C25E0FF9FB01E6FA6.

[19] M. Gupta, P.K. Kulriya, R. Shukla, R.S. Dhaka, R. Kumar, S.S. Ghumman, Reduction and structural modification of zirconolite on $\mathrm{He}+$ ion irradiation, Nucl. Inst. Methods Phys. Res. B. 379 (2016) 119-125. doi:10.1016/j.nimb.2016.04.020.

[20] M. Gilbert, C. Davoisne, M. Stennett, N. Hyatt, N. Peng, C. Jeynes, W.E. Lee, Krypton and helium irradiation damage in neodymium-zirconolite, J. Nucl. Mater. 416 (2011) 221-224. doi:10.1016/j.jnucmat.2010.11.089.

[21] A.H. Mir, J.A. Hinks, S.E. Donnelly, Effect of density and Z-contrast on the visibility of noble gas precipitates and voids with insights from Monte-Carlo simulations, Micron. 126 (2019) 102712. doi:10.1016/j.micron.2019.102712.

[22] E. Maddrell, S. Thornber, N.C. Hyatt, The influence of glass composition on crystalline phase stability in glassceramic wasteforms, J. Nucl. Mater. 456 (2015) 461-466. doi:10.1016/j.jnucmat.2014.10.010.

[23] S.M. Thornber, M.C. Stennett, Neil, Investigation of Ce incorporation in zirconolite glass-ceramic for UK plutonium disposition, MRS Adv. 357 (2017) 699-704. doi:10.1557/adv.201.

[24] G. Greaves, A.H. Mir, R.W. Harrison, M.A. Tunes, S.E. Donnelly, J.A. Hinks, New Microscope and Ion Accelerators for Materials Investigations (MIAMI-2) system at the University of Huddersfield, Nucl. Instruments Methods Phys. 
1117

1118

1119

1120

1121

1122

1123

1124

1125

1126

1127

1128

1129

1130

1131

1132

1133

1134

1135

1136

1137

1138

1139

1140

1141

1142

1143

1144

1145

1146

1147

1148

1149

1150

1151

1152

1153

1154

1155

1156

1157

1158

1159

1160

1161

1162

1163

1164

1165

1166

1167

1168

1169

1170

1171

1172

1173

1174

1175

Res. Sect. A Accel. Spectrometers, Detect. Assoc. Equip. 931 (2019) 37-43. doi:10.1016/j.nima.2019.03.074.

[25] J.F. Ziegler, M.D. Ziegler, J.P. Biersack, SRIM - The stopping and range of ions in matter (2010), Nucl. Inst. Methods Phys. Res. B. 268 (2010) 1818-1823. doi:10.1016/j.nimb.2010.02.091.

[26] H.J. Rossell, Solid solution of metal oxides in the zirconolite phase CaZrTi207. I: Heterotype solid solutions, J. Solid State Chem. 99 (1992) 38-51. https://doi.org/10.1016/0022-4596(92)90286-5.

[27] H.J. Rossell, Solid solution of metal oxides in the zirconolite phase CaZrTi2O7. II. The Ternary Phase CaZrxTi3-xO7, J. Solid State Chem. 99 (1992) 52-57. doi:10.1016/0022-4596(92)90286-5.

[28] J. Verbeeck, D. Van Dyck, G. Van Tendeloo, Energy-filtered transmission electron microscopy: An overview, Spectrochim. Acta - Part B At. Spectrosc. 59 (2004) 1529-1534. doi:10.1016/j.sab.2004.03.020.

[29] H. Shinotsuka, S. Tanuma, C.J. Powell, D.R. Penn, Calculations of electron inelastic mean free paths. X. Data for 41 elemental solids over the $50 \mathrm{eV}$ to $200 \mathrm{keV}$ range with the relativistic full Penn algorithm, Surf. Interface Anal. 47 (2015) 1132. doi:10.1002/sia.5861.

[30] H. Shinotsuka, S. Tanuma, C.J. Powell, D.R. Penn, Calculations of electron inelastic mean free paths. XII. Data for 42 inorganic compounds over the $50 \mathrm{eV}$ to $200 \mathrm{keV}$ range with the full Penn algorithm, Surf. Interface Anal. (2018) 427-457. doi:10.1002/sia.6598.

[31] J. Schindelin, I. Arganda-Carreras, E. Frise, V. Kaynig, M. Longair, T. Pietzsch, S. Preibisch, C. Rueden, S. Saalfeld, B. Schmid, J.Y. Tinevez, D.J. White, V. Hartenstein, K. Eliceiri, P. Tomancak, A. Cardona, Fiji: An open-source platform for biological-image analysis, Nat. Methods. 9 (2012) 676-682. doi:10.1038/nmeth.2019.

[32] N. Ollier, G. Rizza, B. Boizot, G. Petite, Effects of temperature and flux on oxygen bubble formation in Li borosilicate glass under electron beam irradiation, J. Appl. Phys. 99 (2006) 073511. doi:10.1063/1.2189026.

[33] D.E. Swets, R.W. Lee, R.C. Frank, Diffusion coefficients of helium in fused quartz, J. Chem. Phys. 34 (1961) 17-22. doi:10.1063/1.1731562.

[34] R. Bès, T. Sauvage, S. Peuget, J. Haussy, F. Chamssedine, E. Oliviero, T. Fares, L. Vincent, Helium mobility in SON68 borosilicate nuclear glass: A nuclear reaction analysis approach, J. Nucl. Mater. 443 (2013) 544-554. doi:10.1016/j.jnucmat.2013.07.036.

[35] A.H. Mir, Studying precipitation of noble gases using TEM with in-situ ion irradiation: The role of temperature, composition and, diffusion coefficient, Prep. (n.d.).

[36] D. Simeone, J.L. Bechade, D. Gosset, A. Chevarier, P. Daniel, H. Pilliaire, G. Baldinozzi, Investigation on the zirconia phase transition under irradiation, J. Nucl. Mater. 281 (2000) 171-181. doi:10.1016/S0022-3115(00)00183-5.

[37] J.M. Costantini, F. Beuneu, W.J. Weber, Radiation damage in cubic-stabilized zirconia, J. Nucl. Mater. 440 (2013) 508-514. doi:10.1016/j.jnucmat.2013.02.041.

[38] D. Roudil, X. Deschanels, P. Trocellier, F. ç ois Jomard, A. Boutry, C. Jègou, S. Peuget, D. Gosset, P. Nivet, Thermal diffusion of Helium and volatil fission products in UO2 and zirconolite nuclear ceramics, MRS Proc. 824 (2011). doi:10.1557/proc-824-cc8.5.

[39] A.H. Mir, J. Hinks, S.E.Donnelly, Ballistic-damage-induced size changes in equilibrium and under-pressurized Xe precipitates in amorphous silica, J. Nucl. Mater. 519 (2019) 229-238.

[40] G.R. Lumpkin, K.L. Smith, R.G. Blake, TEM Study of Radiation Damage and Annealing of Neutron Irradiated Zirconolite, MRS Proc. 412 (2011) 329-336. doi:10.1557/proc-412-329.

[41] M.L. David, F. Pailloux, V. Mauchamp, L. Pizzagalli, In situ probing of helium desorption from individual nanobubbles under electron irradiation, Appl. Phys. Lett. 98 (2011) 1-4. doi:10.1063/1.3582612.

[42] M.I. Ojovan, B.E. Burakov, W.E. Lee, Radiation-induced microcrystal shape change as a mechanism of wasteform degradation, J. Nucl. Mater. 501 (2018) 162-171. doi:10.1016/j.jnucmat.2018.01.030.

[43] J. Mulroue, M. Watkins, A.J. Morris, D.M. Duffy, Trapping of He in intrinsic defects in zirconolite, J. Nucl. Mater. 437 (2013) 261-266. doi:10.1016/j.jnucmat.2013.02.037.

[44] C. Yang, E. Zarkadoula, M.T. Dove, I.T. Todorov, T. Geisler, V. V. Brazhkin, K. Trachenko, Solid-state diffusion in amorphous zirconolite, J. Appl. Phys. 116 (2014) 1-8. doi:10.1063/1.4901326.

[45] F.J. Norton, Helium Diffusion Through Glass, J. Am. Ceram. Soc. 36 (1953) 90-96. doi:10.1111/j.11512916.1953.tb12843.x.

[46] J.H. Evans, An interbubble fracture mechanism of blister formation on helium-irradiated metals, J. Nucl. Mater. 68 (1977) 129-140. doi:10.1016/0022-3115(77)90232-X.

[47] A.H. Mir, J.A. Hinks, J.-M. Delaye, S. Peuget, S.E. Donnelly, Xenon solubility and formation of supercritical xenon precipitates in glasses under non-equilibrium conditions, Sci. Rep. 8 (2018) 15320. doi:10.1038/s41598-018-33556y.

[48] A.H. Mir, A. Jan, J.-M. Delaye, S.E.Donnelly, J.A. Hinks, S. Gin, Effect of decades of corrosion on the microstructure of altered glasses and their radiation stability, Npj Mater. Degrad. 4 (2020) 1-9. doi:10.1038/s41529-020-0115-0.

[49] M.A. Okunlewski, Y. Ashkenazy, B.J. Heuser, R.S. Averback, Molecular dynamics simulations of void and helium bubble stability in amorphous silicon during heavy-ion bombardment, J. Appl. Phys. 96 (2004) 4181-4188. doi:10.1063/1.1791759.

[50] Y. Lou, B. Siboulet, S. Dourdain, M.R. Rafiuddin, X. Deschanels, J.M. Delaye, Molecular dynamics simulation of 
1176

1177

1178

1179

1180

1181

1182

1183

1184 ballistic effects in mesoporous silica, J. Non. Cryst. Solids. 549 (2020). doi:10.1016/j.jnoncrysol.2020.120346.

[51] R. Dohmen, R. Milke, Diffusion in Polycrystalline Materials: Grain Boundaries, Mathematical Models, and Experimental Data, Rev. Mineral. Geochemistry. 72 (2010) 921-970. doi:10.2138/rmg.2010.72.21.

[52] N. Ollier, B. Boizot, B. Reynard, D. Ghaleb, G. Petite, Beta Irradiation in Borosilicate Glasses: the Role of the Mixed Alkali Effect, Nucl. Inst. Methods Phys. Res. B. 218 (2004) 176-182. doi:10.1016/j.nimb.2003.12.014.

[53] M. Tribet, A.H. Mir, C. Gillet, C. Jegou, S. Mougnaud, J.A. Hinks, S.E.Donnelly, S. Peuget, New insights about the importance of the alteration layer/glass interface, J. Phys. Chem. C. 124 (2020) 10032-10034. doi:https://doi.org/10.1021/acs.jpcc.0c02121. 